\title{
NASA TM - 76670
}

NASA TECHNICAL MEMORANDUM $($ 06SZI00Z86I 0L99L-WL-VSVN

NASA TM-76670

PRESSURE LOSSES AND HEAT TRANSFER

1. IN NON-CIRCULAR CHANNELS WITH HYDRAULICALLY SMOOTH WALLS ,

J. Malak

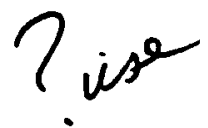

Translation of "Tlakové ztráty a prestup tepla $v$ kanálech nekruhových průřezů s hydraulicky hladkými stěnami," Ceskoslovenská akademie věd, Prague, Czechoslovakia, Ústav jaderného výzkumu, Informační středisko, Kež, ŪJV 2891-R, September 1972,120 pages.

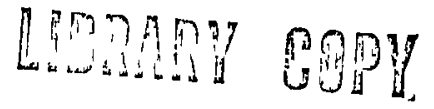

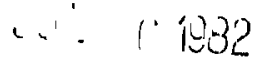 \\ LANGLEY RESEARCH CENTER ${ }^{7}$ \\ LIBRARI, MASA \\ HANETOUI, VIRGINIA'}

NATIONAL AERONAUTICS AND SPACE ADMINISTRATION

WASHINGTON， D.C. 20546

FEBRUARY 1982

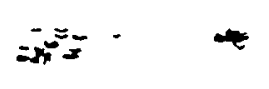


STANDARD TITLE PAGE

\begin{tabular}{|c|c|c|}
\hline $\begin{array}{l}\text { 1. Report No. } \\
\text { NASA TM-76670 }\end{array}$ & 2. Government Accession No. & 3. Recipient's Cotolog No. \\
\hline \multirow{2}{*}{\multicolumn{2}{|c|}{$\begin{array}{l}\text { 4. Tulle and Subinl. } \\
\text { TRANSFER IN NON-CIRCULAR CHANNELS WITH } \\
\text { HYDRAULICALLY SMOOTH WALLS }\end{array}$}} & $\begin{array}{l}\text { 5. Reporl Date } \\
\text { Eebruary } 1982\end{array}$ \\
\hline & & 6. Porforming Orgonization Code \\
\hline \multirow{2}{*}{$\begin{array}{l}\text { 7. Author(s) } \\
\text { J. Malak }\end{array}$} & & 8. Performing Orgonization Report No. \\
\hline & - & 10. Work Unis No. \\
\hline \multirow{2}{*}{\multicolumn{2}{|c|}{$\begin{array}{l}\text { 9. Peilorming Orgonization Nome and Address } \\
\text { Leo Kanner Assoclates, } \\
\text { Redwood Clty, California } 94063\end{array}$}} & $\begin{array}{l}\text { 11. Coniract or Grone No. } \\
\mathrm{NASW}-31341\end{array}$ \\
\hline & & $\begin{array}{l}\text { 11. Typo ol Roport ond Poriod Coveron } \\
\text { Translation }\end{array}$ \\
\hline \multirow{2}{*}{\multicolumn{2}{|c|}{$\begin{array}{l}\text { 12. Sponsoring Ageney Nome ond Address } \\
\text { National Aeronautics and Space Adminis- } \\
\text { tration, Washington, D.C. } 20546\end{array}$}} & \\
\hline & & 14. Sponsoring Agoney Code \\
\hline
\end{tabular}

15. Supplementary Notes

Translatıon of. "Tlakové ztráty a prestup tepla v kanálech nekruhových průřezů s hydraulicky hladkýmı stènami," Československá akademie věd, Prague, Czechoslovakia, Ústav jaderného výzkumu, Informačni středisko, Kež, UjJV 2891-R, September 1972, 120 pages.

16 Abstroct The Influence of channel geometry on pressure losses and heat transfer in non-circular channels with hydraulically smooth walls was studied. As a basic assurption for the description of this influence, new integral geometrical criteria, selected according to experimental experience, were introduced. Usıng these new geometrical criteria, a large set of experımental data for pressure losses and heat.transfer in circular and annular channels with longltudinal fins was evaluated. In this way it was empirlcally proved that the new criteria described channel geometry farrly well.

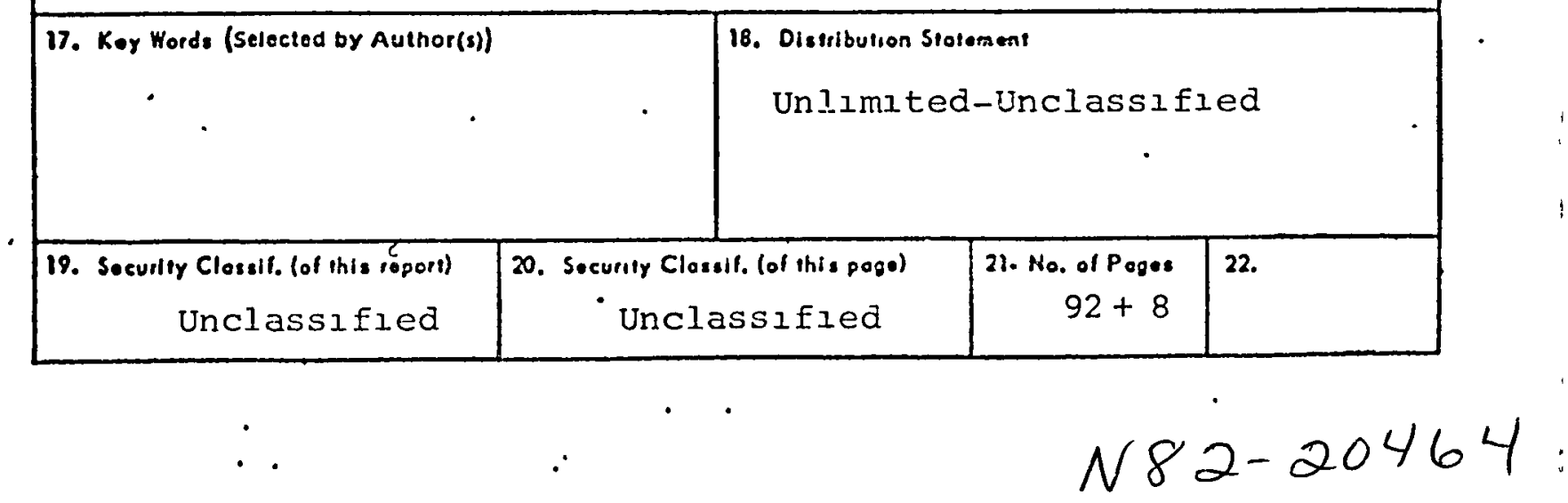




\section{ANNOTATION}

The objective of this study was to determine the influence of the channel geometry on pressure losses and heat transfer in non-circular channels with hydraulically smooth walls. As a basic assumption for the description of this influence, new integral geometrical criteria, selected according to experimental experience, were introduced. Using these new geometrical criteria, a large set of experimental data for pressure losses and heat transfer in circular and annular channels with longitudinal fins was evaluated. (ThIs research work had been performed in the Institute of Nuclear Research during the years 1967 through 1970.)

In this way it was empirically proved that the new criteria described channel geometry fairly unequivocally. Dimensionless relatronships for the friction coefficient $\xi$ and Nusselt number, Nu, expressed by means of these criteria have therefore universal validity. The universality of the new dimensionless relationship for $\xi$ has then been confirmed by adequate transformation of all obtalnable experımental results of similar studies done for all kinds of cross sections.

Detailed analysis and elaboration of experimental material men-' tioned above also made it possible to define with more precision the meaning of such concepts as flow development, transition regime, and non-isothermality influence in noncircular channels. 


\section{FOREWORD}

Knowledge regarding pressure losses and heat transfer in channels with noncircular cross setions is for all practical purposes based to this day only on empirical findings and the key tool for its expansion is experimentation. Computation methods worked out over the past several years on the basis of rudimental experimental findings are still in no position by far to provide with a known degree of accuracy an likely to occur query of what pressure losses and heat transfer would be perimental invest a chan not been subjected to prior exfact that tions (e.g. . configurations used in these methods as basic assumptangential ' configuration of velocity profiles, distribution of local their generaliess, etc.) have a narrowly limited range of validity and nels can lead to

As a matter of fact, the situation in this field is such that experimental findings from each specific channel geometry or crlterial relationships which describe the hydrodynamic and thermokinetic state in a given geometry still form an isolated point in the constantly expanding experimental materiel. Attempts to discover their mutual relationship have been unsuccessful. What we are after is not a completely generalized explanation, but a specific empırıcal method for approach to processing of experimental materiel which would make it possible to unite all extant materiel and discover crlterial relationships of more general valıdıty. In addition to their great practical importance, such criterial relationships -- in divergence to the enormous amount of scattered and diffuse experimental materiel -- would at the same time represent a basis of much better quality for studies oriented toward devising a theory of turbulent flow in channels with random cross sections and hydraulically smooth walls.

However, It ought to be pointed out that the by now relatively extensive experimental materiel has one basic shortcoming. Comparison of the results of measurements made by various authors on channels having an identical geometry shows in many cases that those results evince differences that are far from negligible and, at times, basic differences. As an example we can use a channel with a smooth annular cross section, which is the simplest geometry after a tube. So far, almost every author who investigated the state in annular rings, specifies a criterial relationship for the coefficlent of frlction losses that differs from that of other authors. A comparison oE the results arrived at by various authors is shown in fig. 4 which was taken over from a study by ort [4] and supplemented by results arrived at by Rybáček [3] and by the Institute of Nuclear Research. (The relative coefficient of friction losses in the diagram is related to the coefficient of frlction losses in a circular channel with the same Reynold's criterinels. A detailed comparison of in thermokinetics of annular chanheat transfer in this comparison of the results arrived at by studies of The differences found bet of channel was complled by Quirrenbach [19]. tens of percent. 
There can be a number of causes for such diEEerences, and an objective assessment of all factors that affected the individual results is not possible without a detalled knowledge of the experimental conditions and methodology used in processing of experimental data, etc. Yet, it is specifically in regard to these polnts that most publications provide insufficiently detailed data.

As the first attempt at generalization of experimental data can be considered Introduction of hydraulic diameter as the characteristic dimension of a channel together with the assumption that in defining channel geometry by means of $d_{h}$, criterial relations for a circular channel apply also to noncircular channels. However, it is clear by now that this method has a very limited area of application and that its indiscriminate use could lead to utterly wrong conclusions. At the same time it should be emphasized that the area of applicability of $d_{h}$ has not been clearly defined.

The presented study represents another such attempt at generalization of experlmental findings. It is based on a wealth of materlel obtained in the Institute of Nuclear Research auring investigation of pressure losses and heat transfer in channels with a smooth annular cross section, annular cross section having a core with longltudinal fins and a tube with internal longitudinal fins. Approximately sixty channels with strongly varying geometry [1], [2] have been Investigated in the course of these experiments. Detalled knowtained, together with the amount of such findings. facilitated a detailed analysis of the results and assessment of individual factors that could have influenced those results. In this manner were lald the basic prerequisites for such an experiment.

The result of the study was discovery of integral geometrical characteristics which unambiguously define channels with a noncircular cross section with hydraulically smooth walls from the viewpoint of pressure losses and heat transfer. By means of these geometrical characteristics it became possible to process the experimental materiel into universally valid criterial relations for the coefficient of friction losses and Nusselt's criterion.

The term "universally valid" used for descriolng these relationships is to be interpreted as not confining their validity only to a certain geometry, as comparison of these relations with published experımental values has shown their sultability for use with channels of the most varied geometries that find application in technical practice.

The author considers it to be a delightful obligation and an expression of thanks for valuable cooperation to emchasize the significant contribution made by his collaborators to the presented study.

Engr Jaroslay Hejna closely collaborated on this entire study and contributed a number of valuable suggestions and critical comments to
its final shape. 
Engr Josef Schmid, CSc, proposed and worked out all the requisite challenging programs for an automatic computer and carrled out extensive calculations on the computer GIER.

Last, but not least, the author's thanks go to his team of collaborators -- Engr M. Kezníček, Engr J. Cervenka, J. Stibor, S. Marušák and L. Vosáhlo -- for their selfless and inspired efforts in the design and production of experimental equipment, models, measuring instrumentation and in carrying out the actual measurements.

In conclusion the author thanks Engr V. Stach, Csc, for valuable suggestions and useful discussions which facilltated classification and polarization of opinions and findings. 
1. Foreword III

2. List of symbols VII

3. Brief description of experiments conducted at the Institute of Nuclear Research; method used in processing the results 1

4. Effects distorting experimental results 3

4.1 Transitory Region of Flow 4

4.2 Hydrodynamic Entry Sector 8

4.3 Thermal Entry Sector 10

4.4 Effects of Nonisothermal Flow 13

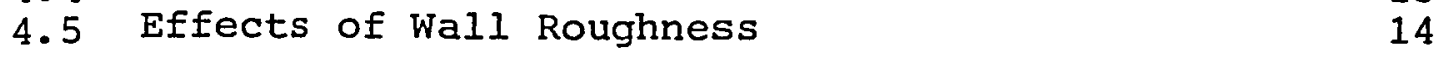

5. Basıc findings and assumptions 15

5.1 Pressure losses 15

$\begin{array}{ll}5.2 \text { Heat transfer } & 16\end{array}$

6. Integral geometrical characteristics 17

$\begin{array}{ll}6.1 & \text { Pressure losses } \\ 6.2 & 17\end{array}$

6.2 Heat transfer 20

7. Unıversally valıd criterial relations 21

7.1 Universal crlterial relation for $\xi \quad 21$

7.2 Unıversal crlterial relation for $\mathrm{Nu} \quad 22$

7.3 Thermal entry sector 24

7.4 Effect of thermal factor $\psi \quad 25$

8. Comparıson of the universally valid criterıal
relation for with experimental results of others 26

8.1 Triangular and Square Lattices of Parallel Rods 26

8.2 Channels with triangular cross section 27

8.3 Sheaf of Rods with Longltudinal Fins 28

8.4 Eccentric Annulus 28

9. Conclusions 29

10. References 30

11. IIst of diagrams and tables 33 


\section{LIST OF SYMBOLS}

\begin{tabular}{|c|c|c|}
\hline$x$ & longitudinal coordinate & [ m] \\
\hline$h$ & height of fin & [ $\mathrm{m}]$ \\
\hline$s$ & width of fin; rod spacıng & {$[\mathrm{m}]$} \\
\hline$n$ & number od fins; exponent & {$[1]$} \\
\hline$d$ & diameter of circular channel, rod diameter & {$[\mathrm{m}]$} \\
\hline$D$ & root diameter of finned tube & {$[\mathrm{m}]$} \\
\hline$D_{1}, D_{2}$ & inner, outer annular diameter & {$[\mathrm{m}]$} \\
\hline$\ell$ & length of model; length of measured section & {$[\mathrm{m}]$} \\
\hline$\ell_{T}$ & length of heated section & {$[\mathrm{m}]$} \\
\hline$\ell_{H}$ & length of hydrodynamic & {$[\mathrm{m}]$} \\
\hline$L_{T}$ & length of thermal & {$[\mathrm{m}]$} \\
\hline$S$ & wetted circuit & {$[\mathrm{m}]$} \\
\hline$F$ & cross-sectional area of flow & {$\left[\mathrm{m}^{2}\right]$} \\
\hline$S_{z}$ & fin circumference & {$[\mathrm{m}]$} \\
\hline$d_{h / 2}$ & hydraulic diameter & {$[\mathrm{m}]$} \\
\hline$\zeta$ & specific weight of gas & {$\left[\mathrm{kg} / \mathrm{m}^{-3}\right]$} \\
\hline$\lambda$ & thermal conductıvity of gas & {$\left[\mathrm{w} / \mathrm{m}^{-1} /\right.$ deg $\left.^{-1}\right]$} \\
\hline$\lambda_{m}$ & thermal conductivity of model tube material & {$\left[\mathrm{W} / \mathrm{m}^{-1} / \mathrm{deg}^{-1}\right]$} \\
\hline$\mu \nu$ & dynamic, kınematıc viscosity & {$\left[\mathrm{N} / \mathrm{s} / \mathrm{m}^{-2} ; \mathrm{m}^{2} / \mathrm{s}^{-1}\right]$} \\
\hline$c_{p}$ & specific heat at constant pressure & {$\left[\mathrm{J} / \mathrm{kg}^{-1} / \mathrm{deg}^{-1}\right]$} \\
\hline$p$ & static pressure & {$\left[\mathrm{N} / \mathrm{m}^{-2}\right]$} \\
\hline$t$ & local temperature; temp. at root circle & {$[\mathrm{deg}]$} \\
\hline$\theta$ & median gas temperature & [ deg] \\
\hline$\psi$ & thermal factor & [1] \\
\hline$u$ & velocity & {$\left[\mathrm{m} / \mathrm{s}^{-1}\right]$} \\
\hline$u^{+}$ & dimensionless velocity & [ 1] \\
\hline$y^{+}$ & dimensionless distance from wall & {$[1]$} \\
\hline$u^{*}$ & friction velocity & {$\left[\mathrm{m} / \mathrm{s}^{-1}\right]$} \\
\hline$G$ & flow-through weight & {$\left[\mathrm{kg} / \mathrm{s}^{-1}\right]$} \\
\hline N & overall thermal output & {$[\mathrm{W}]$} \\
\hline$q_{L}$ & thermal output per unit of length & {$\left[\mathrm{w} / \mathrm{m}^{-1}\right]$} \\
\hline$\alpha$ & coefficient of heat transfer & {$\left[\mathrm{W} / \mathrm{m}^{-2} / \mathrm{deg}^{-1}\right]$} \\
\hline$\tau$ & tangential stress on wall & {$\left[\mathrm{N} / \mathrm{m}^{-2}\right]$} \\
\hline$n_{\check{Z}}$ & fin efficlency & {$[1]$} \\
\hline$L$ & see relation in definition (29) & {$[\mathrm{m}]$} \\
\hline
\end{tabular}




\begin{tabular}{|c|c|}
\hline $\bar{I}$ & see definition in equation (29) \\
\hline$I_{0} \quad T$ & see definition in equation (31) \\
\hline & integral geometrical criterion \\
\hline$S_{r}, F_{r}^{o}, d_{r}$ & $\begin{array}{l}\text { see para } 6.2 \\
\text { geometrical factor }\end{array}$ \\
\hline$\xi$ & coefficient of fruction losses \\
\hline $\begin{array}{l}\text { Nu, Re, Pr } \\
\bar{N}\end{array}$ & $\begin{array}{l}\text { criteria of Nusselt, Reynolds and Prandt } \\
\text { median value of factor } N \text { along } \\
\text { cross-sectional area of flow } \\
\text { or along }\end{array}$ \\
\hline $\max$ & maximum value of factor $\mathrm{N}$ in channel \\
\hline
\end{tabular}




\section{PRESSURE LOSSES AND HEAT TRANSFER
IN NONCIRCULAR CHANNELS WITH HYDRAULICALIY SMO}

\section{J. Malak}

Czechoslovak Academy of Sciences, Prague, Czechoslovakıa,
Institute of Nuclear Research - Information Center in Rež 3. Brief Description of Experiments Conducted at the Institute of Nu-/7
clear Research; Method Used in Processing the Results A detailed description of experimental research into pressure
losses and heat transfer in channels with a circular and section having longltudinal fins, which was condular and annular cross of Nuclear Research in the years wich was conducted at the Institute and [2]. These reports also list the $1967-70$, Is provided in reports [1] form of relationships also list the results of measurements in the

$$
\xi=6(R e) \text { and } \mathrm{Nu}=6(\mathrm{Re})
$$

for the individual channels investigated. At this point we shall offer only a brief outline of basic information essential for this study.

The first stage of research included experiments with annular channels with longitudinal fins and a heated core. (ThIs geometry will be subsequently referred to as geometry $A_{\text {.) }}$ The fins were of was a total of 27 varlants with a wldth of $\sim 1.2 \mathrm{~mm}$. Investigated values of three basic geometrich represented combinations of three lected: channel width (or cross parameters for which they were sefins and height of fins. The lengthion of outer tube $D_{2}$ ), number of cases and was equal to $1,200 \mathrm{~mm}$. which could affect the results of Inlet into the experimental channel in fig. 1 .

The second stage involved experiments with circular channels with inner logltudinal fins. (This geometry will be referred to as geometry B.) The fins were essentially the same as those in geometry $A$. Simiing to combinations of three values to examine 27 variants correspondand height of fins. However, three varinner diameter of tube, spacing all, as finned tubes for those variants prescribed tolerances and with acceptab could not be produced with the of channels in all varlants was 2,050able surface quality. The length inlet is shown In fig. 2.

These experiments were then supplemented by investigation of pressure losses in $\mathrm{s} \mathrm{x}$ annular channels $(1,200 \mathrm{~mm}$ long) whlch represented $/ \underline{8}$

* Numbers in the margin indicate pagınatıon in the foreıgn text. 
Detalled data regarding all of the investigated channel models are listed in appended tables.

All experiments were conducted in an open air line with a ventılator located behind the outlet from the experimental section. The models were heated by resistance heating at a constant thermal output per unit of length of the model.

The measurements included in all cases the flow-through weight of alr, thermal output, distribution of static pressure along the channel, distrubution of temperatures of the heat-exchange surface on the root clrcle along the length of the heated model and alr temperature at the input and output of the experimental section.

Investigation of pressure losses was done in all cases at isothermal flow. The friction loss coefficient was computed with respecting the difference of the pulse at input and output of the measured sector according to the equation

$$
\xi=2 d_{h} \frac{\Delta p}{\ell}\left[\bar{\zeta}\left(\frac{F}{G}\right)^{2}-\frac{1}{\bar{p}}\right]
$$

wherein $\Delta \underline{p}=$ pressure loss in channel sector of length 1

$$
\begin{aligned}
\bar{p}, \bar{\zeta} & =\text { median values of pressure and specific weight of alr in } \\
G & =\text { flow-through weight } \\
F & =\text { cross-sectional area of flow }
\end{aligned}
$$

Reynold's criterion is given by the relation

$$
R e=\frac{G \cdot d_{h}}{F \cdot}
$$

For computation of the median value of the coefficient of heat transfer $\bar{\alpha}$ (centered along the heated circumference) was used equation

$$
q_{l}=\bar{\alpha}\left(\pi \cdot D-n \cdot s+\eta_{\check{z}} \cdot n \cdot S_{\check{z}}\right)(t-\theta)
$$

Derivation and analysis of the validity condltions for the equation/9, is contained in [1]. Of Importance to us is the fact that in our experimental conditions this equation is valid irregardless of the actual distribution $\alpha$ along the heated surface.

The connotation of individual values in equation (3):

$$
\begin{aligned}
n, s & =\text { number and width of fins } \\
D & =\text { root diameter of fins } \\
s_{y} & =\text { fln circumference } \\
t & =\text { wall temperature at root clrcle } \\
\theta & =\text { medlan temperature of gas }
\end{aligned}
$$

Efflciency of fins with a rectangular cross section was taken according to Gardner [16]:

$$
\eta_{\check{z}}=\frac{\operatorname{tgh} \omega}{\omega} \quad \omega=h^{\sqrt{2 \bar{\alpha}}}
$$

where $\lambda_{m}$ is thermal conductivity of the fins' material.

In determination of the delivered thermal output from unit length of the model $q$. in view of the structure of the used models (thrckwalled tube with fins) consideration had to be glven to axial heat sonductance. In view of the high thermal conductivity of the material of 
the finned tubes and the structure of the heating system we can assume an automodel distribution of temperatures in radial cross cuts of the model. This can be put in the form of

$$
q_{L}=\frac{N}{l_{r}}+F_{m} \cdot \lambda_{m} \frac{\partial^{2} t}{\partial x^{2}}
$$

The median temperature of gas at distance from input into the heated model at random distribution is determined by the relation

where $N=$ overall thermal output

$$
\theta=\theta_{0}+\delta^{x} \frac{q_{1}}{G \cdot c_{p}} d_{x}
$$

$1_{T}=$ length of the heated model

$F_{m}=$ cross section of finned tube

$\theta_{0}=$ gas temperature at input into experımental section.

A program was compiled for analysis of experımental values on the computer GIER. To facilitate solution of the system of equations $(3) \div(6)$, the experimentally determined distribution of temperatures along the length of the model was substituted for each regime by the method of least squares with a polynomial of the fifth order. At the same time, for the sake of comparison, was also determined the median coefficient of heat transfer without taking into consideration the effects of axlal heat conductance. Results of thermokinetic research were processed in the form of the relation

$$
\mathrm{Nu}=6|\mathrm{Re}|
$$

where values of Reynold's and Nusset's criterıa are counted with values of thermophysical properties of the coolant in relation to median temperature and gas pressure in the given radlal cross cut of the experimental channel.

In addition to $\bar{\alpha}, \mathrm{Nu}$ and $\mathrm{Re}$, in all cross cuts with measured surface temperature was also determined the thermal factor $\psi$

$$
\psi=\frac{t}{\theta}
$$

\section{Effects Distorting Experımental Results}

The basic prerequisite for succeeding in out attempt to unify and generalize the experimental material was to base this study only on cases in which measurements were not subjected to distorting effects. Talking of factors that can distort experimental results, our natural premise was that the objective of our experiments was to measure pressure losses or heat transfer in the region with developed hydrodynamic conditions (distribution of velocity, distribution of tangential stress on channel walls)or, eventually, with developed thermal conditions (automodel thermal profile $(t-\theta)$ ) in channels with hydraulically smooth walls.

Distorting factors can essentially be divided into two categories: The first category includes factors which in their essence are bound with the examined physical process and their distorting effect must be viewed as the consequence of our insufficient knowledge of the examined process. They are:

1. transitory region of flow

4. non-isothermity of flow

2. hydrodynamic entry-end sector 5 . roughness of walls.

3. thermal entry-end sector 
In addition to these factors, in individual cases come more-orless into play factors of the second category which are a consequence of the selected experimental concept, fallure to maintain the specified boundary conditions in its implementation, lack of surtability or Inaccuracy of the used measuring methods, etc. Assessment of such distorting effects (which should rather be called experimental errors) and an eventual making of suitable corrections in processing of experimental data 1s, however, within the realm of possibility of only and solely of the author of any given experiment.

Let us have a closer look at the factors in the first category, which in our oplnion are the key reason for a number of contradictory data found in experimental materiel. We attempted to cull from all accesible references the current state of knowledge regarding these problems and supplement them by our findings as well as by the results of an analysis of our own experimental materiel and that of others. Our objective was to redefine more accurately individual terms as well as to qualitatively assess the effects of individual factors in the case of noncircular channels.

\subsection{Transitory Region of Fjow}

The term "transitory region of flow" is used in hydrodynamics in two different connotations. In most cases we associate this term with that part of dependence of the coefflclent of frlction losses in a circular channel on the Reynold's criterlon, in which $\xi$ in transition from dependence on laminar flow to dependence on turbulent flow increases with Increasing Re. For the sake of difforentiation we shall refer to this region and the transitory region $\xi$.

We encounter this term in its second connotation in describing the velocity distribution in turbulent flow. This distribution is usually expressed in the form of the relation

$$
\left.u^{+}=\frac{u}{v^{*}} \begin{array}{c}
u^{+}=\delta\left(y^{+}\right) \\
v^{*}=\frac{\sqrt{\tau}}{\zeta}=\text { friction velocity }
\end{array}\right\}
$$

Here $u$ is local velocity ay distance $y$ from channel wall and $\tau$ is tangential stress on the wall.

In the area of the laminar substratum applies that

$$
u^{+}=y^{+}
$$

In turbulent core of flow in a circular channel -- and, accordIng to a number of experimental results also in nonclrcular channels -- the distribution of velocity occurs in accordance with the relation

$$
u^{+}=a \cdot \log y^{+}+b
$$

where constants $a, b$ according to some authors have universal validity while, according to others, they depend of the geometry of a channel. 
Between these two regions lies the region of transient flow --

which we shall refer to as transient region $u^{+}$-- in which occurs a laminar as well as a turbulent transfer ofthe momentum of motion. However, according to the latest findings this process cannot be interpreted as simultaneous effects of these tivo types of transfer, but as an irregular alternation of laminar and turbulent flow. A factor called coefficient of intermittence (discontinulty) $\gamma--$ which is defined as the time component during which turbulent flow prevails at a monitored polnt of the examined space -- Is used due to Its vividness for description of transient flow. Thus, if applies that $\gamma=0$, the flow is purely laminar, while at $\gamma=1$ the flow is completely turbulent.

In a circular channel the extent of the transitory region $\xi$ (expressed by the extent of $\mathrm{Re}$ ) as well as its lower boundary depends on a number of factors, the most important among them being geometrical conditions and the degree of turbulance at entry into the channel. In routine practice It is assumed that the transitory region lies at $\operatorname{Re}=(2,3+3,5) \cdot 10^{3}$. Nevertheless, during special conditions at entry, it became possible to maintain laminary flow into substantially higher values of Re.

The best insight into the processes that occur in the transitory region $\xi$ in a circular channel from the viewpoint of velocity conditions is provided by the results obtained by J. Rotta [15]. From detalled measurements of velocity states and their chronological changes he found out that in the transitory region $\xi$ throughout the flowthrough cross section the velocity distribution irregularly transfers from a developed laminar profile into a developed turbulent profile and vice versa. Hereby the coefficient of intermittence is not dependent only on Re, but simultaneously undergoes strong changes with distance from entry Into the channel (flg. 5). Thus, in a clcular channel the transitory region $\xi$ corresponds to velocity regimes during which the transient region $u^{+}$affects practically the entıre Elow-through cross -section of the channel.

Velocity conditions in a noncircular channel will differ from those in a clrcular channel in direct relation to the complexity of channel configuration. As a measure of complexity of configuration we can use the ratio of the maximum and median wldth of channel in the direction of normals to the surface, or the ratio of the maximum and median curvature of the wetted clrcuit. The most sultable and most objective measure of the complex configuration of a channel is distribution of tangential stress on the wall, or $\left(\tau_{\max } / \bar{\tau}\right)$.

In channels with complex configuration we do not deal any more with / 1 a cross section represented by a single simple region as is the case in a tube. In extreme cases we could rather talk of several regions that strongly differ from the hydrodynamic viewpoint and that retain a certaln measure of "autonomy". For better visualızation in limiting cases we can think of Individual reglons as independent channels connected in parallel. The hydrodynamic condltions in each of them would then be defined by its own Re. 
In a tube during developed turbulent regimes the laminar substratum region as well as the transient region $u^{+}$affects only a negligible part of the flow-through cross section. However, in channels with a highly complex configuration, laminar flow can be retained in some parts of the flow-through cross section up to relatively high values of $R e$, irregardless of the fact that in the remaining parts of the cross section prevails parallel turbulent flow, whereby the share of regions with laminar flow can be relatively high in regards to the overall flow-through cross section.

These regimes are vividly reflected in the results of measurements done by Eckert and Irvine [30] who investigated conditions in a channel with a cross section in the shape of an isosceles triangle with an apex angle of $11.5^{\circ}$. By means of visualization of flow and measuring of velocity profiles they delineated in the cross section the area of laminar flow and the dependence of 1 ts extent on Re (see fig. 51). At a still relatively high value of $R e=10^{4}$, at the apex of the triangle, up to $\frac{1}{10}$ of 1 ts height prevails purely' laminar flow.

The compounded structure of flow in a single channel, or simultaneous effects of laminar and turbulent transfer of motion necessarIly must become reflected also in a loss of pressure. Under these conditions the dependence of the coefflcient of Erlction losses on $R e$ will be analogous in character to that of $\xi$ in the transition area in a tube. Thus, from the viewpoint of local velocity conditions, the term "transitory region $\xi$ " assumes a broader connotation in the case of channels with complex configuration than was the case with a tube. However, from the viewpolnt of physical substance the connotation of this term is the same for all channel geometries. Thus, under the term transitory region $\xi$ we shall subsequently understand that part of Re in which in a given channel the frlction pressure loss is the result of the effects of laminar and turbulent transfer of motion.

On the basis of what was sald about velocity conditions in noncircular channels it could be expected that the transitory region in noncircular channels will be wider than in a circular channel and that the lower boundary of the region of purely turbulent flow will be shifted toward higher values of Re. This assumption is fully confirmed by experımental results.

From the hydrod-namic viewpolnt, the nonclrcular channel closest to a circular channel is an annular channel. The results of our measurements of pressure losses in six annular channels with a curvature of $D_{r} / D_{2}=0.65$ to 0.95 show that great differences exist already between clrcular and annular channels. Our results are plotted in fig. 3 in the form $1 / I \xi=6$ (Re $\Gamma_{\xi}$ ) supplemented by theoretical dependence of laminar flow in annular channels with $D_{1} / D_{2}=1$. For the sake of comparison the dlagram also shows the corresponding dependences for a smooth tube. It is obvious that the transitory region in the case of an annular channel is substantially wider than that of a tube. When we attempt to estimate from the progression of the dependence $1 / \mathbb{T}=$ $=f(R e \Gamma \xi)$, Interspaced by exp. points, the limlts of the transitory region, we obtain the values

$$
\begin{aligned}
& \operatorname{Re}_{D^{2}} \approx 2 \cdot 10^{3} \\
& \operatorname{Re}_{H} \geqslant 2 \cdot 4 \cdot 10^{4}
\end{aligned}
$$


where Indices $\mathrm{D}$ and $\mathrm{H}$ denote the lower and upper boundary, respectively. In determination of the upper boundary it is questionable whether the line interspersed with experimental points does really correspond to a purely turbulent regime, or whether at higher values of Re the actual progress might not resemble more closely, e.g., the relationship (21) which will be discussed in detall sub para 6 and 7 . The fact that in annular channels the boundary between the transient and turbulent region is less conspicuously defined than in the case of a tube, is the logical consequence of the already mentioned difference in velocity conditions. Nevertheless, it is clear that the region of purely turbulent flow in annular channels lies roughly by 1 order of Re higher than in the case of a circular channel.

Results analogous to those for annular channels were also obtained in our measurements on channels of geometry $A$ and $B$ which represent channels with one of the most complex conflgurations that have been investigated so far. Among our results there are a number of cases with a signiflcant share of the transitory region, or even completely dominated by the transitory region. Figures 11 and 12 show several/16 such typical cases for geometry $A$ and $B$.

The effects of geometrical conditions at the entry into the channel on the extent and boundaries of the transitory region $\xi$ can come to the fore very strongly even in channels with a complex configuration. Figures 7 and 8 show the plotted results of our measurements of four variants of geometry $A$ at varying entry conditions. Each of the measurements was done using two models. In spite of the fact that these models were to be absolutely identlcal from the hydrodynamical viewpolnt, measurements of pressure losses differed. Regretably, when we found out about these differences, the models II had already been destroyed and we could not undertake a detalled comparison of both models. However, supplementary verification of the production process turned up the fact that in some cases the edges of the model at its entry were rounded while in other cases their sharp edges were retained. Experiments with models I were therefore repeated under modified conditions at thelr entry, which we achleved by placing sheet-metal screens in front of the entry as is shown in fig. 1. In this manner we obtalned a third group of results which, in some cases approximate more the original results obtained with model $I$, in other cases the results obtalned with model II. For enhanced orlentation and easier comparison the results have again been plotted in fig. 9 and 10 in the form $1 / I \xi=f(R e I \xi)$. From the progress of individual measurements 1 t can be deduced that with increasing value of Re these dependences transform into a single dependence.

Analysis of the results obtained by other authors in measurement of pressure losses in channels of the most varlec geometries led us to the conclusion that a number of those results were obtalned in the transitory region $\xi$ without the authors of those studies being aware of it. It is a consequence of incorrect application of findings regarding the extent and boundaries of the transitory region $\xi$ in circular channels to noncircular channels. That, as a result, leads to a number of incorrect conclusions deduced from experimental results affected by the transitory region. 
In conclusion we ought to mention one more factor on the effects of which we were withdrawing comment for the time being. The results obtalned by $J$. Rotta clearly show that stabilization of flux conditions in the transitory region $\xi$ in the case of a tube calls for abnormally long channels (see fig. 5 and 6) on the order of several hundred $d_{h}$. The situation wlll be even worse in the case of nonclrcular channels. As channels used in investigation of pressure losses never attain such lengths, the results of measurement in the transitory region will probably be distorted even more by the effects of the entry sector.

\subsection{Hydrodynamic Entry Sector}

The term "hydrodynamic entry sector" denotes that part of the channel beyond the entry in which occurs developrent of the velocity profile from the initial profile at entry up to a fully developed profile corresponding to the preset hydrodynamic regime. Connected with the development of the velocity profile is also development of tangential stress or Its distribution along the wetted circuit, and development of transfer characteristics. The length of the entry sector depends on the hydrodynamic regime, the geometry of the channel, configuration of entry or, eventualiy, on defective flow prior to the experimental part.

Let us first examine the case of a tube. For laminar flow and a sharp-edged entry (i.e., with a balanced velocity profile of Input velocity) we theoretically derived the relation

$$
\frac{L H}{d}=\cdot R e
$$

The constant of proportionality differs from one author to another and ranges between 0.03 to 0.06 (see, e.g.. [11]).

In the case of turbulent flow, the decisive effect on the length of the entry sector accrues to the shape of the channel entrance. It is this shape that determines whether the boundary layer in the development of the velocity profile will be turbulent from the start, or whether at the beginning part of the channel it will first be laminar and only after a certain distance from it transforms into a turbulent boundary layer. As a rule of thumb, the aerodynamically smoother the entrance, the longer the entry sector. From experimentation we know that an aerodynamically smooth entrance calls for a channel length of at least $50 \mathrm{~d}$ If we are to achleve a perfectly developed velocity profile. The effect of Re are for all practical reasons absent.

As we already mentioned, the situation in the transitory region $\xi$ is entirely different, as is also shown by the results obtained by $\mathrm{J}$. Rotta. Figure 5 shows the dependence of the coefficient of intermittence in the transitory region on the relative distance from the entrance into the channel, and fig. 6 shows change of velocity in the /18 axis of a tube with Re for 3 distances from the entrance. Both figures show that stabilization of the velocity profile in the transitory region calls for channel length on the order of hundreds of diameters. 
In case of a geometry most closely resembling a tube, i.e., a smooth annular channel, the situation in the turbulent region is not clear. On the one hand, only very few experimental data are avallable and, on the other hand, these data show basic differences. In investigating pressure losses in annular channels in a range $D_{1} / D_{2}=$ $=0.77$ through $0.93, \mathrm{~J}$. Ort [4] measured the values of the entry sector in a range of $L_{H} / d_{h}=7$ through 21 . In keeplng with his results is also Dreissler's datum for a flat channel $\mathrm{LH}_{H} / \mathrm{d}_{h} \doteq 10$ (quoted from Ort's study).

Results analogous to ort's were also obtalned in our experiments with models of geometry $A$ and $B$. The values of $L_{H} / d_{h}$ ranged between 5 through 30, whereby a majorıty of cases were at the lower limit of that range?

Extreme maximum values of $L_{H} / d_{h}$ were determined for variants in which the investigated range of Re was completely or partially in the transitory region $\xi$.

We were assessing the length of the entry sector, simllarly to ort, from the progression of statıc pressure along the channel, or, to be more speciflc, from a comparison of the actual distribution of pressure with linear progression which was interspersed by experimental points in the region without apparent effects of the entry sector. The dijference between actual and linear progression was in most cases very small. In view of the aforementioned and with a view to the relatively short length of the entry sector (and the resulting small number of experimental points in the entry region) this procedure does not appear to be very accurate and the quoted values of $L_{H} / d_{h}$ must be regarded as only approximative information.

However, on the other hand, Rothfus with his collaborators [41]/19 in experimental investigation of annular channels in the range of $D_{1} / D_{2}=0.12$ through 0.35 came to the conclusion thatstabilization of hydrodynamic conditions calls for a channel length in excess of $200 d_{h}$. They based it on direct measurement of tangential stress on the inner diameter and its changes with distance from the entrance into the channel.

From what was said about experimental techniques used in individual cases we get an explanation of the difference between our results and those of ort on the one hand, and Rothfus' results on the other. While Rothfus based his approach on measurement of local values, our and Ort's measurements provide information only about the median value of tangentral stress on the wetted circult. And that is a substantial difference, the consequences of which we will best realize by a comparison of conditions in a circular and a noncircular channel.

\footnotetext{
In keeping with these values are also the results of experiments on enlarged models of geometry $A$ at $D_{1} / D_{2}=1$ that are currently conducted at the Institute of Nuclear Research. The accuracy of all measurements is at the same time substantially higher than was the case in experiments described in the report [1].
} 
Let us start out with a tube. We assume the presence of balanced entry conditions at the entrance into the channel. Under this assumption the local tangential pressure on the wall is identical with its median value along the clrcumference of the channel. With increasing distance from the entrance the gradually balanced velocity profile transforms into a developed profile. In the region close to the wall the velocity decreases whlle, conversely, it increases in the central part of the channel. There is a drop in the radial gradient of velocity at the wall and, as a result, with Increasing distance from the entrance there is also a monotonous decrease in tangential pressure on the wall.

The situation is substantially different in the case of a noncircular channel. Let us again assume a balanced velocity profile at the entrance, meaning that input velocity coincides with the median velocity in the channel. However, during development of the velocity profile the situation is not as unequivocal as was the case in a circular channel. In view of the configuration of the channel in some regions of the flow-through cross section the "median" velocity will decrease while the opposite will apply to other regions.. Tangential stress on the wall in individual reglons will also change correspondingly. From our and Ort's experiments we can draw the conclusion that development of hydrodynamic conditions in channels with cross sections of a complex configuration (i.e.. with $\tau_{\max } / \bar{\tau}>1$ ) progresses in such a manner so that - - with the exception of a small region beyond the entrance corresponding to values of $L_{H} / d / h$ from our and ort's experiments -- the development of local velocity condltions and local valus of $\tau$ has no effect on the median value of $\bar{\tau}$ and the latter, for all practical pur $-/ 20$ poses, does not change along the channel. According to our results, this conclusion should essentrally apply also to the transitory region $\xi$.

\subsection{Thermal entry sector}

The term "thermal entry sector" or, also, "sector of thermal stabilizatıon" denotes for us that part of the heated channel in which occurs the development of thermal condltions from the initial balanced thermal profile in coolant at the entrance to the heated section up to the region of automodel of thermal profile $(t-\theta)$.

In implementing an experiment or the real thing there can occur two different cases:

1. The beginning of the heated section is identical with the entrance into the investigated channel. Development of velocity and thermal conditions progresses simultaneously.

2. Ahead of the heated section is an unheated channel of 1 dentical geometry and, as a result, at the beginning of the heated section the velocity proflle is already fully developed in isothermal flow. Another relatively small change in hydrodynamic conditions occurs only in the flow ceasing to be isothermal. 
As in actual practice in a majority of cases is encountered the first case, and because our experiments were also conducted under such conditions, we shall subsequently deal only with this arrangement. As the development of hydrodynamic and thermal conditions progresses in the entry sector simultaneously with mutual interaction, these two processes cannot be separated from each other. Thus, whenever we refer to the thermal entry sector we will be referring to that part of the channel where there occurs development of flow simultaneously with the development of thermal conditions.

According to experimental findings, the lengths of hydrodynamlc and thermal entry sectors in a clcular channel are for all practical purposes approximately the same [11]. Most authors who have experimentally investigated this problem specify values of $L T / d_{h}$ ranging between 40 and 60 . In the case of noncircular channels, same as was the case of local hydrodynamic conditions, substantially higher values can be expected to be encountered than was the case with a tube. A few experiments conducted in this respect fully confirm such an assumption. Thus, e.g.: Eckert and Irvine in their already quoted study /21 [30] specify for the investigated triangular channel $L_{T} \geqslant 100 d_{h}$. The effects of the entry sector together with those of the transitory region $\xi$ also became strongly reflected in most published studies devoted to heat transfer in annular channels that used the method of constant temperature of the heat-exchange surface in determination of the median coefficient of heat transfer in the entire channel. Assessment of errors and limitations of this method from the viewpoint of determination of $\bar{\alpha}$ in the region with developed velocity and thermal conditions was done under the assumption applicable to a tube. This would also account for the great differences between the results of experiments conducted by various authors (see [19]).

We based our assessment of the effects of the thermal entry sector during our experiments with channels of geometry $A$ and $B$ on measurements of the progress of temperature of wall along the length of the model and the corresponding distribution of $\bar{\alpha}$. To enhance clarity and suppress the effects of $\mathrm{Re}$ the results were processed in the form

$$
\frac{\bar{\alpha}}{\bar{\alpha}_{r}}=b(x)
$$
For reference value $\bar{\alpha} r$ was taken the value of $\bar{\alpha}$ in the last measured
cross cut near the channel exit.

In assessment of the processed results, in the case of some variants there appeared certain errors and lack of logic in the distribution of $\bar{\alpha} / \bar{\alpha}_{r}$ that were caused by loss of heat at the end of the model. The method used for inclusion of the effects of axial heat conductance in the model on the distribution of $q_{L}$ did not manage to eliminate the effects of heat losses in some cases. This calculation method -- described in para 3,1 s based on experimentally determined distribution of temperature in the wall of the model, whlch by the method of least squares it replaces by a polynomial of the fifth order. This polynomial, which described temperature distrıbutions with a high degree of precision, did not suffice in some cases for the first and second derivation of temperature at the ends of the model. In such cases the assessed progress of $\bar{\alpha}$ at the end of the channel again rises. Then $1 t$ 
became necessary to carry out an analysis and comparison of progressions of $\bar{\alpha}$, evaluated with respecting as well as neglecting the effects of heat conductance, compare the progressions $\bar{\alpha} / \bar{\alpha}$ for various values of $R e$ and determine to what distance from the end the effects of heat loss extend. Such an example can be seen, e.g.. In fig. 14. To facilitate comparison, fIg. 13 and 15 show cases when the effect of terminal losses falled to materialize.

We determined that the length of the thermal entry sector in our experiments ranged between $L_{T}=(17-80) d_{h}$ according to the type of the examined geometrical variant. As the length of the models ranged between $50-400 d_{h}$, the region with developed velocity and thermal conditions was never reached in the case of some variants.

In assessment of the effects of the transitory region and of the entry sector, very effective proved comparison of the relations

$$
\begin{aligned}
& \frac{1}{\sqrt{\xi}}=6(\operatorname{Re} \sqrt{\xi}) \\
& \frac{\bar{\alpha}}{\overline{\bar{\alpha}}_{\Omega}}=6(x) \\
& N u=6(\operatorname{Re})
\end{aligned}
$$

Such a comparıson and placement of the relationships $(\xi),(\alpha)$ and $(\mathrm{Nu})$ into mutual connection provides a more comprehensive idea of the hydrodynamlc and thermokinetrc conditions in the channel and thelr change along the channel. Let us clte a few typical cases:

In variant 13 the relationshıp ( $\xi$ ) (fig. 11) up to a value of $\operatorname{Re}$ equal to $8.10^{3}$ has the character of a transitory region. At the same value of Re also the relationship ( $\alpha$ ) (fig. 13) shows a strong region of laminar heat transfer, and the relationship ( $\mathrm{Nu}$ ) (fig. 18), only at values of $\operatorname{Re}>8.10^{3}$ transforms into a relation of the type

$$
\mathrm{Nu}=\cdot \mathrm{Re}^{0.8}
$$

Analogous facts could be found in the case of variant $A 15$.

In the case of variant A 25 (flg. 11, 16, 18) all three relationships lie clearly in the transitory region and closer to the laminar region. (Values of $\mathrm{Nu}$ in fig. 18 were assessed in the one-before-last measured cross cut only for Illustration of the conditions.)

Variant B 18 represents a case in which there occurred a distortion of the relationship $(\alpha)$ (fIg. 17) as a result of a terminal loss, primarily in the last cross cut. For the progression of the relation / $/ 23$ $(\alpha)$ at varlous values of $R e$ it is readily obvious that in the region $\mathrm{Re}<3.10^{4}$ practically the whole model lies in the entry sector. In view of the fact that relationship ( $\xi)$ (fig. 12) up to $\mathrm{Re}=4.10^{4}$ is in the transitory region, the great length of the entry sector is to be expected. The relationship (Nu) also behaves in keeping with these factors (fig. 19).

These several typical examples clearly show how interrelation of the relationships $(\alpha),(\xi)$ and $(N u)$ makes it possible to identify even the relatively weak effects of distortıng factors. 
In conclusion, the effects of the entry sector (or effects of the length of a model) on the relationship $\mathrm{Nu}=f$ (Re) can be most vividly demonstrated in fig. 20 which shows the results of measurements on the variant B7 as a typical example. The points marked by circles are 10cal values of $\mathrm{Nu}$ at varyıng distances from the entrance into the channel plotted in relation to the local value of $\mathrm{Re}$. The almost vertical intermittent lines represent the progression of $\mathrm{Nu}$ along the length of the model at constant flow of coolant. Values of $\mathrm{Nu}$ decrease with increasing distance from the entry and at balanced conditions gradually attain a value corresponding to the sought after relation $\mathrm{Nu}=\mathrm{f}(\mathrm{Re})$. The second system of intermittent lines shows how would progress if we used models of varying length in our experiments. The resultant relation $\mathrm{Nu}=f(\mathrm{Re})$ is then distorted by the effects of the entry sector not only in regards to absolute values, but also form. The resultant form of the relation $N u=\zeta(R e)$ for the varlant $B 7$, shown by the thick solid line throughout the investıgated extent of $\mathrm{Re}$, corresponds to the typical form of this relationship for a circular channel with inclusion of the transitory region of flow (see, e.g., [3]).

\section{4 Effects of Nonisothermal Flow}

In assessment of thermokinetic experiments we relate all thermophysical properties of the coolant to its median temperature, i.e.. temperature computed from thermal balance. It appears, however, that with Increasing difference between the temperature of the wall and the median temperature of the coolant (i.e., with increasing thermal flow) at otherwise identical conditions of the experiment, the value of the thermal coefficient decreases. This phenomenon is caused by a change in the thermophysical properties of the coolant in the region at the heated wall as a result of high temperature gradients. This means that median temperature of coolant is not suitable as the defining temperature for thermophysical properties and that the correct value is to be found somewhere in the reglon between $t$ and $\theta$. This fact is respected in the criterlal equation for Nusselt's criterion by a sultable function of the so-called temperature factor $\psi$ which is defined as the ratio of wall temperature and the medlum temperature of coolant (see equation (7)).

Kutateladze 12 derıved on the basis of an analogy between transfer of motion and heat for gas-cooled clrcular channels the relation between the coefficlents of heat transfer at isothermal and nonisothermal flow in the form

$$
\frac{\alpha}{\alpha_{0}}=\left(\frac{2}{\sqrt{\psi+1}}\right)^{2}
$$

wherein $\alpha_{0}$ is the coefficient at $=1$.

However, most empirical findings are expressed in the form

$$
\frac{\alpha}{\alpha_{0}}=\psi^{-n}
$$

Relation (13) can then be replaced by relation (14) with $n=0.55$. The values of $n$ from the experiments range between 0.3 to 0.55 . However, we must realize that conducting an experiment that would facilitate direct assessment of the effects of the thermal factor is for all practical purposes impossible. In actual implementation of an experiment of 
this kind a change in $\psi$ is immediately accompanied by a change in and Re. As a result, assessment of the effects of $\psi$ is always indirect and burdened with large errors.

Since we are unable to describe the effects of nonisothermal flow with any degree of accuracy even in a circular channel, then in regard to channels with a complex configuration, where temperature of the heat-exchange surface varies along the circumference, we know practically nothing about these effects. At the same time, the error caused by the thermal factor can be considerably large. In the case of a tube, e.g., change in $\psi$ from a value of 1 to 1.3 corresponds to a change in $\mathrm{Nu}$ by approximately $13 \%$.

For that reason, operational conditions in investigation of heat transfer in geometry $A$ and $B$ were selected so that the thermal factor in the region of balanced thermal conditions be as identical as pos- /25 sible for all regimes of all tested geometrical variants. The thermal factor in our experiments is related to the wall temperature on the root circle.

We also attempted at the same time (as we shall mention later) to experimentally determine this effect for at least several variants.

\subsection{Effects of Wall Roughness}

Another factor that can strongly affect measurement of pressure losses in roughness of walls. The effects of roughness are relatively well known in the case of circular channels, the so-called sand roughness. This involves a case when the density of unevennesses 25 high and when the effects of roughness depend only on a single parameter $k / R$ ( $k=$ helght of unevennesses). We know substantially less in regards to cases when the density of unevenesses is low and when the effects are produced by their geometrical configuration.

As was the case in para 4.4, we must state that we dc not know anything about these effects in noncircular channels. Use of relations for a tube with sand roughness by means of the hydraulic diameter would in the case of channels with a complex configuration be illogical and make no sense. From what we know about circular channels it follows that we can regard a channel as hydraulically smooth (i.e.. there is no manifestation of the effects of roughness) in a case when the helght of unevennesses is smaller than the thickness of the laminar substratum. In view of the complex structure of flow in variegated channels the same absolute roughness will manifest itself in Individual parts of the channel in a different manner.

We only know that, same as in case of a tube, manifestation of the effects of wall roughness increases with increasing Reynold's criterion. As soon as wall roughness starts to affect the flow ccnditions, the gradient of the relation $\xi=f(R e)$ starts to drol and. in the end, this relation will transfer into the automodel region.

Rendering an objective decision whether the effects of roughness became manifested in a specific case - with the exception of the 
automodel region -- is impossible as long as we do not posses a detailed knowledge of circulation in noncircular channels. At the present time such assessment depends on the subjective explanation of the experiment's author or, more precisely, on the criteria selected by him for the assessment.

According to the criterion selected by us, no effects of roughness were encountered in our experiments.

5. Basic Findings and Assumptions

\subsection{Pressure Losses}

From a detailed processing and comparison of experımental data from our own as well as others' experiments, accompanied by a detailed analysis of experimental conditions, we reached the conclusion that in all cases, in which there is no manifestation of the formerly mentioned distorting effects, the coefflcient of friction losses in the region of developed turbulent flow corresponds to the general equation

$$
\frac{1}{\sqrt{\xi}}=c_{1} \cdot \log \operatorname{Re} \sqrt{\xi}+c_{2}
$$

wherein constants $C_{1}$ and $C_{2}$ are the function of channel geometry.

The empirically proven general validity of equation (15) thus narrows down the problem of finding a criterial relationship for the coefficient of friction losses to determination of the dependence of constants $C_{1}$ and $C_{2}$ on channel geometry. However, from this viewpoint, processing of experimental data in the form of the relation $1 / \sqrt{\xi}=6(\operatorname{Re} \sqrt{\xi})$ proved unsuitable. In this system the effects of experimental errors is reflected much stronger than in the system ( $\xi$ : Re), resulting in a larger scattering of experimental points. In view of the fact that our experiments in individual cases did not cover even one whole order of Re, we found it very difficult and problematic to accurately determine constants $C_{1}$ and $C_{2}$, which are very sensitive to interpolation of the relation (15). This applies primarly
to constant $C_{2}$.

Nevertheless, an informative assessment of constants $C_{1}$ and $C_{2}$ supplemented by an analysis of the the relationships $\xi=($ (Re) resulted in another finding which simplified the whole task. By simple transformation, with a precision corresponding to the precision of relation for a smooth tube. Such transformation corresponds to substitution of the hydraulic diameter by a more suitable characteristic
geometrical dimension. plies that

For given pressure losses and flow-through weight of coolant ap-
that

$$
\begin{aligned}
\xi & =\cdot d_{h} \\
\operatorname{Re} & =\cdot d_{h}
\end{aligned}
$$


If we desıgnate a suitable characterıstic dimension, which makes /27 the mentioned transformation possible, as $d_{0}$ and the corresponsong values of the coefficient of friction losses and the Reynolds criterion as $\xi_{0}$ and $R e_{0}$, then it applies that

We denote

$$
\frac{\xi_{0}}{\xi}=\frac{R e_{0}}{R e}=\frac{d_{0}}{d h}
$$

$$
\frac{d h}{d 0}=H
$$

and call this value a geometrical factor. The

$$
\begin{aligned}
\xi_{0} & =\frac{\xi}{H} \\
R e_{0} & =\frac{R e}{H}
\end{aligned}
$$

and because the values $\xi_{0}$ and $R e_{0}$ apply to Prandtl's universal law of friction, i.e.,

we can put it in the form of

$$
\frac{1}{\sqrt{\xi_{0}}}=2 . \log \operatorname{Re}_{0} \sqrt{\xi_{0}}-0.8
$$

$$
\frac{\sqrt{H}}{\xi}=2 . \log \frac{R e \sqrt{\xi}}{H^{3}-2}-0.8
$$

\subsection{Heat Transfer}

Heat transfer into a channel with a varlegated cross section can be described by means of a simple equation, such as, e.g., equation (3). only in certain cases and under certain conditions. Heat Transfer us generally described by equation

$$
q_{L}=s^{\int} \alpha(t-\theta) d S
$$

wherein

$$
\begin{aligned}
q_{L}= & \text { thermal output transferred from unit length } \\
& \text { of the heating element into the cooling gas } \\
t= & \text { local temperature of heat-exchanging surface } \\
\theta= & \text { median temperature of gas } \\
S= & \text { circumference of heat-exchanging surface }
\end{aligned}
$$

We can simplify this equation on the basis of the analogy between the transfer of motion and heat. We assume that distribution $\tau / \tau$, as well as distribution $\alpha / \bar{\alpha}$, merely a function of channel geometry. Ergo

$$
\frac{\alpha}{\bar{\alpha}}=b_{1}(S)
$$

In regions with stabilized thermal conditions we can further assume that the prerequisite of automodel distribution of wall temperature
has been met

$$
\frac{t-\theta}{\bar{t}-\theta}=b_{2}(S)
$$


Equation (22) can then be written in the form

$$
q_{L}=\bar{\alpha} \cdot(\bar{x}-\theta) \cdot s \delta b_{1}(S) \cdot b_{2}(S) \cdot d S
$$

The possibility for further simplification of equation (25) must always be considered in connection with the specific geometry of the channel and the specific design and material composition of the heated element. The justiflcation for each simplification must be verlfied by preliminary calculations made under various assumptions and distributions of $\alpha$ along the heat-exchanging surface. Consideration in this case must be given to both internal as well as external factors (i.e.. distribution of temperatures and thermal flows in the heated element). The objective of these calculations is to find out in what way use of simplifications could distort energy calculations or the information which the experiment is to provide.

Our subsequent comments involve only cases for which description of heat transfer could use an equation of the type

$$
q_{L}=\bar{\alpha}(\overline{t-\theta}) . S
$$

where centering is done along the circumference of the heat-exchanging surface.

Equation (3) used in assessment of thermokinetıc experiments on geometry A and B represents application of equation (26) to our speciflc geometrical conditions. The suitablitty for use of equation (3) as well as its limitations for channels with longitudinal fins was proven by a theoretical analysis and a number of calculations using the computer GIER. Detalls are contained in report [1].

Simllarly as was the case with hydrodynamics, we first concentrated on the form of dependence of Nusselt's criterion on Reynold's criterion. We undertook a detalled analysis of our own as well as accessible experimental materiel of others and eliminated all cases in which we reached the conclusion that measurement was not performed at balanced hydrodynamic and thermal conditions. In a great majorlty of cases we then determined the dependence of

$$
\mathrm{Nu}=\text { const. } R e^{0.8}
$$

The constant is a function of channel geometry, thermophysical properties of coolant and the thermal factor. If we further assume that the effects of thermophysical properties of the gasseous coolant can be expressed in the same way as for a tube, then relation (27) can be put in the form

$$
\mathrm{Nu}=0 \cdot \mathrm{Pr}^{0 \cdot 4} \cdot \mathrm{Re}^{0.8} \cdot \psi^{-n}
$$

where constant $D$ is merely a function of geometry.

\section{Integral Geometrıcal Characteristics}

\subsection{Pressure Losses}

The relation (21) generalizes our old experience that in certain cases involving nonclrcular channels the relation for a smooth tube /30 
can be used for determination of $\xi$ provided that we use hydraulic diameter as a characteristic dimension of the channel, while in other instances this procedure could lead to misleading conclusions.

Some authors tried to apply this experience in such a manner that In speciflc cases, where use of $d_{h}$ did not facilitate unification of experimental results, they made use of another dimension of the given geometry as the characteristic dimension. As an example we can cite triangular lattices of rods with longltudinal bypass flow. If we use as a characteristic dimension the diameter of a circle plotted onto the lattice, the results show good colncidence with a smooth tube. Such an approach - - if it produces results in the first place -- is always dependent on the author's estimate and cannot be used without prior knowledge of experimental results.

The kind of conclusions to which can lead an indiscriminate use of the hydraulic diameter and criterial relation for a tube can be 11lustrated on three typical cases.

Let us first consider a clrcular channel with very thin and deep internal radial slots. In such a case there is practically no difference in the flow-through diameter in comparison with a smooth tube, while the wetted circumference can increase by a number of times. The hydraulic diameter and the frlction loss coefficient will decrease in the same ratio. But it is clear that hydrodynamic conditions will not substantially differ from those in a smooth tube.

As a converse case we can take the eccentric annulus. According/31 to the definition of $d_{h}$ it should not be affected by accentricity and the latter should consequently also not affect pressure losses. However, we know from the experiment that pressure loss decreases with increasing eccentricity and that the difference in pressure loss between a concentric annulus and an annulus with eccentricity equal to 1 amounts to 30 to $40 \%$. However, hydraulic diameter in not an unequivocal characterıstic value even for such simple geometry as is a concentrıc annulus. Experıments have again proven that $\xi$ depends fairly heavily on curvature $D_{1} / D_{2}$ which is not reflected in $d_{h}$.

The relation (21) formally reduces this problem to the question of what determines the geometrical factor $H$ and what does it depend on. That means that we must find a factor that would be merely a function of channel geometry and whlch would respect in a correct manner the indlcated extreme cases. This factor must in some sultable way "weigh" the effects of Individual parts of the wetted diameter on flow in the channel. If such a factor is to unequivocally define channels of the most varied geometrical configurations from the viewpoint of hydrodynamics, this factor must be of an integral character.

I For simplification's sake we have so far neglected general conditions that some authors (e.g.. [13]) refer to as limiting the use of $d_{h, 1 . e .,}$ that in all parts of the flow-through dlameter the width of the channel in the direction of the normal must be higher than the thickness of the "boundary" layer in which occurs maximum change in velocity during turbulent flow. 
These general requirements could be used to define an infinite number of factors. We therefore embarked upon a search for a factor that would have the simplest and logical definltion which would be, relatively speaking, the easiest for assessment and which could be applied at least in part to some descriptions of turbulent flux. After various considerations and carrying out a number of auxiliary calculations and unsuccessful experiments which we will not describe here, we decided on a factor that some authors use as a local measure of turbulence and which in the case of a clrcular channel is interpreted essentially as the mixıng length.

The dissipative effect of an element of channel wall on random interference with flow in the vicinlty of polnt $M$ is quantitatively bound to reciprocal value of the distance of point $M$ from the given wall element. For that reason the characteristic distance $L$ of point $M$ from the channel wall is given by the integral

$$
\frac{1}{L}=\frac{1}{2}{ }_{2}{ }^{\pi} \frac{1}{l} d \varphi
$$

where 1 is the distance of point $M$ from the channel wall in the direc-/32 tion of $\varphi$. Relation (29) was used in his study [6] by Buleyev. According this relation the factor $L$ very closely resembles the measure of turbulence derived under assumption of resemblance of turbulent processes in various regions of liquid flux by $A$. M. Obukhov [40]. If we use relation (29) to assess the distribution of $L$ in a circular channel we find out that

$$
1=0.44 \mathrm{~L}
$$

The factor 1 in this case is the mixing path of Prandtl's semiempirical theory of turbulent flow, arrived at by Nikuradze from experlmental values of velocity distribution in a circular channel with respecting the actual distribution of tangential stress in the tube cross section.

The factor $L$, even though it respects the shape of the channel, is merely a local factor. However, the maximum value of $L\left(L_{\max }\right.$ ) median value of $L$ in the given cross section could be taken as a value characterizing the channel.

$$
\tau=\frac{1}{F} F^{S L} d F
$$

This factor which has the dimension of width is not only a function of channel configuration, but is at the same time a function of its absolute size. We therefore used as channel characteristic the factor

$$
L^{*}=\frac{I}{L_{0}}
$$

which we shall refer to as the integral geometrical criterion or characteristic.

The factor $L_{0}$ in relation (30) denotes the median characteristic distance $I$ for an equivalent tube:

$$
I_{0}=0.0887 \cdot d_{h}
$$


The flow-through cross section of noncircular channels can form an $n$-times coherent region bounded by $n$ closed curves. Each of these curves corresponds to a part of the wetted clrcuit that can be indlvidually heated. If in processing the values from investigation of pressure losses we could define channel geometry by a single geometrical characteristic, similar approach is not possible when dealing with heat transfer in a region with multiple connections. In such a case we must respect the distribution of $\alpha$ in the individual parts of the wetted circult. (However, from the viewpoint of Individual parts of the circult, we agaln work with the median value of $\bar{\alpha}$ in the given part -- see equation (26)). Thus, we need one more geometrical factor which would respect distribution of $\alpha$. We undertook selection of this factor on the basis of the following simple contemplation:

If we assume the validity of Reynold's analogy between transfer of motion and heat, then applies that

$$
\frac{\bar{\alpha}_{i}}{\bar{\alpha}}=6\left(\frac{\bar{\tau} i}{\bar{\tau}}\right)
$$

where factor with the index " $i$ " are related to the $i$-th part of the wetted circuit. We further assume that no transfer in motion occurs accross the orthogonal trajectory to isotachs which intersects the relative maxima of velocity. This line is then plotted in approximation of the corresponding line in field L. ${ }^{1}$

If we now designate the area bounded by this trajectory and the heated circuit as $F_{T}$ and the heated circuit $S_{T}$ we can formulate

$$
\frac{\bar{\alpha}_{i}}{\bar{\alpha}}=61 \frac{d T_{i}}{d h} \quad d_{T}=\frac{4 F_{T}}{S_{T}}
$$

We then used the factor $d_{T} / d_{h}$ together wath the factor $L^{*}$ in processing experimental data regarding heat transfer in channels the flowthrough cross section of whlch represents a doubly connected region.

For a simply connected region it applies that

$$
d_{T} \equiv d_{h}
$$

Computation of both integral geometrical characterıstics $L^{*}$ and $d_{h} / d_{T}$ in the case of more complex geometries is practically impossible without a computer. Programs and calculations for our needs were provided by Engr J. Schmid, CSC. Detailed methodology is in report [17].

1 We verlfied this assumption for the case of a smooth annulus, it belng the only one for which experimental documentation is available. A part of the authors stipulates that the position of maximum velocity arrived at through assessment of the experiment conforms to the theoretical relation for laminar flow also in the region of turbulent flow. Roberts in his theoretical study [18] uses for turbulent flow a relation derived from experiments, one that differs from laminar flow. The relative position of maximum velocity in relation to the curvature of the annulus according to both relations is shown in fig. 26. The relative position of $L_{\max }$ lies between these two progressions. 


\subsection{Universal Criterial Relation for $\xi$}

In assessment of the geometrical factor for the individual types of channels investigated we used the experimental relation $1 / \sqrt{\xi}=$ $=6(\operatorname{Re} \sqrt{\zeta})$ as a guide for determining whether the entire measurement or its part was affected by the transitory region $\xi$. Actual assessment of $H$ was done graphlcally from experimental relations $\xi=f(\operatorname{Re})$. With the use of a simple mechanical device (template) it was easy to perform transformation to Prandtl's universally valid law of friction and directly read off the value of $H$.

In our search for the dependence of $H$ on channel geometry, the experimental values of $H$ were plotted consecutively in relation to $L^{*}$. $L_{\max } / d_{h}$ and a combination of the two in the form ( $\left.L_{\text {max }}^{2} / \tau, d_{h}\right)$. The results are shown in fig. 21 through 24 in such a manner that. the individual investıgated variants can be identified by markıngs of experimental points. (The used symbols are shown in tables for geometry $A$ and $B$.$) Figures 21$ and 22 are practically identical, however the latter figure shows only differentiation of geometry $A$ and $B$ and also includes results obtaıned by Rybáček [3].

Smooth annulus is represented by a single point with indicated dispersion which includes the results obtained by the Institute of Nuclear Researrch, by Rybáček [3] and ort [4], as shown in fig. 27. The factor $L^{*}$ does not depend on it practicaliy at all in the case of small annuli from a curvature of $D_{1} / D_{2} \approx 0.4$ and up (see fig. 53) and has a value of 0.934 . This value of $L^{*}$ represents the absolute minimum of $L^{*}$. There is no geometry that could have a lower $L^{*}$.

Comparison of fig. 21, 23 and 24 clearly shows that the relation $H=E\left(L^{*}\right)$ results in a substantially smaller dispersion of experimental points than is dependence of on two other factors. Thus, we are of the opinion that the integral geometrical criterion $L^{*}$ defines channel geometry better than factors $\left(L_{\max } / d_{h}\right)$ and $\left(L_{\max }^{2} / L_{0} d_{h}\right)$.

The dependence of on channel geometry can be now expressed by the relation

$$
H=0.268 \text { tio } 0.842\left(L^{*}\right)^{-1.2}
$$

Nevertheless, the exception in this relation is formed specifical- /36 Iy by a smooth tube, the law of turbulent friction of which we used as the basis for our processing. Relation (35) yield for a tube the value of $H=1.1$ instead of the correct value $H=1$.

We have failed so far in finding a satısfactory explanation for this contradiction. The simplest and most probable explanation might be that the used method, to include the integral geometrical characteristic, represents only a certain degree of approximation of actual condltions and, as such, cannot be in agreement wlth all empirical findings. 
However, we must realize at the same time that a circular channel represents from the viewpoint of all other types of channels a certain extreme in two directions:

1. It is the only channel in which the local value of tangential stress on the wall is Identical with the median value of $\tau$.

2. Of substantially more importance is tine fact that for all practical purposes purely longltudinal flow exists solely in circular channels. In all other types of channels that were subjected to experimental investigation, there was evidence of a secondary transverse flow which strongly affects the distribution of $\tau$ along the wetted circuit and which necessarily must also become reflected in the extent of pressure losses. A possible exception from this allegation might be formed by annular channels. However, the results of measurements made so far still show enough divergence to preclude formation of an unequivocal conclusion.

An answer to these problems could be provided only by a well-founded theory of turbulent flow in channels with a random cross section -if it can be formulated.

Finally, plotted in fig. 25 are all our experimental results processed in the form of relation (21) with theoretical values of $H$ accordlng to relation (35). The median error in comparison with relation $(20)$ is less than $10 \%$, which in view of the overall accuracy of the experiments can be considered to be a very good result.

In this manner the relation (21) in connection with relation (35) represents a criterlal equation for the coefficient of friction losses the validity of which is not limited to merely a certain channel geometry. We will prove its potential application to all types of channels sub para 8 .

\subsection{Universal Criterial Relation for Nusselt's Criterion}

All of our experiments were conducted in such a manner as to have the thermal factor in the region of balanced thermal conditions range between $\psi=1.2$ to 1.3 ; median temperature $\psi=1.27$. As the characteristic thermokinetıc factor for individual geometrical varlants was selected and computed from experiments the value of nusselt's criterion for $\mathrm{Re}=5.10^{4}$. We then gradually verlfied whether this value can be brought into an unequivocal dependence on some of the simple combinations of factors $L^{*}, L_{\max }$ and $d_{h} / d_{T}$. whlch can be arrived on the basis of certain clear concepts of the transfer conditzons in a channel. In this manner we have proven that this requirement can be met only by the geometrical criterion $L^{*}$. The dependence of the values $N u_{5}$ on the geometrical criterion $L^{*} \frac{d}{d}$ is shown in fig. 28. Marking of the experimental points again facilitates identification of the individual varlants being investigated.

Figure 29 shows the same dependence, but point markings serve only to differentiate geometry $A$ and $B$. Experımental results arrived at by 
K. Rybǎček [3] are also Included. His experıments were carried out at other values of $\psi$ than were our experıments. As much as facilitated by data in [3], we computed the thermal conditions for the experiments done by Rybáček and converted his results to our conditions by means of Kutateladze's relation (13). In spite of the fact that the chosen approach can be considered to be only a rough approximation of actual conditions, the coincidence between those values and our own results is good.

The Interpolated relation in fig. 28 could be expressed by

$$
\mathrm{Nu}=97 .\left(L^{*} \frac{d h}{d T}\right)^{-0.91}
$$

If we assume that even in the case of channels with a complex cinfiguration the effects of termophysical properties of the coolant can be expressed by means of the factor $\mathrm{Pr}^{0} \cdot{ }^{4}$ and the effect of the thermal factor by Kutateladze's relation, than from relation (36) we obtain a modified known relation for a circular channel:

$$
N u=0.022 \cdot P^{0.4} \cdot R e^{0.8} \cdot\left(L^{*} \frac{d h}{d}\right)^{-0.91} \cdot \psi^{-0.55}
$$

Thus, relation (36) precisely intersects the point which corres- /38 ponds tothe value $\mathrm{Nu}_{5}$ for an air-cooled clrcular channel.

Let us return one more time to the diagrams in figures 28 and 29 . In comparison with investigation of pressure losses, the results ontained in experimental investigation of heat transfer with a view to the number and type of measured factors always burdened by larger errors. At the same time, investigation of heat transfer is more subjected to the distorting effects of the transitory region $\xi$ and of the entry sector. If we become aware of this fact, we can assess the dispersion of experimental points on these diagrams as relatively small.

Figures 30 and 31 show plotting of all experimental relations $N u=6(R e)$ adapted in the form

$$
\frac{\mathrm{Nu} \cdot\left(L^{*} \frac{d h}{d T}\right)^{0.91}}{97}=6(\operatorname{Re})
$$

Points which lie beyond the region of $\pm 10 \%$ in comparison to the relation (37) belong for their major part to a few geometrical configurations for which it was not possible to unequivocally determine whether the measurement was affected by one of the mantioned factors or not.

Equation (37) can again be regarded as a criterlal relation for Nusselt's number, which is not bound to a single specific geometry. Nevertheless, in comparison with the criterial relation for $\xi$, the use of this equation is limited by several conditions:

1. The basıc condition, which we polnted out already sub para 5. is suitability of equation (26) for computation of heat transfer in a specific case. Otherwise this condition may be defined so that heat transfer must be dependent on the actual distribution of the local coefflcient of heat transfer along the heat-exchanging surface. 
2. Relation (37) was derived from experimental values measured in channels with a flow-through cross section represented by a singly of doubly connected region. No experimental documentation aws avallable for multiple connected regions and suitability of relation (37) for such cases would first have to be established.

3. Contrary to relation (21), it was not possible to compare equation (37) with a larger number of other authors' experimental findlngs regarding varıous channel geometries.

\subsection{Thermal Entry Sector}

In an effort to make widest possible use of experimental materiel and to obtain as many specifically formulated findings, I attempted to derlve from the experimental progressions of $\frac{a}{\sigma_{r}}=6(x)$ the dependence whether integral geometrical characteristics could also be used in this case as an unequivocal geometrical criterıon. We were aware at the same time of the fact that experimental documentation, in view of the overall concept of our experiments and accuracy of measurements, was not exactly the most sultable for this purpose. For that reason we regard our results to be merely the first bit of information offered about this problem and an incentive showing the approach to this particular problem. Thus, we shall limit our comments to a mere listing of our conclusions:

Distribution of the coefflcient of heat transfer along the model can be described by equation

$$
\frac{\bar{\alpha}}{\overline{\alpha_{\infty}}}=1+0.1 \frac{L T_{1.1}}{\chi}
$$

This equation formally coincides with the equation for distribution of $\alpha$ in a cIrcular channel, which -- with reference to the study of Boelter, Young and Iverson -- is quoted in study [11].

The factor $L_{T_{1.1}}$ is an $x$-th section coordinate $w 1$ th $\frac{\bar{\alpha}}{\bar{\alpha}_{\infty}}=1.1$. This factor is a function of channel geometry and of Reynold's criterion, whereby dependency on Re is substantially weaker. In most variants, the experimental results of which could be used for this purpose, $L_{T}{ }_{1.1}$ increases with the Reynold's criterion up to values of $\mathrm{e}^{\mathrm{p}}=2$ to 3.10. For higher values of $R e$ the value $L T_{1}, 1$ remains constant. For these cases and for the region $\mathrm{Re}>3.10^{4}$ we devised the relations

$$
\begin{aligned}
& \frac{L T_{d_{h} L}}{d_{h}}=6\left(L^{*}\right) \\
& \frac{L T_{L_{h} L}}{d_{h}}=6\left(L^{*} \frac{d_{h}}{d_{T}}\right.
\end{aligned}
$$

The results are plotted in fig. 32 and 33. The geometrical characteristic $L^{*}$ even in this case is not an unequivocal characterlstic of the channel. As a result, relation (40) has one form for geometry A
and another form for geometry B. 
Relation (41) in comparison with the preceding relation is rela- /40 tively unequivocal, but experimental points show considerable scattering. From interpolation of experimental points we can express this relation by the equation

$$
\frac{L T_{1.1}}{d h}=25\left(L^{*} \frac{d h}{d T}\right)-22
$$
For lilustration we computed the experimental progress of $\frac{\bar{\alpha}}{\bar{\alpha}_{\infty}}$ in
the form of relation

$$
\frac{\bar{\alpha}}{\bar{\alpha}_{\infty}}-1=6\left(\frac{x}{L_{T_{1.1}}}\right)
$$

The value $L T_{1.1}$ was for this purpose computed for individual varlants from relation (42). The results are shown in fig. 34, which is being introduced without comment.

\subsection{Effects of Thermal Factor $\psi$}

For some variants of geometry A we conducted experiments designed to produce results that would offer more accurate information about the effects of thermal factor $\psi$ in channels with complex configuration. Wall temperatures of the model were measured at a constant flow-through weight of coolant and at vaying values of thermal output and we determined the coefficient of heat transfer in the region of developed thermal conditions. This approach was designed to suppress the effects of Reynold's criterion as much as possible.

The results were processed in two ways:

1. The first approach did not take into consideration any change in the Reynold's criterion in the investigated cross section as a result of varying values of median gas temperature in individual regimes. Thus, effects in changes of Re on the Nusselt criterion were also disregarded. The results obtained through this approach are shown in fig.
35 in the form of the relation

$$
\frac{N u}{N u(\psi=1 \cdot I)}=6(\psi)
$$

To prevent an eventual distortion of the results as a consequence of an erroneous extrapolation of the relation $\mathrm{Nu}=6(\psi)$ into $=1$, we related the relative value of Nusselt's criterion to the value of $\mathrm{Nu}$ at $\psi=1.2$. This value lies for all variants in the investigated range of

It stands to reason that this approach is neither correct nor is /41 it logical. Nevertheless, it is interesting that the experimental results can be well described by Kutateladze's relation (13).

2. The second approach did take into consideration the effects of changes in gas temperature on the value of Re and the effects of
the change on the value of $\mathrm{Nu}$. 
The results are shown in fig. 36. Their analysis showed that for all the investigated variants the effects of the thermal factor can be expressed by the relation

$$
\frac{N u}{N u(\psi=\pi)}=\psi^{-n}
$$

but that the exponent $n$ is again a function of geometry. The dependence of $n$ on channel geometry ${ }^{1} s$ expressed in two ways in fig. 37 and 38:- One makes use of factor $L^{*}$, the other $\left(L^{*} \frac{d}{d} \frac{h}{T}\right)$ as the geometrical criterion.

In view of the conduct and precision of experiments and the used methodology for processing the results, point dispersion is not excessive in either case. However, there were entirely too few experimental points to warrant drawing of any conclusions from these results.

As these experiments were conducted only on models of the geometry $A_{1}$, it is not possible to judge which geometrlcal criterion would be more surtable for this purpose. However, it can be assumed that same as was the case with the thermal entry sector, the most unequivocel geometrical characteristic will turn out to be the criterion $\left(L^{*} \frac{d h}{d T}\right)^{\text {. }}$

8. Comparison of the Unlversal Criterial Relation for $\xi$ With Exper- /42 imental Results obtained by Other Authors

To prove the universal applicability of the criterial relations (21) and (35) for the coefficient of friction losses in a wide range of channel geometries, we undertook a comparison of this relation with experimental values for all types of channels for which we could find credible documentation in technlcal literature.

\subsection{Triangular and Square Lattices of Parallel Rods}

A sheaf of parallel rods arranged into a triangular or square lattice may be regarded as one of the key geometries of channels from the viewpoint of nuclear power englneerıng. There is also a relatively large volume of experimental materiel avallable for this geometry. For these reasons, sheaves of rods with parallel by-pass flow recelved the greatest amount of our attention.

Documentation for computation of $H$ in both types of an infinite lattice represents the dependence of the grometrical criterion $L^{*}$ or of the geometrical factor $H$ on lattice density $s / d$. The graphic form of these dependencies processed on computer GIER is shown in fig. 39. Comparıson of experimental and computed values can be most vividly performed by comparing the relations

$$
\frac{\xi_{0}}{\xi_{0}}=\sigma\langle s / d\rfloor
$$

wherein $\xi_{0}$ is the coefficient of friction losses in a circular channel at a given $\mathrm{Re}$. The relation (45) can be substantially simplified for computation. The criterial relation for the coefficient of friction 
losses (21) can be substituted in the region $R e<10^{5}$ by the relation

$$
\frac{\xi}{H}=0.316\left(\frac{R e}{H}\right)^{-0.25}
$$

After substitution from equation (46) Into the relation (45) we obtain

wherein $H=6(s / d)$.

$$
\frac{\xi}{\xi_{0}}=H^{125}
$$

A comparison of this relation with experimental values for a tri- /43 angular lattice is shown in fig. 41. It can be stated that there is a congruence of almost $100 \%$.

Investigations of velocity fields and of the distrubution of tangentral stress in an infinite triangulat lattıce routinely make use of models with a configuration shown in fig. 42. However, due to their infinite dimensions these models are not suited for investigation of pressure losses, as has been experimentally shown a number of times already. Fig. 42 shows a comparison of experimental and computed values for this type of channel. For the sake of comparıson, the same figure shows the theoretical dependence for an infinite lattice. The deviations of experımental values from theoretical dependence are smaller than is the dispersion of experlmental points. Figures 43 and 44 show a comparison of the experimental dependence of $\xi=6$ (Re) with theoretical dependence for various types of lattice density. Their coincidence is outstanding in all cases. Figure 44 also shows the potential extent of effects on overall losses that can be caused by inert draughts between sheaves of rods and the channel proper.

The same conclusions, in regards to congruence between theoretical dependence and experimental results, can be drawn from diagrams 45 , 46 and 47, which show a comparison for the elements of a square lattice and an inifinite square lattice.

Into this group of channels we could also include the channel in fig. 54. Three rods are placed in a triangular channel with rounded corners. Study [33] investigated the dependence of pressure losses in relation to the relative separation of rods. The forms of theoretical and experimental dependence are very simllar in splte of the fact that dependence $\xi=f(S / d)$ is not monotonous. However, with decreasing value of $S / d$ the differences between the two progresses increase. Nevertheless, it is difficult to reach any conclusions from this comparison. Experimental values were obtained for small values and a narrow range of Reynold's number. Figure 55 shows experimental results recomputed into the relationship $1 / \sqrt{\xi}=6$ (Red $\sqrt{\xi})$. It is very difficult to determine from these progressions whether the measurement was affected by the transitory region of $\xi$. However, that possibility should not be excluded.

\subsection{Channels with a Triangular Cross Section}

Comparison of theoretical dependence with experimental values for channels with a cross section in the shape of an isosceles triangle turned out to go less in favor of theoretical dependence than was the / 44 
case in the preceding instance. Comparison of theory and experiment at varying values of the apex angle $\beta$ of a channel is shown in fig. 49 whIch has been essentially taken over from study [32]. In regard to form, theoretical and experimental dependence is mutually similar and at a value of $\beta=60^{\circ}$ they coincide also as to their absolute value. However, with decreasing $\beta$ the difference between the two dependencies increases up to $12 \%$. The progress of both depenconces is interesting in the region $\beta \rightarrow 0$. We originally mistakenly assumed that this limiting case corresponds to parallel plates. Only computation of the geometrical crlterion $L^{*}$ for a unlform trapezold with varying values of the apex angle and varying ratio of helght to base (fig. 52) showed how strongly changes the character of the dependence $L^{*}=6(t / H)$ in the region $\beta \rightarrow 0, t / h \rightarrow 0$.

The small divergence between theoretical and experimental progress could be explained on the basis of the results obtained in the previously cited study [30]. The latter does not exclude the possibility that in the reglon of Re, in which the triangular channels were investigated, in a part of the channel could occur laminar flow. In that case the measurement results would be affected by the transitory region $\xi$.

\subsection{Sheaf of Rods With Longitudinalfins}

We undertook a comparison of the theoretical relation with experimental results obtained by $V$. Krett [37] for a sheaf of rods. each with three longitudinal fins. The channel diagram and the measurement results are shown in fig. 56. Theoretrcal dependence Is very well centered on experimental results obtained for isothermal and nonisothermal flow.

\section{4 Eccentric Annulus}

Eccentric annulus represents a typical example of a channel in which use of hydraulic dlameter as a characteristic dımension fals. The more we were interested to find out how well would apply the criterial relation (21) with relation (35). As we did not have at our disposal any studies providing experimental values, we used for comparison the relation

$$
\frac{\xi}{\xi_{\varepsilon=0}}=(1-\varepsilon)^{0.178}
$$

(where is eccentricity) which was used in study [34] and was assess- /45 ed on the basis of experimental findings in studies [35] and [36]. This relation does not take into consideration the experimentally detected weak effects of curvature. Its validity is also limited in the direction of an increase in $\varepsilon$.

In fig. 57 this relation is compared to two theoretical dependences for $D_{1} / D_{2}=0.5 ; 0.95$. Congruence is agaln very good. 
1. An analysis of our and other authors' experımental findings in the measurement of friction and pressure losses in noncircular channels with hydraulically smooth walls showed that in all cases in which the results have not been affected by distorting factors, the dependence $\xi=6$ (Re) can be applied by sumple transformation to the Prandtlian universal law of friction in a smooth tube. The transformation relation is hereby merely a function of channel geometry.

2. On the basis of empirical findings we formulated general requirements for selection of geometrical characteristics factors which could play at a higher level a role simllar to that played by hydraulic diameter at the outset of research into flux in noncircular channels. On the basis of these requirements we defined integral geometrical characteristics (criteria) and it was empirically proven that these criteria relatively unequivocally define the geometry of noncircular channels from the viewpoint of pressure losses and transfer of heat.

3. We used these geometrical criteria to process experimental materiel from research of pressure losses and of heat transfer in circular and annular channels with longitudinal fins. In this manner we obtained universal criterlal relations for the coefficient of pressure losses and the Nusselt criterion. (Validity of the relation for $\mathrm{Nu}$ is of course milited to gaseous medla with $\mathrm{Pr} \sim 1$. )

4. Comparison of the criterial relation for $\xi$ with published experimental values for noncircular channels showed applicability of this relation for channels with the most varied configuration with hydraulically smooth walls.

5. Unification and generalization of experimental materlel which is facilitated by these criterial relations make it possible to expand our knowledge in regards to flux conditions in noncircular channels as regards integral characteristics and provide an improved basis for the study of turbulent flow theory than was offered previously by the widely splintered experimental materiel. 


\section{REFERENCES}

I. Maläk, J., Řeznǐček, M., Červenka J. and J. Hejna, "Hydrodynamics and Thermokinetics in Annular Channels With Longitudinal Fins," Institute of Nuclear Research, Report 2187/R,T/1969.

2. Červenka, J., Hejna, J. Malák, J. and M. Řeznǐček, "Hydrodynamics and Thermokinetics in Circular Channels With Longitudinal Fins," Institute of Nuclear Research, Report 2501/R,T/1970.

3. Rybáček, K., "Selected Cases of Heat Transmission During Longıtudinal By-Pass Flow of Elements, Particularly Those With an Expanded Transfer Surface," State Research Institute of Thermal Engineering, Report 63-05033.

4. Ort, J., "Experimental Research of Turbulent Flow and Heat Transfer in Annular Joints Flown-through by a Gaseous Medium," State Research Institute of Thermal Englneering, Report 64-08004.

5. Gotovskiy, M.A. and E.V. Fırsova, "Heat Transfer and Hydrodynamıcs in Elements of. Power Systems," Trudy CKTI, 73, 1966.

6. Buleyev, N.I., "Heat Transfer," Compendium, Moscow 1962.

7. Ibragımov, M.Ch., Isupoc, Y.A., Kobzar, L.L. and V.I. Subbotin, Atomnaya energiya $21,1966$.

8. Subbotin, V.I., Ushakov, P.A., Levchenko, Y.D. and A.M. Aleksandrov, "Modelling of Thermodynamic Phenomena in the Active Zone of Fast Reactors." Paper presented at Czecho-Soviet Conference in CSSR, February 1970 .

9. Shlykov, Y.P. and S.N. Tsarevskiy-Dyakin, Teploenergetika, 12.

10. Schlichting, H. "Boundary-Layer Theory," 6th edition, McGraw-Hill Book Company 1968.

11. Knudsen, J.G. and D.L. Katz, "Fluid Dynamlcs and Heat Transfer," McGraw-Hill Book Company 1958.

12. Kutateladze Ts.Ts., "Theory of Heat Exchange," Mashgiz 1962.

13. Novikov, Y.Y. and K.D. Voskresenskiy, "Applied Thermodynamıcs and Heat Transfer," Moscow 1961.

14. Mıkheyev, M.A., "Basıcs of Heat Transmıssion," 2nd ed., Prague 1953.

15. Rotta, J., Ingenieur-Archıv, 24, 1956.

16. Gardner, K.A., Trans. ASME, November 1945.

17. Hejna, J., Malák, J., Pecha, P. and J. Schmid,, "Energy Optımızation of Channel Geometry With Longıtudinal Fins," Institute of Nuclear Research, Report 2544/R/1970. 
18. Roberts, A., Int. J. of H. and M. Transfer, $10 / 5,1967$.

19. Guirrenbach, F.J., "Heat Transfer During Turbulent Flow in Circular Channels," Allg. Wärmetechnik, 9/13.

20. Sheynina, A.V., "Lıquid Metals," (Compendrum), Moscow 1967.

21. Levchenko, S.D., Subbotin, V.I., Ushakov, P.A. and A.V. Sheynina, "Liquid Metals," (Compendium), Moscow 1967.

22. Subbotın, V.I. et al., Atomnaya energıya, $9 / 4,1960$.

- 23. Firsova, E.V., Inzh. Eiz. zhurnal, 15, 1963.

24. Mlller P., et al., A.I.Ch.E. Journal, 2/2, 1956.

25. Eifler, W. and R. Nijsing, Nuclear Engineering and Design $\underline{5} 1,1967$.

26. Tourneau, B.Le, at al., Trans. ASME 79/8, 1957.

27. Gunn, D.J. and C.W.W. Darling, Trans. Inst. Chem. Engrs. 41, 1963.

28. Ushakov, P.A. et al, Atomnaya enerqiya $13 / 2,1962$.

29. Schiller, L., Zeitschrift f. angw. M. und M. 3/1, 1925.

30. Eckert, E.R.G. and T.F. Irvine,Jr, Trans. ASME 78, 1956.

31. Eckert, E.R.G. and T.F. Irvine,Jr, Trans. ASME, Journal of Heat Transfer, May 1960.

32. Carlson, L.W. and T.F. Irvine,Jr., Trans. ASME, Journal of Heat Transfer, November 1961.

33. Ibragimov, M. Kh., Isupov, I.A. and V.I. Subbotin, "Liquıd Metals," (Compendium), Moscow 1967.

34. Yu, Wen-Shi and Orrıngton E. Dwyer, Nuclear Science and Engineerıng, $24,1966$.

35. Diskind, T., Matos, C.A. and R.P. Stein, "Initial Experiments on Pressure Drop for Flow-through Eccentric Annull, "Columbia Univ., TID-5670, 1959.

36. Diskind, T., Leo, D., Lummis, R. and J. Vohr, "Basic Studies in Heat Transfer and Fluid Flow," NYO-9646 (1961). Columbia Univ. Quarterly Progress Report to the AEC.

37. Krett, V.. "Research Into Heat Transfer and Hydraulic Losses in a Sheaf of Finned Rods,", SKODA Plant Report no. Ae 1126/Concl.

38. Wantland, J.L., "Reactor Heat Transfer Conference of 1956," AEC Report TID, 7529, 525 (1957).

39. Gelin, P, Comptes - rendus de 1'Académie des Sciences 243, 1956. 
40. Obukhov, A.M., Prikladnaya matematıka 1 mekhanıka VI. 1942 .

41. Rothfus, R.R., Monrad, C.C., Sikchi, K.G. and W.J. Heideger, Ind. and Eng. Chemistry $47 / 5$, May 1955. 
11. List of Diagrams and Tables

Fig. 1 - Geometrical condıtions at entry Into Investigated channel geometry A.

2 - Geometrical conditıons at entry into investigated channel geometry $\mathrm{B}$.

3 - Coefficient of friction losses in a smooth annulus. Results of measurements by the Institute of Nuclear Research.

4 - Dependence of coefficient of frlction losses in a smooth annulus on channel curvature according to various authors. (Taken over from study [4].)

5 - Dependence of coefficient of intermittency in a smooth tube on the distance from entry and the Reynold's criterion according to J. Rotta [15].

6 - Velocity changes along tube axis with Reynold's number for three distances away from the entry [15]. 7 - Dependence $\xi=6(R e)$ at varying conditions at entry into
channels $A 2$ and $A 3$.

8 - Dependence $\xi=6(R e)$ at varying conditions at entry into channels $A 10$ and $A 11$.

9 - Dependence $1 / \sqrt{\xi}=6(\operatorname{Re} \sqrt{\xi})$ at varying conditions at entry into channels $A 2$ and $A 3$.

10 - Dependence $1 / \sqrt{\xi}=6(\operatorname{Re} \sqrt{\xi})$ at varying conditıons at entry into channels $A 10$ and $A 11$.

11 - Several examples of the form of experimental dependence of $1 / \sqrt{\xi}=6(\operatorname{Re} \sqrt{\xi})$ for geometry $A$.

12 - Several examples of the form of experimental dependence of $1 / \sqrt{\xi}=6(\operatorname{Re} \sqrt{\xi})$ for geometry $\mathrm{B}$.

13-17 - Progress of $\bar{\alpha}$ along the length of the model at varying $\operatorname{Re}$.

18 - Several examples of experimental dependence of $\mathrm{Nu}=6(\mathrm{Re})$ for geometry A.

19 - Several examples of experimental dependence of $\mathrm{Nu}=6(\mathrm{Re})$ for geometry $B$.

20 - Effects of the length of a heated model on the accuracy of determination of the dependence of $\mathrm{Nu}=6|\mathrm{Re}|$.

21 - Assessment of the dependence of the geometrical factor on the geometrical criterion $L^{*}$ from experiments by the Institute of Nuclear Research. 
Fig. 22 - Experimental dependence of $H=6\left(L^{*}\right)$ - results for geometries $A$ and $B$ and results obtained by $K$. Rybáček [3].

23 - Dependence of geometrical factor on geometrical criterion $\left(L_{\max } / d_{h}\right)$.

24 - Dependence of geometrical factor on geometrical criterion $\left|L_{\max }^{2} / T \cdot d_{h}\right|$.

25 - processing of experimental results in the form of the relation $H=6\left(\frac{R e}{H}\right)$ with geometrical factor value acc. to equation (35).

26 - Comparison of maximum velocity in laminar and turbulent flow through smooth annuli with maximum value of $L$.

27 - Values of the geometrical factor for varying curvatures of an annular channel derived from experiments and progress of $H=6\left(D_{1} / D_{2}\right)$ according to the relation (35).

28 - Experimental values of Nusselt's criterion for $R e 5.10^{4}$ and $\left(L^{*} \frac{d}{d} \frac{h}{T}\right)^{27}$.

29 - Experimental values of Nusselt's criterion for $R e=5.10^{4}$ and $\left.\bar{\psi} L^{*} d h_{h}\right)^{2}$; and their dependence on the geometrical criterion $\left(L^{*}\left(\frac{h}{d}\right) ;\right.$ differentiation between geometry $A$ and $B$, including
results obtained by K. Rybáček [3].

30 - Processing of the results of thermokinetic experiments on geometry $A$ into the dependence form $\frac{1}{97}\left(L^{*} \frac{d_{h}}{d T}\right)^{0.91} . N u=6(R e)$

31 - Processing of the results of thermokinetic experiments on geometry B into the dependence form $\frac{1}{97}\left(L^{*} \frac{d}{h}\right)^{0.91}$

32 - Experimental values of $\frac{L_{T_{1.1}}}{d h}$ and their deperhdence on ${ }^{*} 6(R e)$

33 - Experimental values of $\frac{L T_{1.1}}{d h}$ and thelr dependence on $\left(L^{*} \frac{d h}{d T}\right)$.

34 - Distribution of $\bar{\alpha}$ along the length of the model in the form of dependence $\frac{\alpha}{\alpha \bar{a}_{2}}-1=6\left(\frac{\chi}{L T+1}\right)$. Values of $L_{T}{ }_{1.1}$ for Individual variants computed from eciluation (42).

35 - Effects of the thermal factor on Nusselt's criterion at constant flow-through (no consideration given to change in Reynold's number due to thermal effects and effects of this change on $\mathrm{Nu}$ ).

36 - Effects of the thermal factor on Nusselt's criterion at constant values of Re.

37 - Experimental values of exponent $n$ as a function of criterion

38 - Experımental values of exponent $n$ as a function of criterion $L^{*}$.

39 - Dependence of the geometrical criterion $L^{*}$ and the geometrical factor $\|$ on the density of triangular and square lattices. 
Fig. 40 - Computed progress of $\frac{\xi}{\xi_{0}}=6\left(\frac{\delta}{d}\right)$ for a triangular and square lat-

41 - Change of coefficient of friction losses with the density of a triangular lattice; comparıson of crlterial relation (21) with experiments.

42 - Comparison of computed and experımental values of $\xi_{/ \prime} \xi_{0}$ for the used cell models of an infinite triangular lattice.

43 - Comparison of experiments and computations for a triangular. lattice (in cases when it can be regarded as inflnite).

44 - Continuation of fig. 43 .

45 - Comparison of experiments and computations for elements of a square lattice [27].

46 - Continuation of fig. 45.

47 - Comparison of computations and experıments for a square lattice.

48 - Dependence of $L^{*}$ and $H$ on the apex angle of an isosceles triangle.

49 - Comparison of computed and experimental values [32] for a channel with an isosceles triangle cross section.

50 - Coefficient of friction losses in an isosceles triangle [29].

51 - Extent of the laminar region in a channel with an isosceles triangle cross section with an apex angle of $11.5^{\circ}$ [30].

52 - Values of $L^{*}$ for a regular trapezoid.

53 - Values of $L^{*}$ for a rectangle and an annulus.

54 - Comparison of computed and experimental data of study [33].

55 - Results of the study [33], recomputed into form $1 / \sqrt{\xi}=f(R e \sqrt{\xi})$

56 - Coefficient of friction losses in a sheaf of rods with longitudinal fins [37].

57 - Dependence of the coefficient of frlction losses on eccentricity of an annular channel. Comparison of computations with relation from study [34].

Tables: Geometrical characteristics of models A. Table I and II.

Geometrlcal characteristics of models B.

Table of annular channels made at the Insttitute of Nuclear Resear Geometrical characterıstics of models from study [3]. 


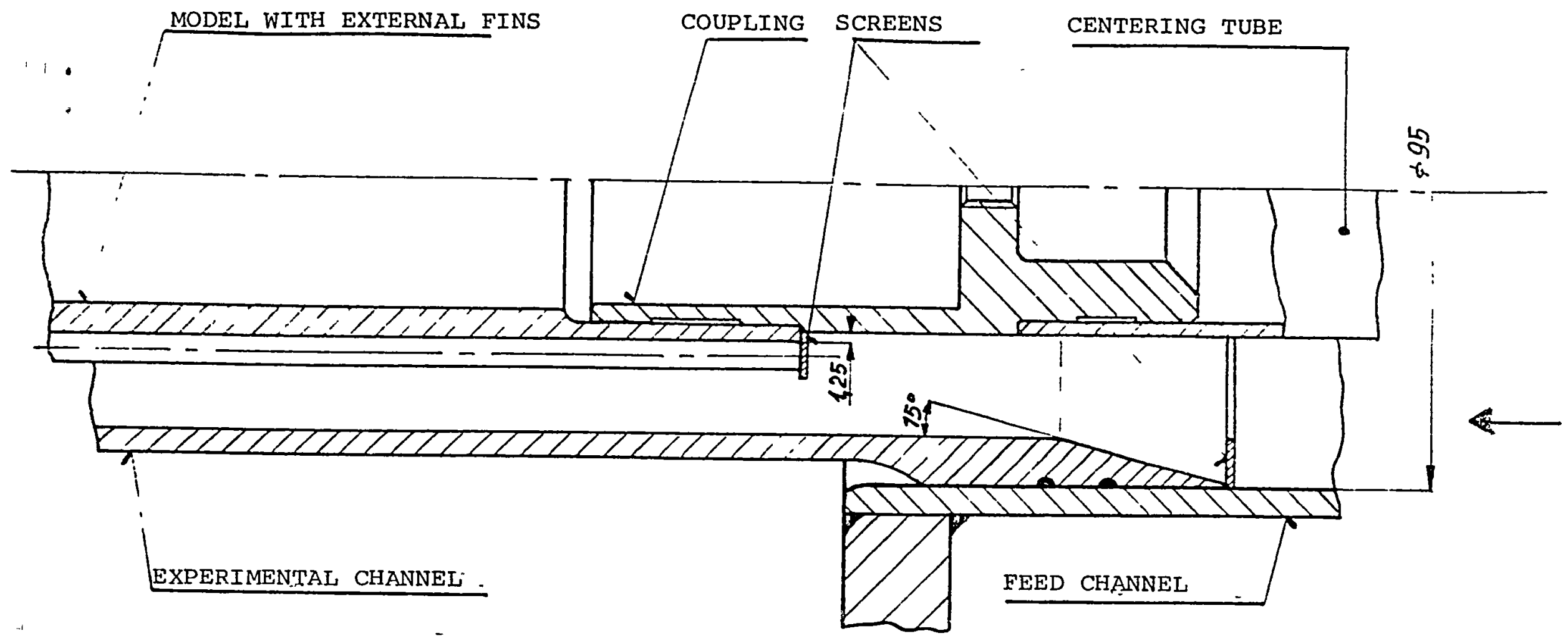

Fig. 1. Geometrical conditions at entry into investigated channel - geometry A. 


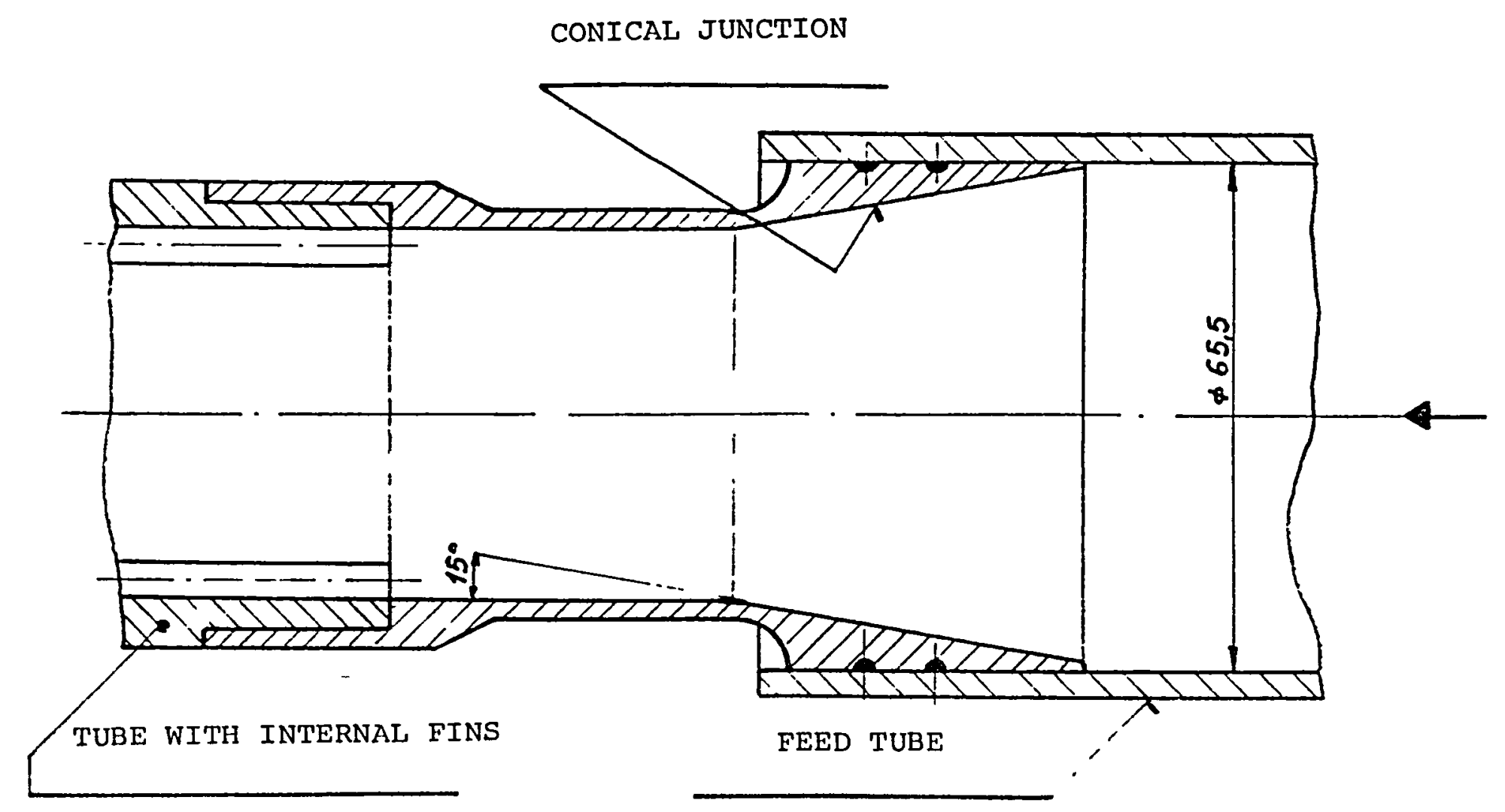

Fig. 2. Geometrical conditions at entry into investigated channel - geometry B. 
$W_{D}^{\infty}$

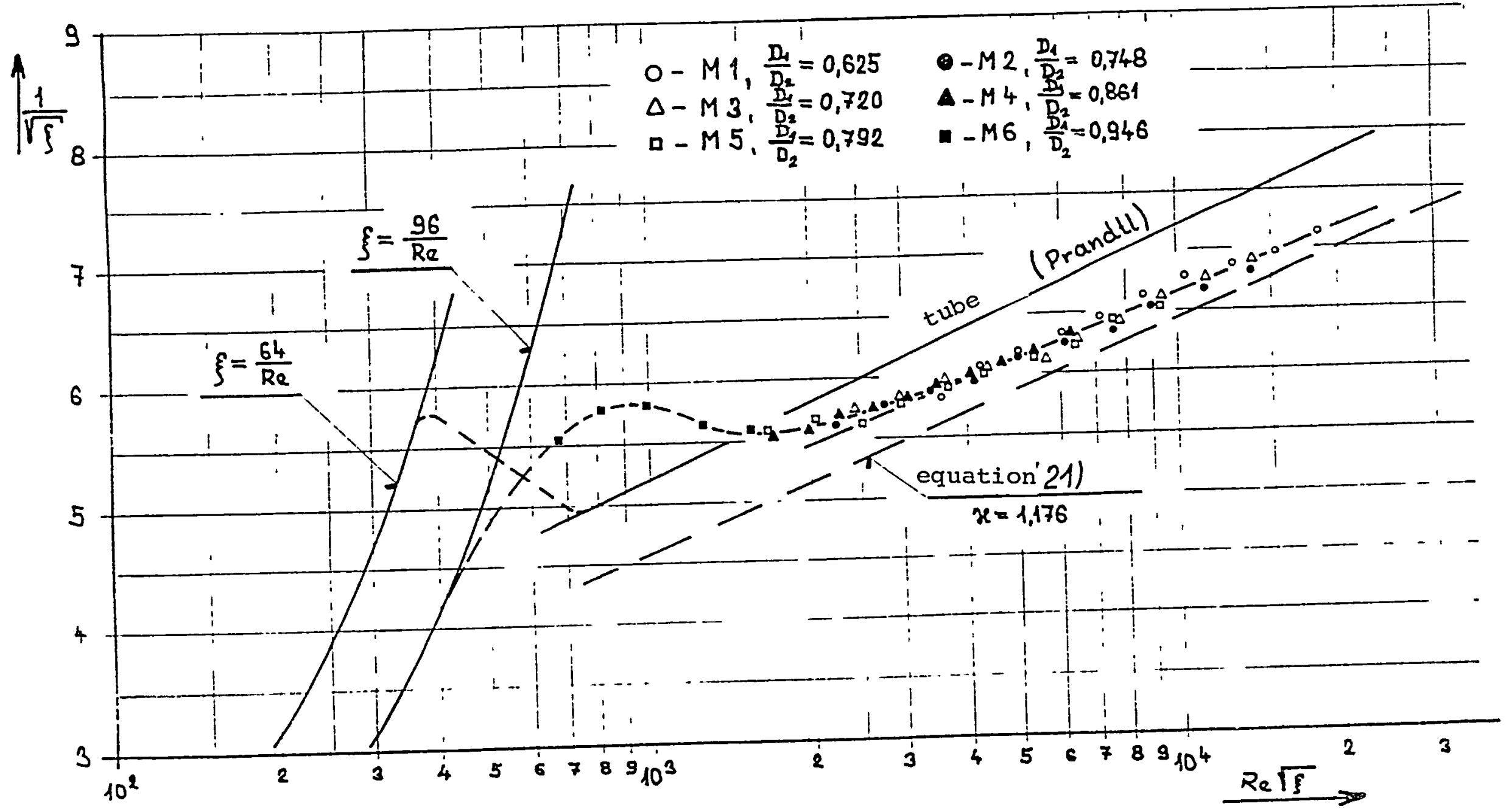

Fig. 3. Coefficient of friction losses in a smooth annulus. Rig. 3. Cf measurements by the Institute of Nuclear Research. 


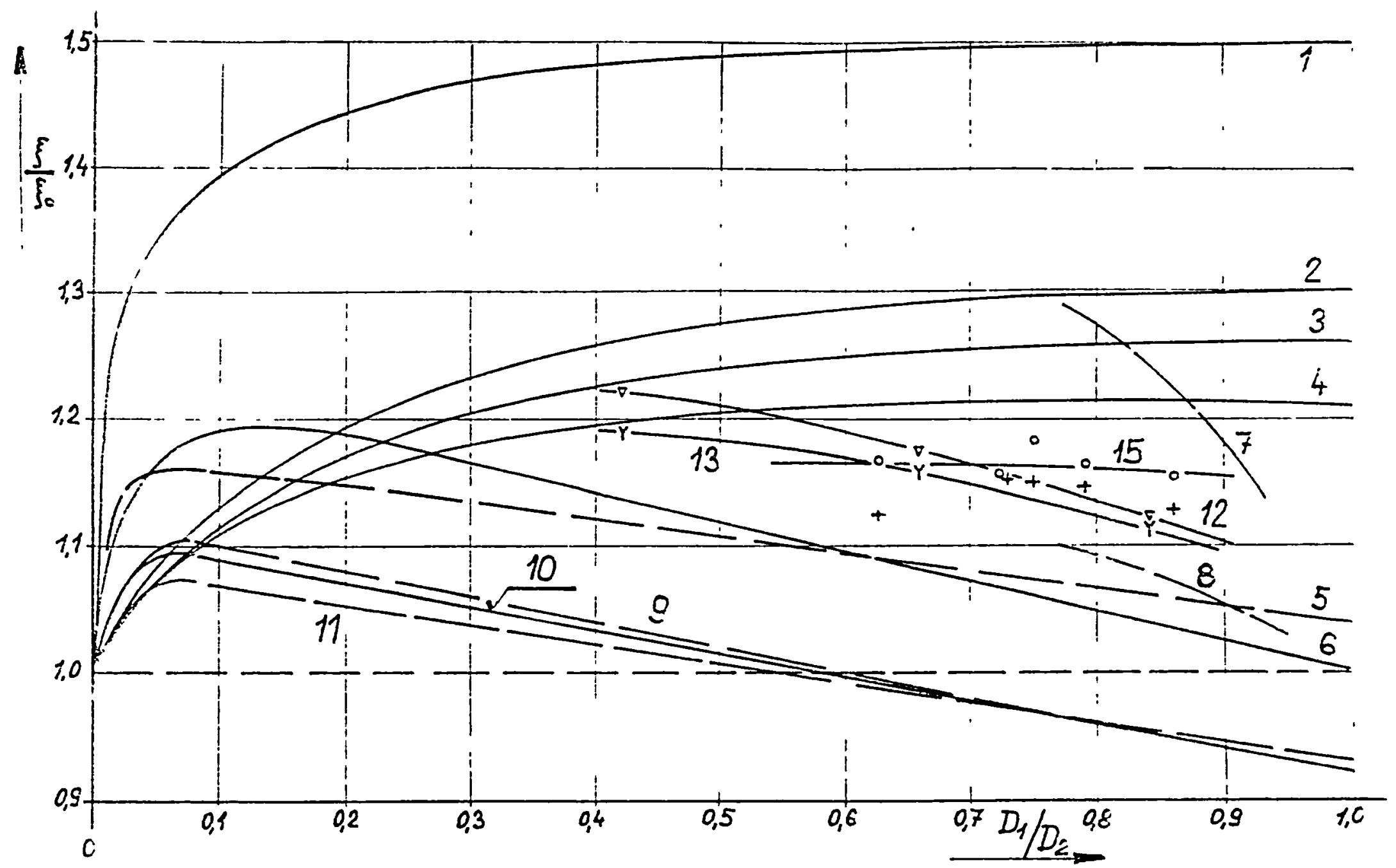

Fig. 4. Dependence of the coefficient of friction losses in a smooth annulus on channel curvature according to various authors. (Taken over from study [4].) For key to this figure see table on next page. 
OUTLINE OF STUDIES REGARDING PRESSURE LOSSES IN SMOOTH ANNULI, THE RESILTS OF WHICH ARE COMPARED IN Fig. 4.

\begin{tabular}{|c|c|c|c|c|}
\hline Ser.\# & Author & Title & Re & Range $D_{1 / D_{2}}$ \\
\hline 1 & & & $<2,3 \cdot 10^{3}$ & $0 \div 1,0$ \\
\hline 2 & 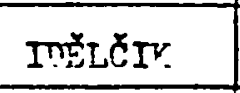 & \multirow{3}{*}{ 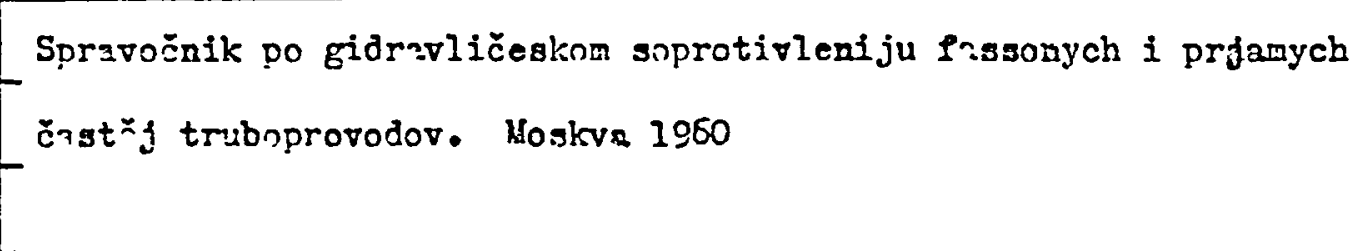 } & $7.10^{6}$ & $0 \div 0,6 ; 1,0$ \\
\hline 3 & $-n-$ & & $3.10^{6}$ & $0 \div 0,6 ; 1,0$ \\
\hline 4 & $-\infty-$ & & $1,6.1 c^{6}$ & $0 \div 0,6 ; 1,0$ \\
\hline 5 & BEAlUR & $\begin{array}{l}\text { Wirmeübereasg in ningsenlten bel orzmungener Konveltion und } \\
\text { örtlichen Sieden; :torkernaergie, č.l, } 1963\end{array}$ & $2.10^{3}-10^{5}$ & $0 \div 0,8$ \\
\hline 6 & ROTRFIIS & Fluid friction in noncircular ducts, Jour. AIS E Dec.1357 & $3.10^{3} \div 4.10^{4}$ & $0 \div 0,6 ; 1,0$ \\
\hline 7 & orn & Report SVITT: c. $64-03804$ & $1.10^{5}$ & $0,77-0,93$ \\
\hline 8 & Op? & $-n-$ & $1.10^{4}$ & $0,77 \div 0,03$ \\
\hline 9 & $v \pi=8-n I m$ & \multirow[t]{3}{*}{ 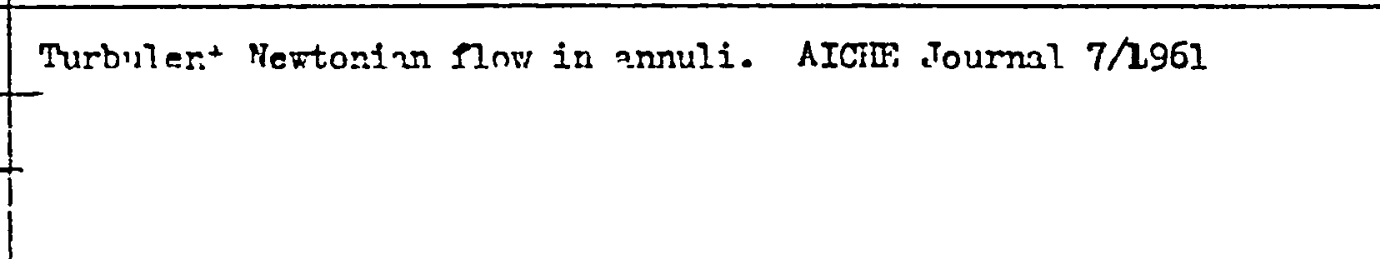 } & $5.10^{3}$ & $0 \div 0,5 ; 1,0$ \\
\hline 10 & $-n-$ & & $3,5 \cdot 10^{3} \div 2 \cdot 10^{4}$ & $0 \div 0,5 ; 2,0$ \\
\hline 11 & $-n$ & & $2.10^{4}$ & $0 \div 0,5 ; 1,0$ \\
\hline 12 & MFíXER & Report Svifre c..63-05033 & $3.10^{4}$ & $0,42 \div 0,84$ \\
\hline 13 & 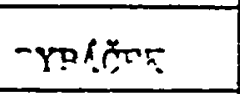 & $-n-$ & $10^{5}$ & $0,42 \div 3,84$ \\
\hline+ & & Institute of Nuclear Research & $3.10^{4}$ & $0,625 \div 0,861$ \\
\hline 15 & & Institute of Nuclear Research & $10^{5}$ & $0,625 \div 0,851$ \\
\hline
\end{tabular}




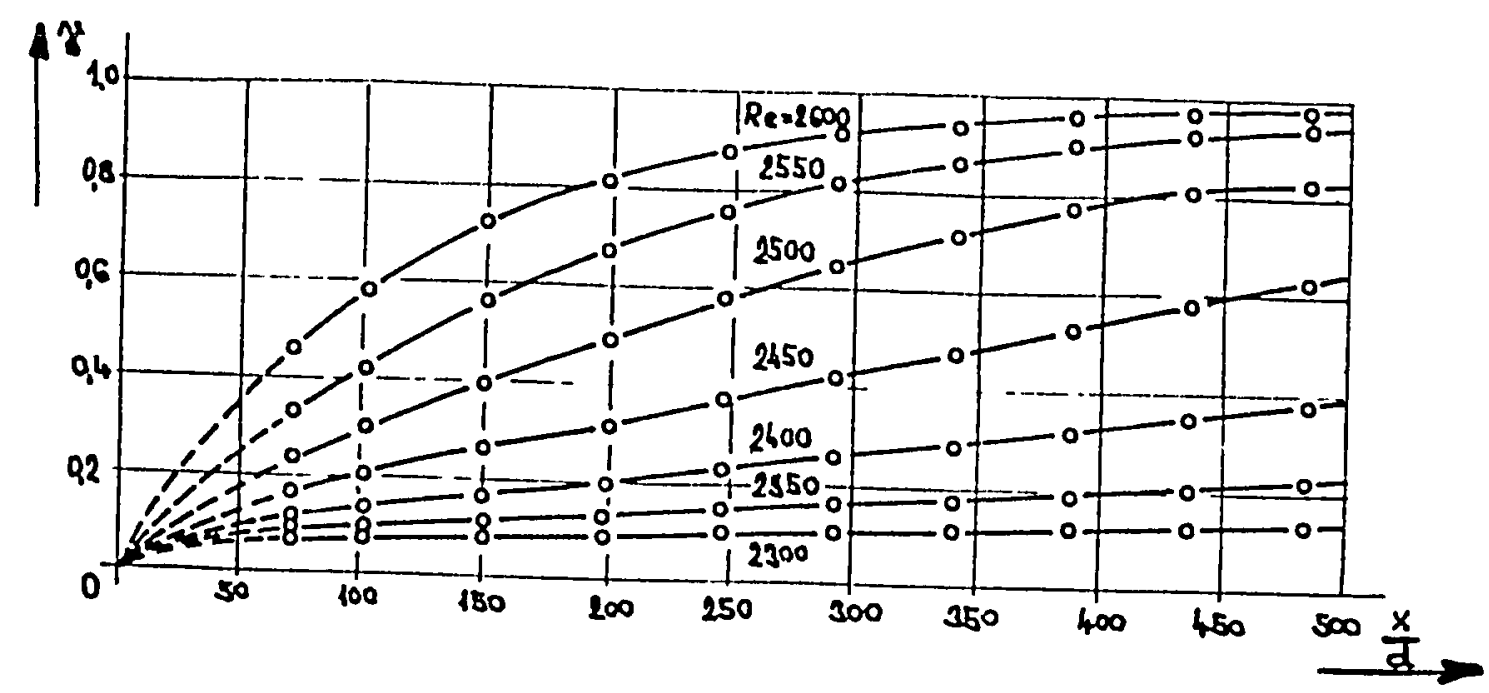

Fig. 5. Dependence of the coefflcient of intermittency in a smooth tube on the distance from entry and the Reynold's criterion according to J. Rotta [15].

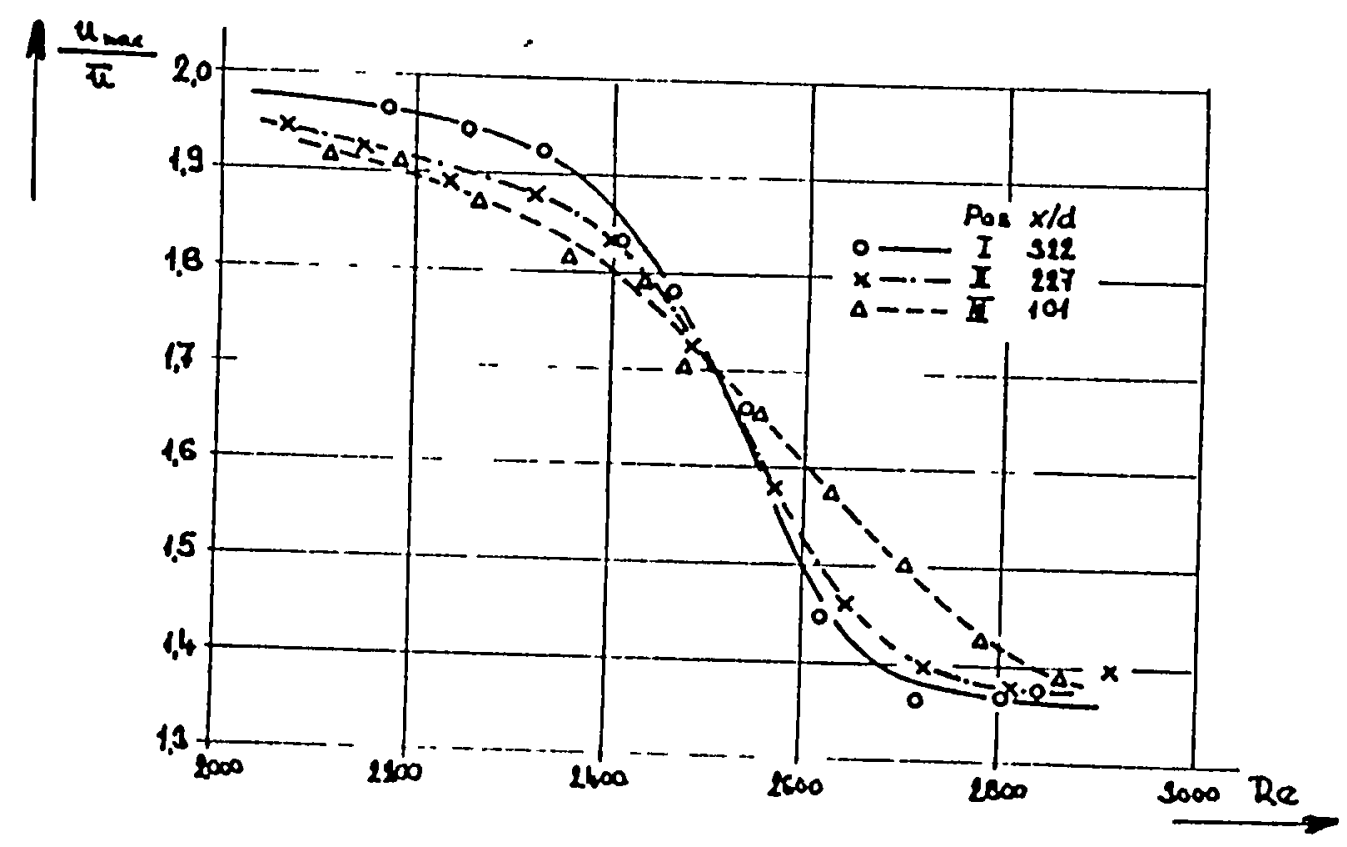

Fig. 6. Velocity changes along tube axis with the Reynold's number for three distances from entry [15]. 

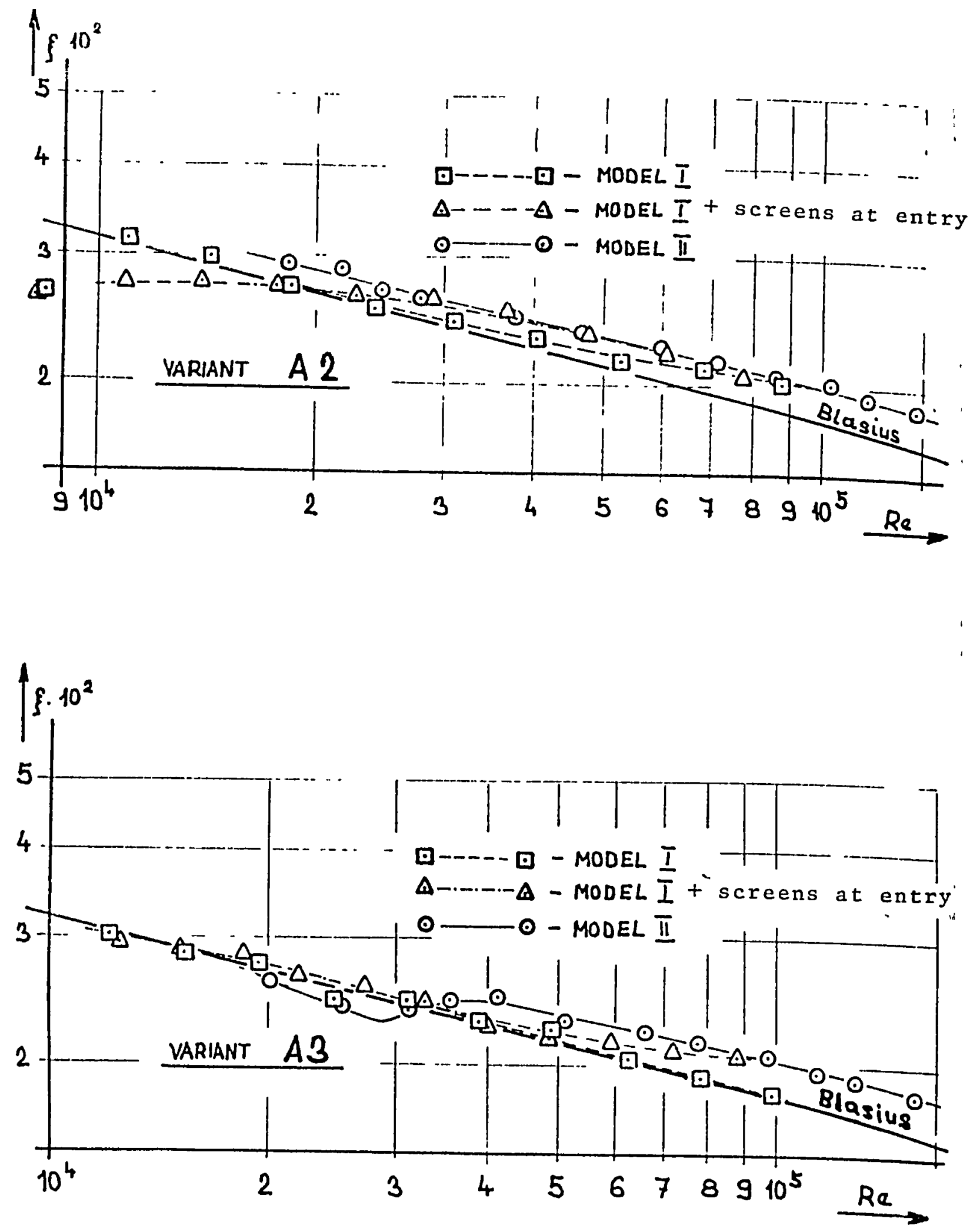

Fig. 7. Dependence of $\xi=6(R e)$ at varying conditions at entry into channels $A 2$ and $A 3$. 

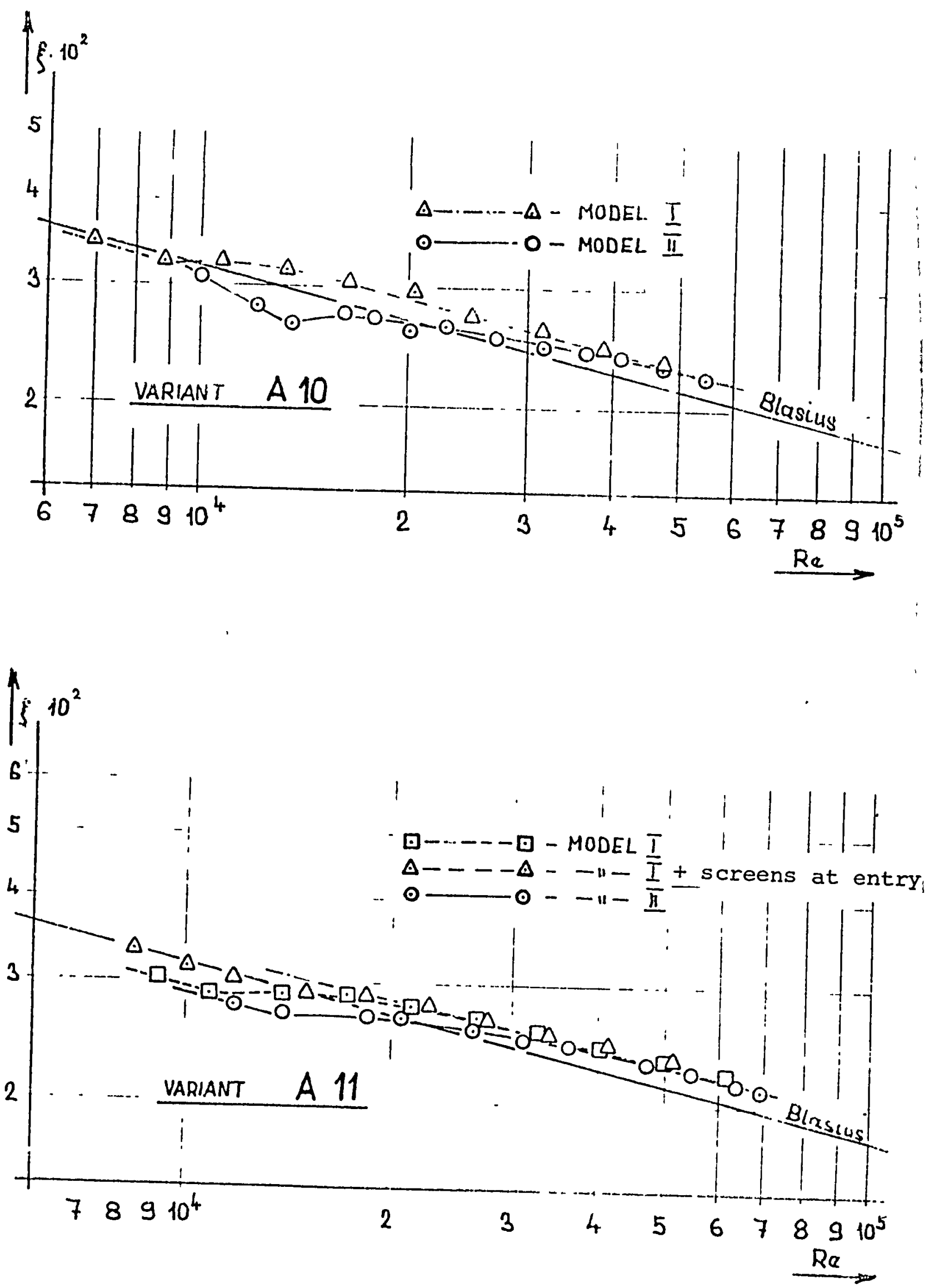

Fig. 8. Dependence of $\xi=6(R e)$ during varying conditions at entry into channels $A 10$ and A11. 

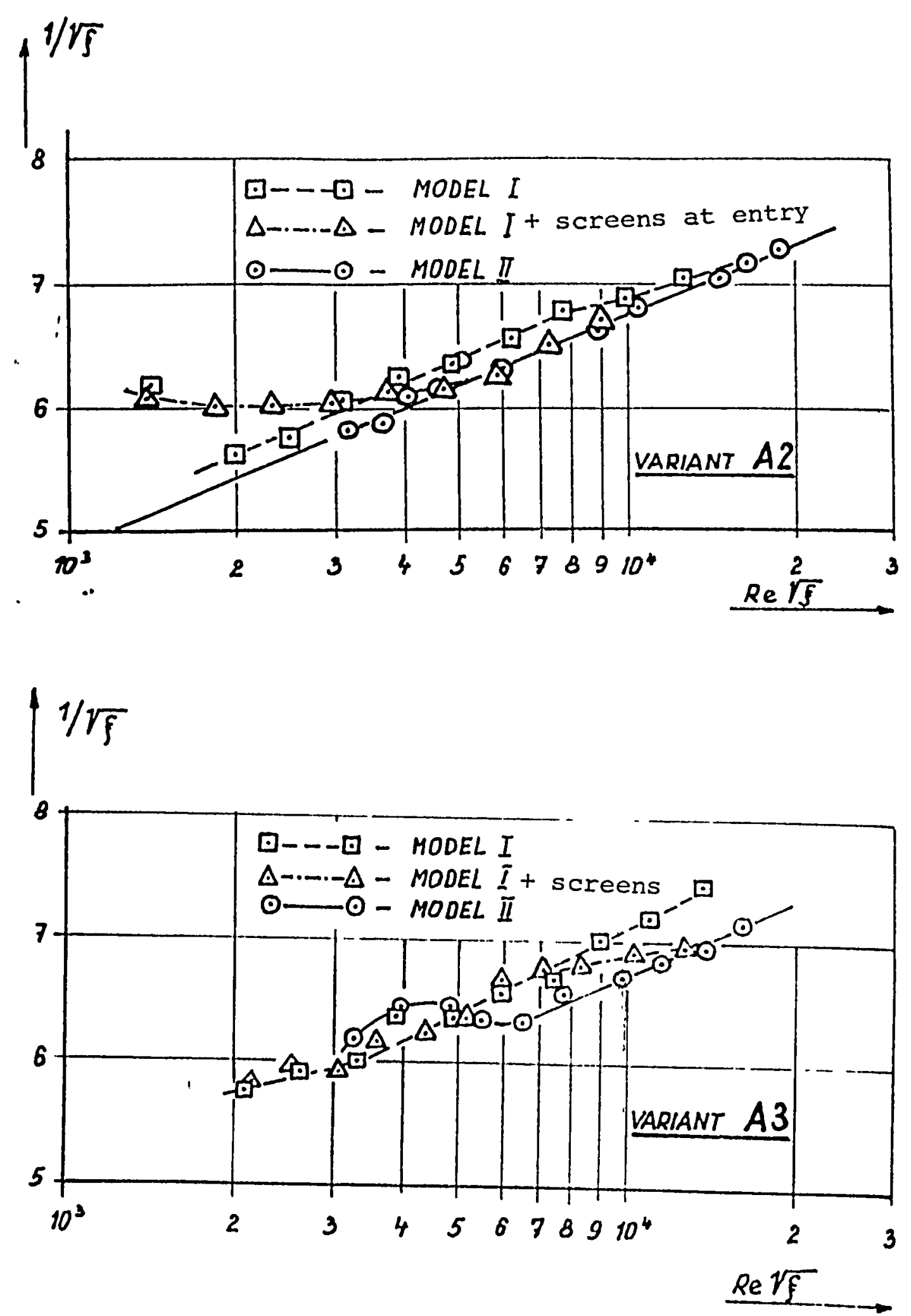

Fig. 9. Dependence of $1 / \sqrt{\xi}=6(\operatorname{Re} \sqrt{\xi})$ during varying conditions at entry into channels $A 2$ and $A 3$. 

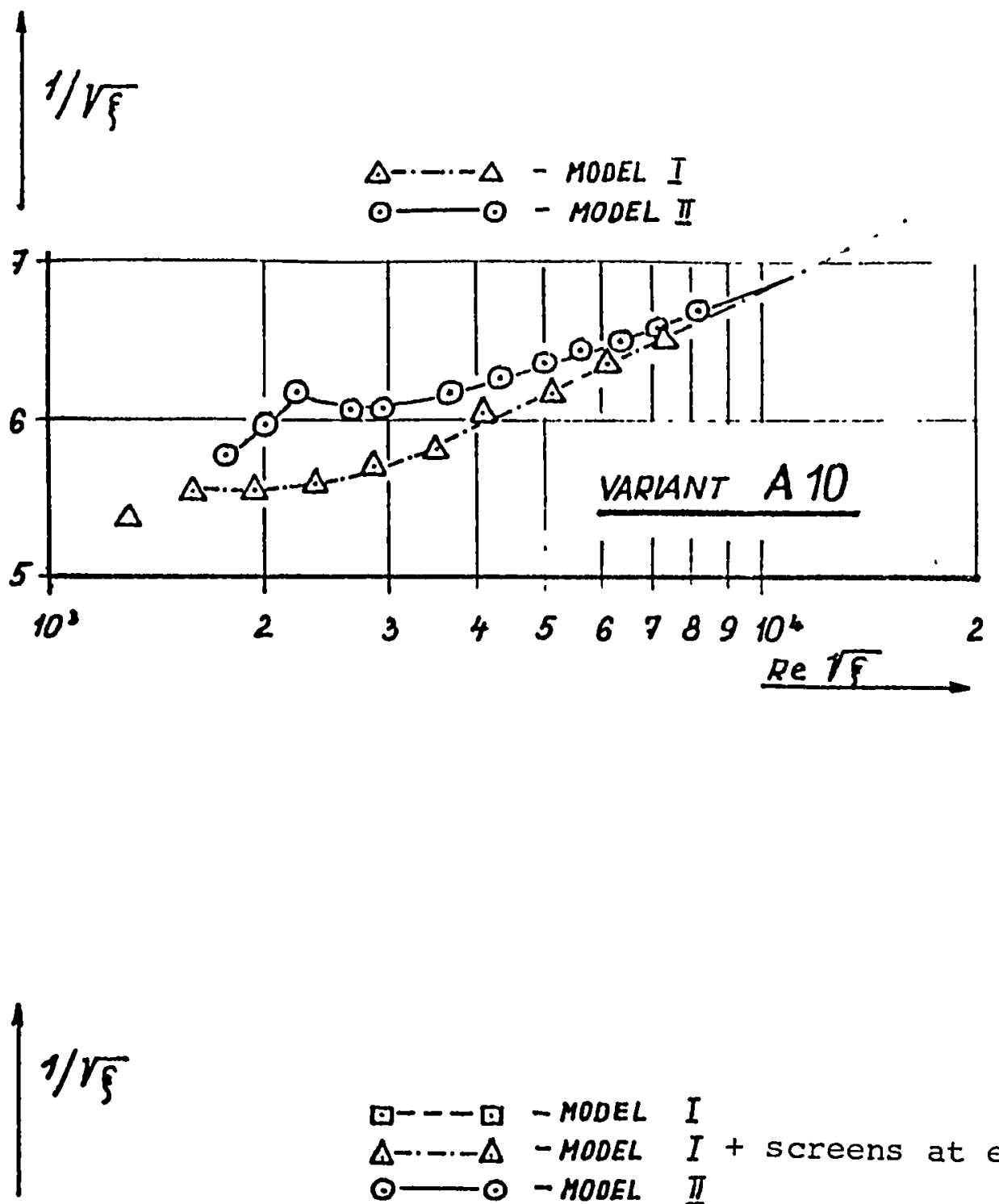

$$
\begin{array}{ll}
\square---\square-M O D E L & I \\
\Delta-\cdot-\Delta-M O D E L & I \\
\odot-\text { screens at entry }
\end{array}
$$

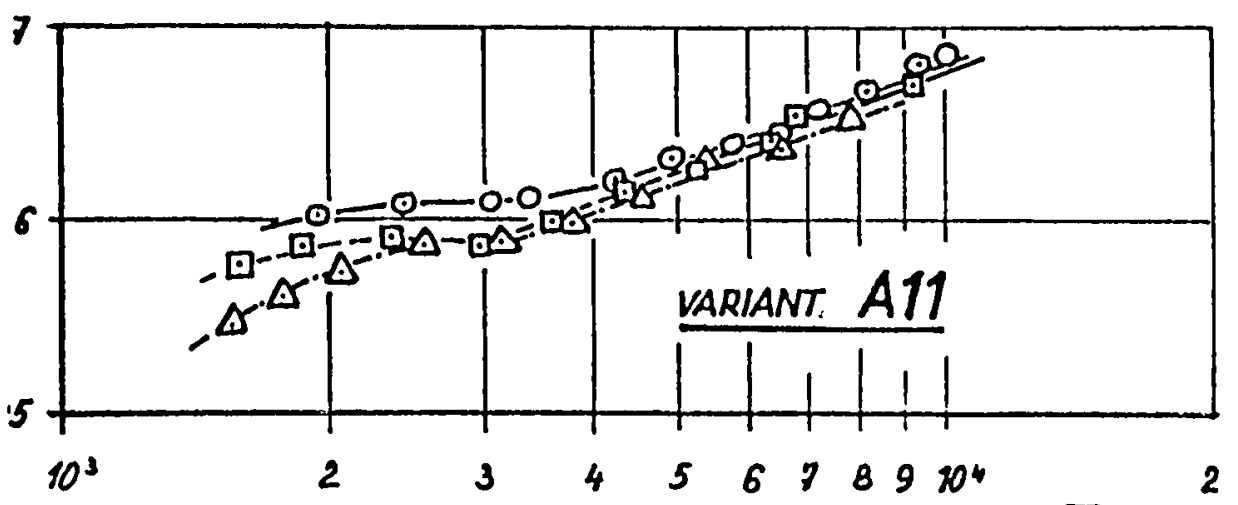
Re $\sqrt{\xi}$

Fig. 10. Dependence of $1 / \sqrt{\xi}=6(\operatorname{Re} \sqrt{\xi})$ during varyıng conditions at entry into channels $A 10$ and $A 11$. 


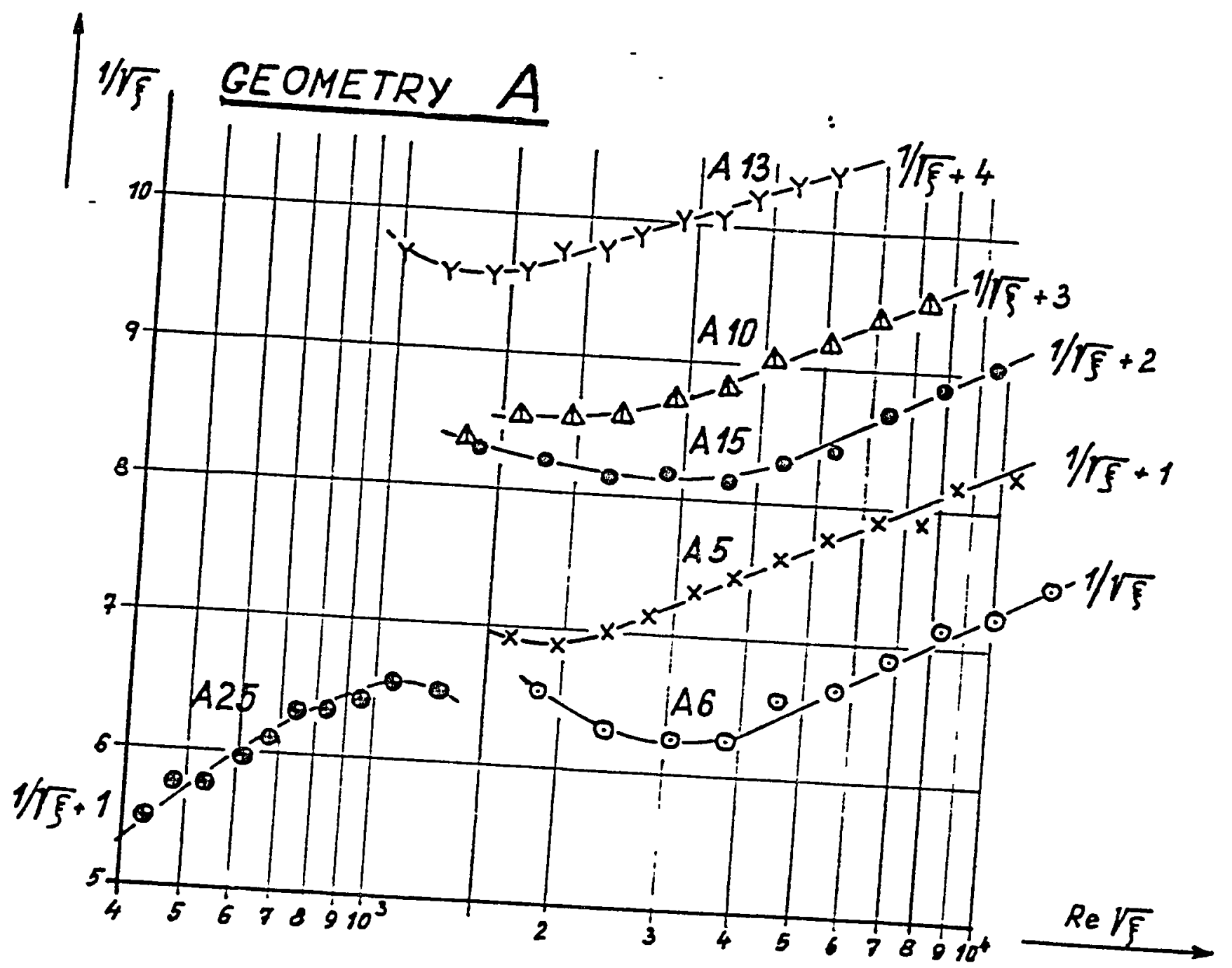

Fig. 11. Several examples of the form of experimental dependence of
$1 / \sqrt{\xi}=6(\operatorname{Re} \sqrt{\xi})$ for 


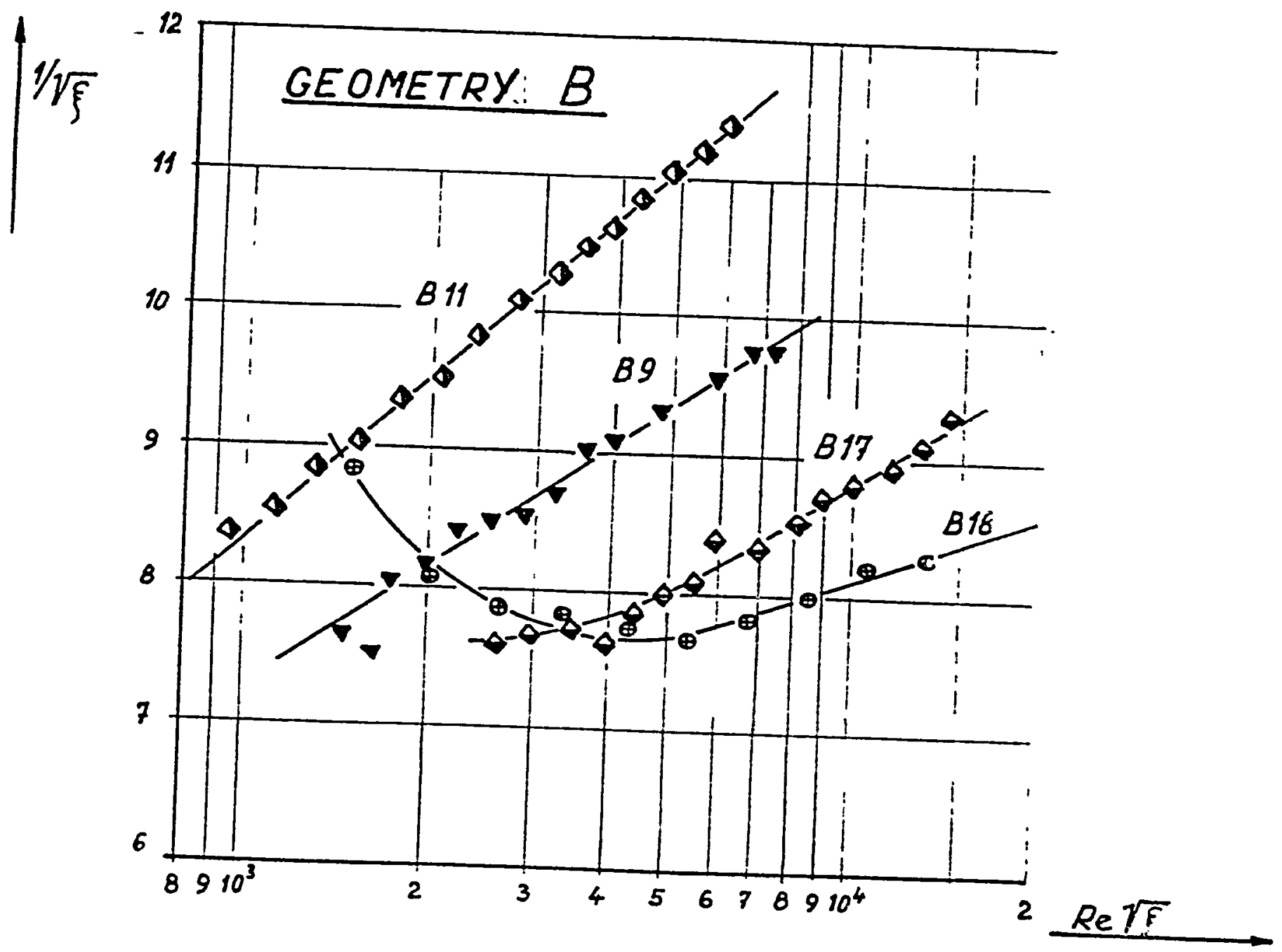
Fig. 12. Several examples of the form of experimental dependence of
$1 / \sqrt{\xi}=6(\operatorname{Re} \sqrt{\xi})$ for geometry $B$. 


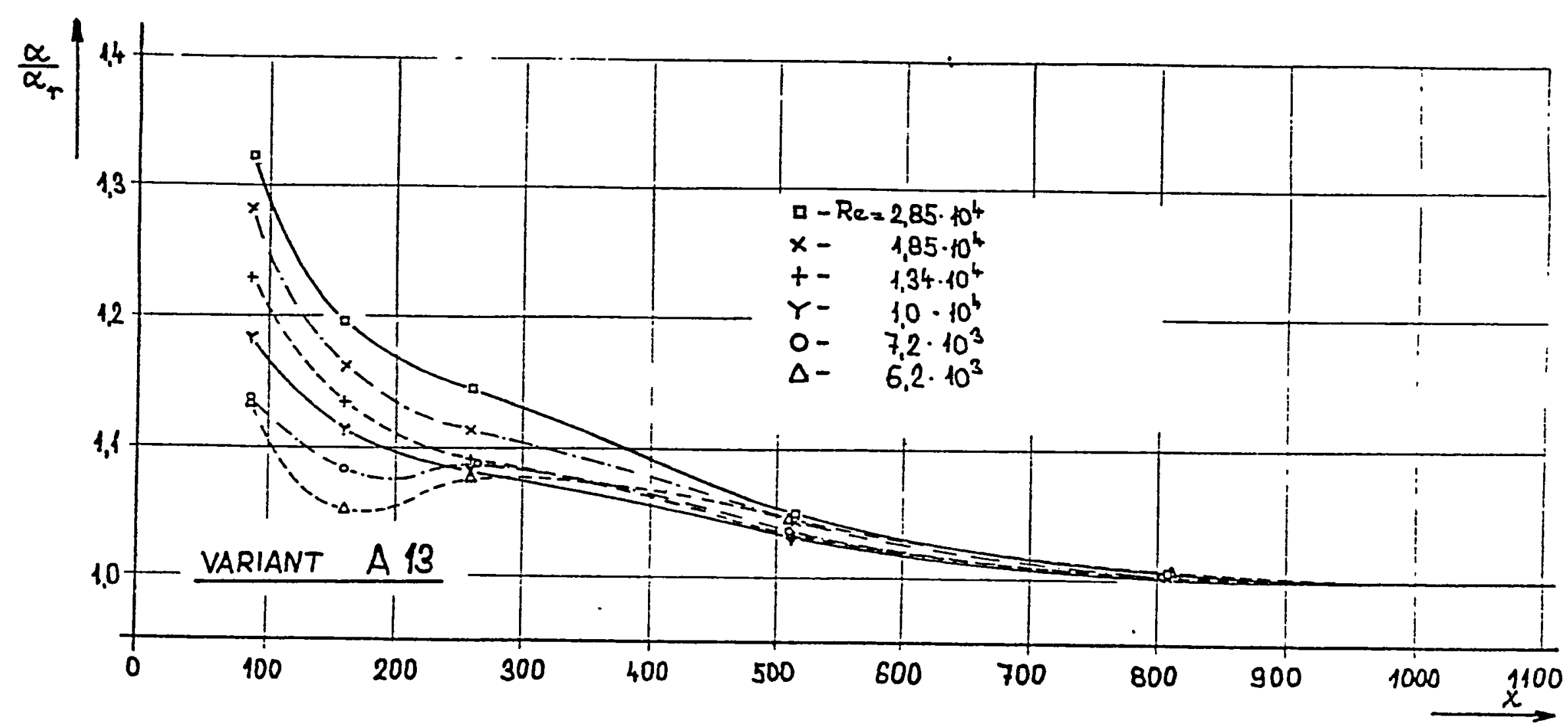

Fig. 13. Progress of $\alpha$ along the length of the model at varying $\operatorname{Re}$. 


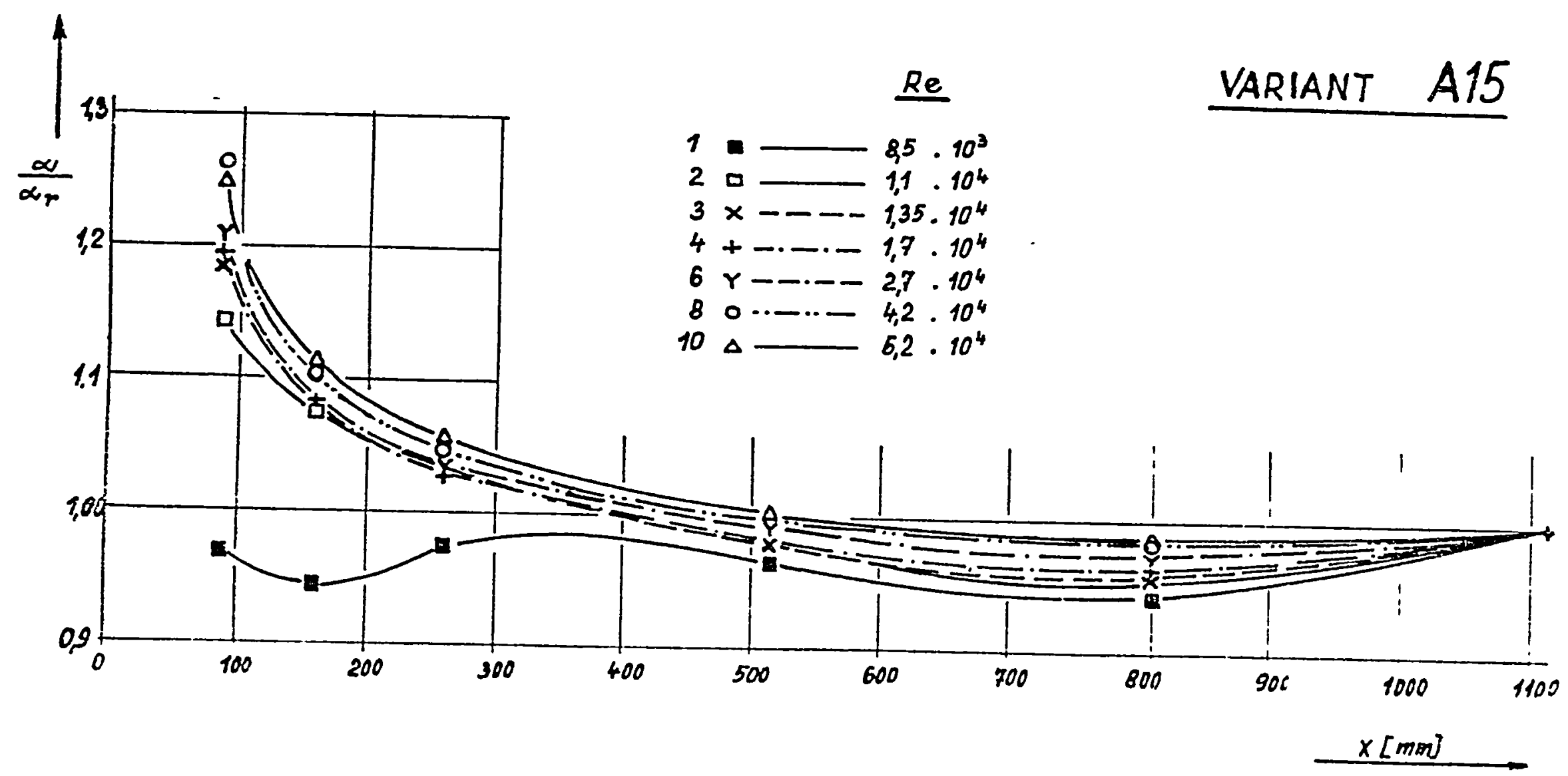

Fig. 14. Progress of a along the length of the model at varying Re. 


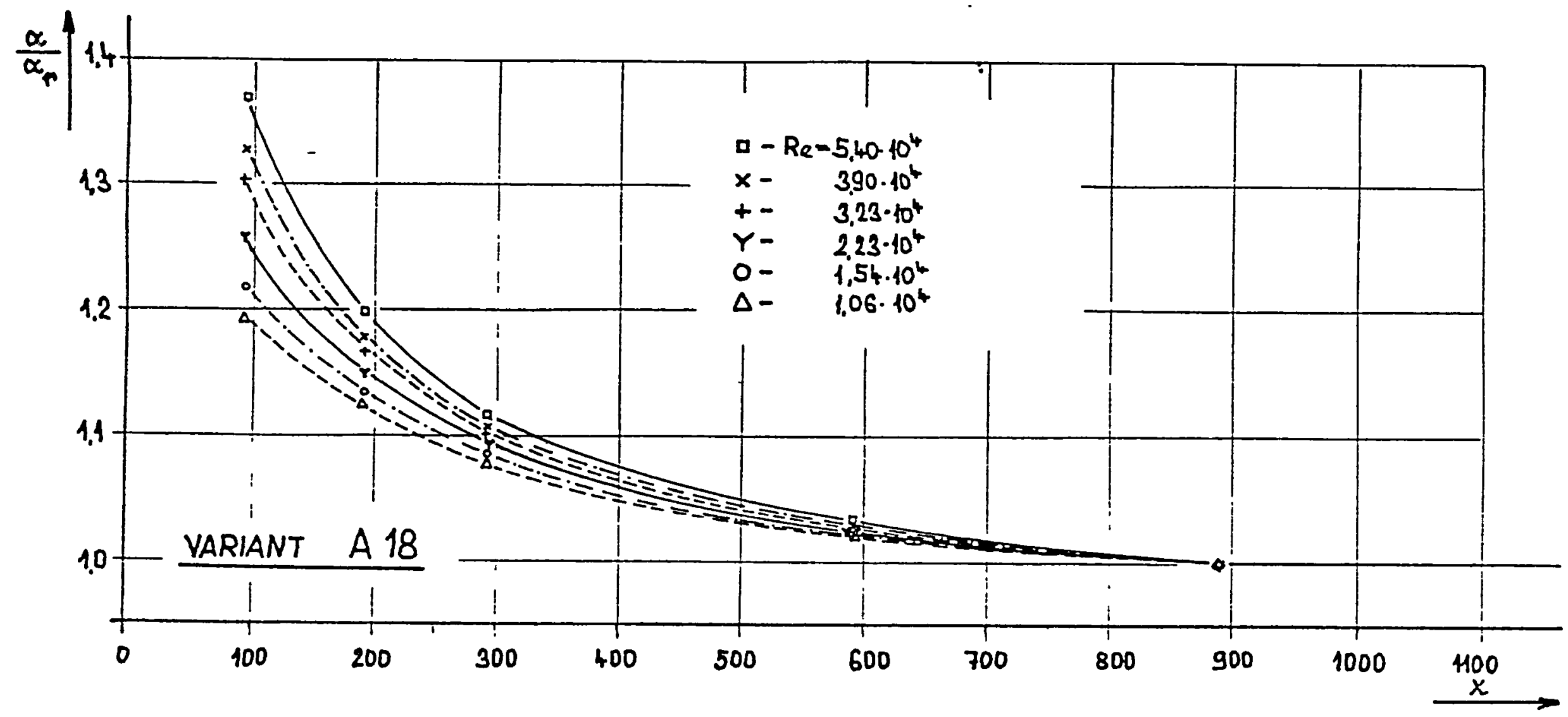

Fig. 15. Progress of $\alpha$ along the length of the model at varying Re. 


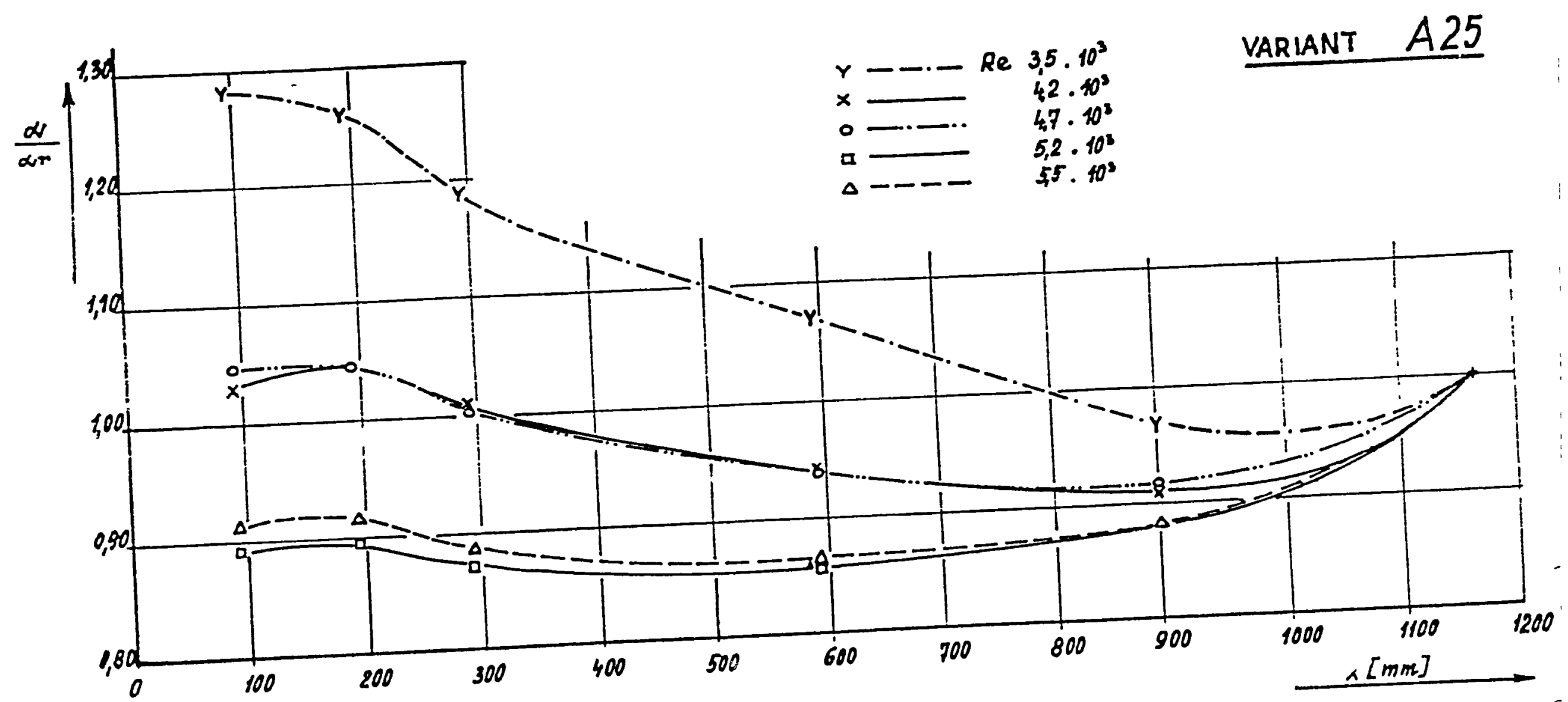

Figure 16. Progress of $\alpha$ along the length of the model at varying Re. 


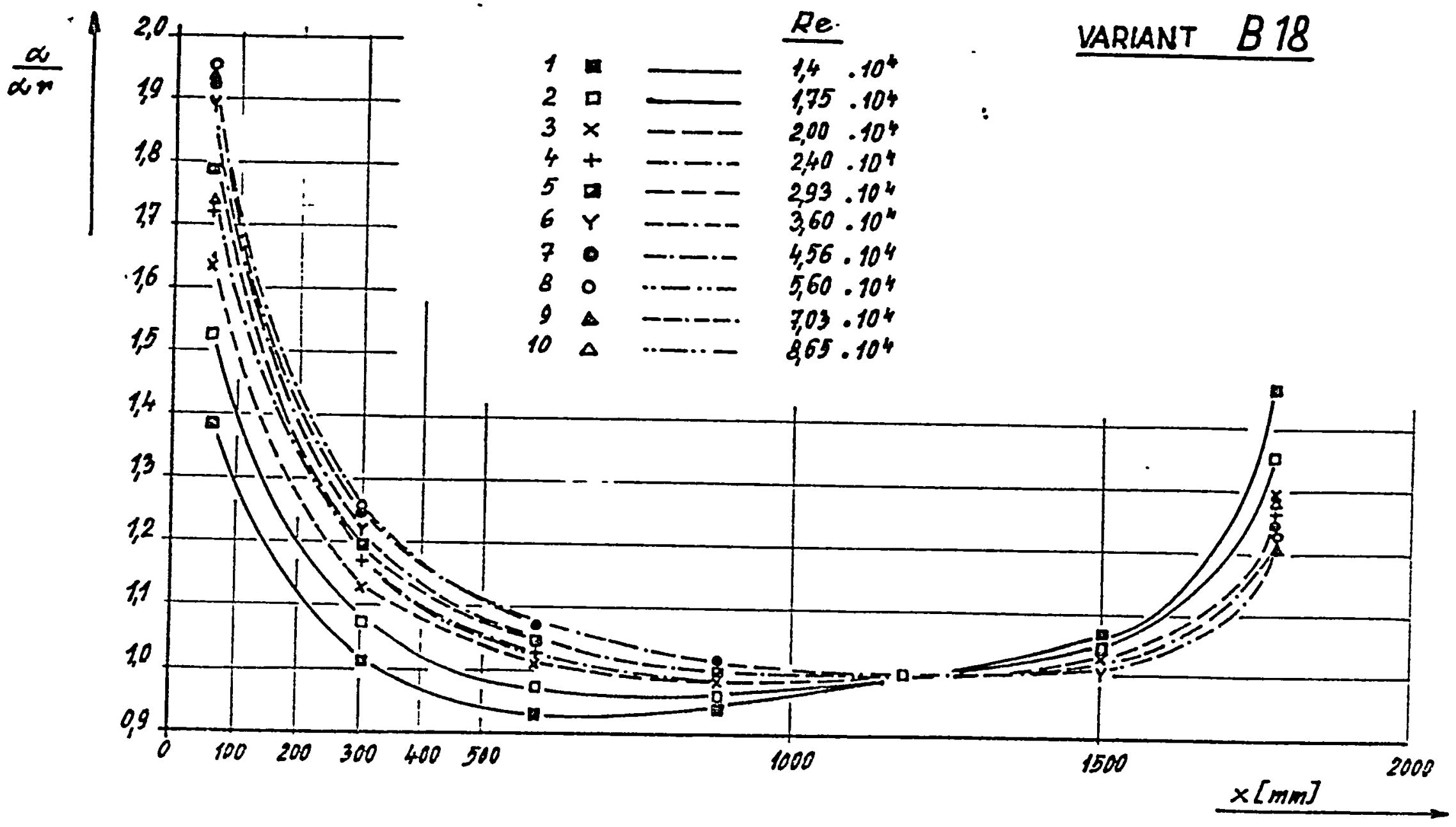

Fig. 17. Progress of $\alpha$ along the length of the model at varying Re. 


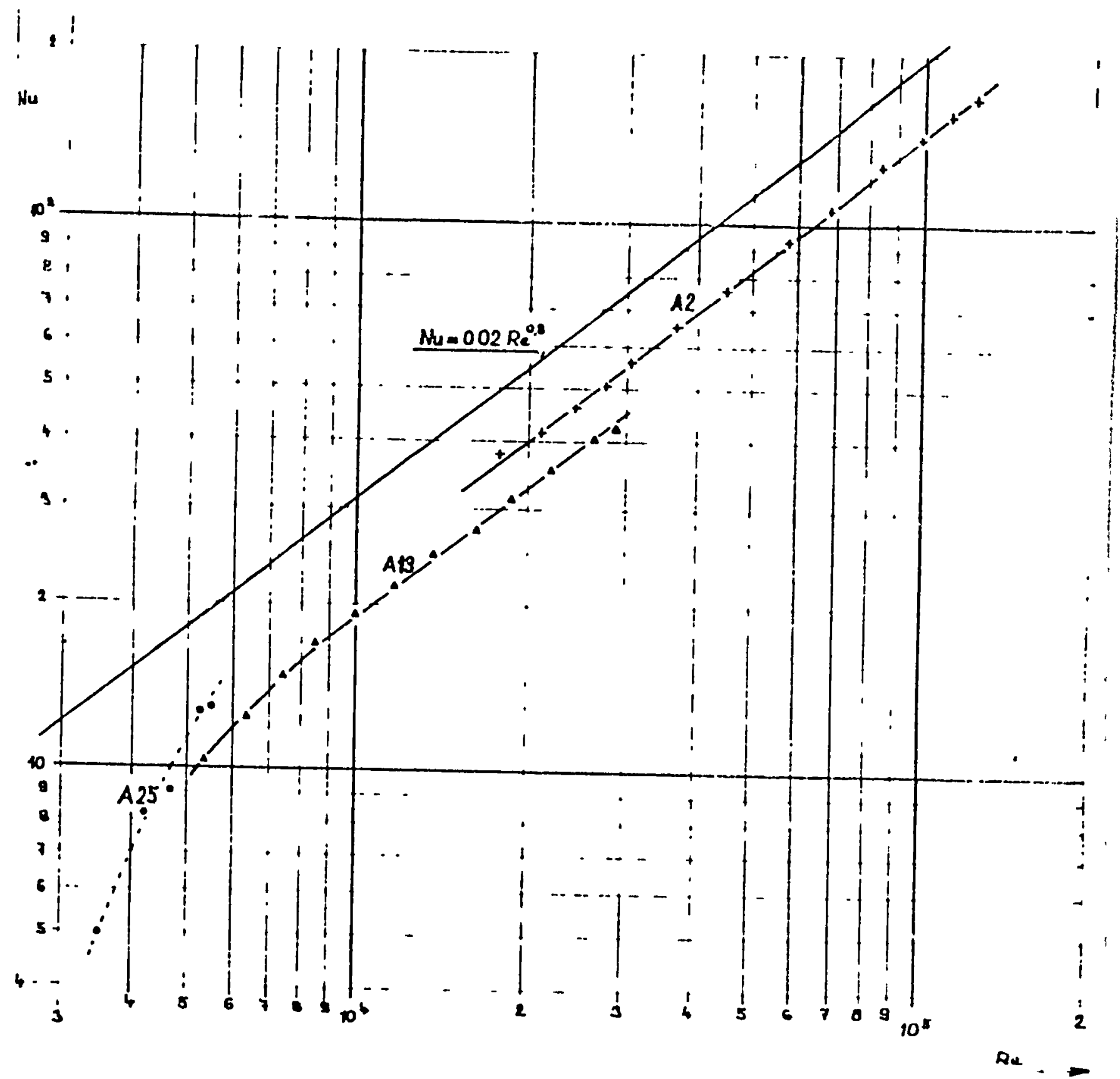

Fıg. 18. Several examples of experimental dependence of $N u=6(R e)$ for geometry A. 


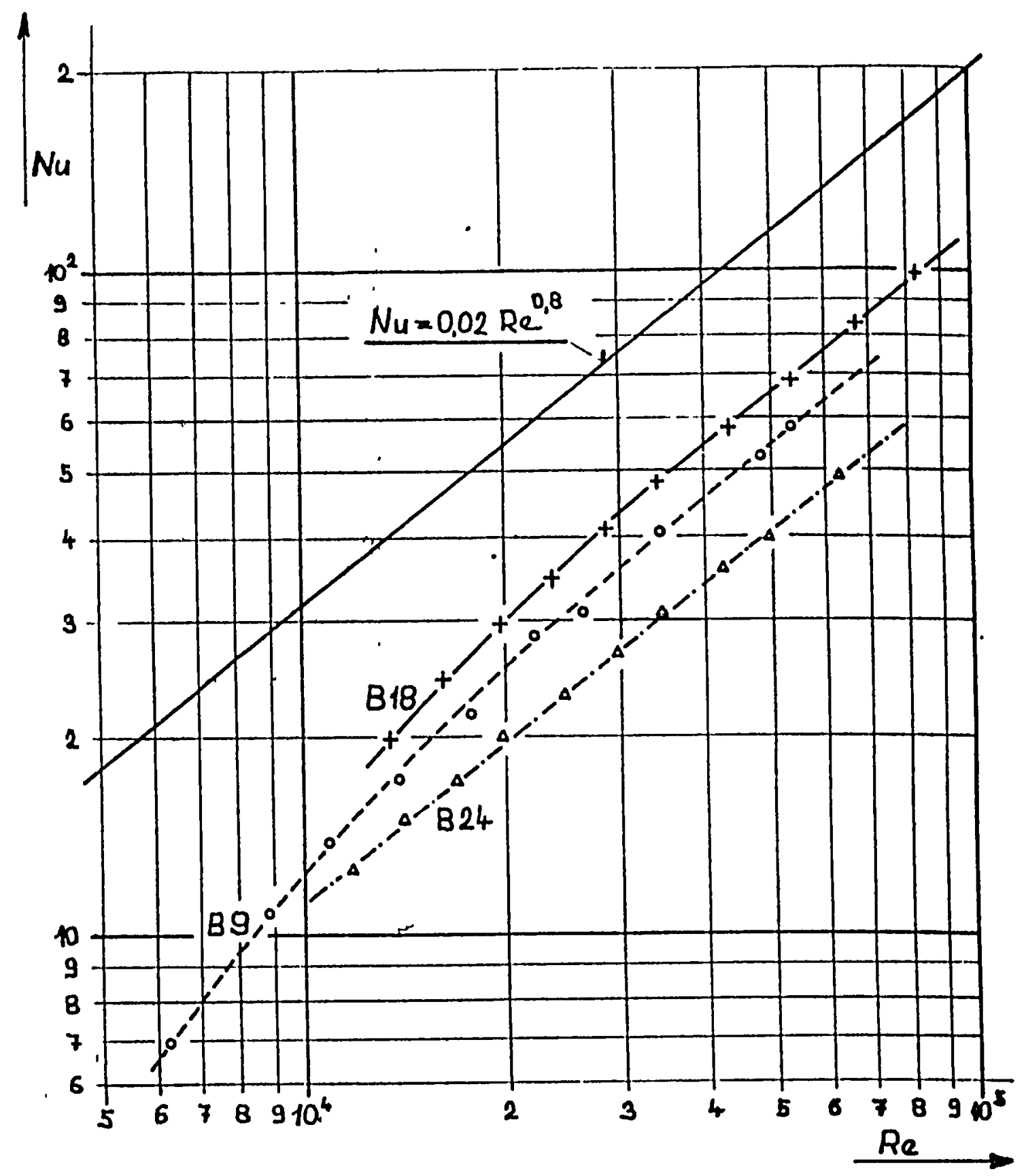

Fig. 19. Several examples od experimental dependence of $\mathrm{NU}=6(\mathrm{Re})$ for geometry $\mathrm{B}$. 


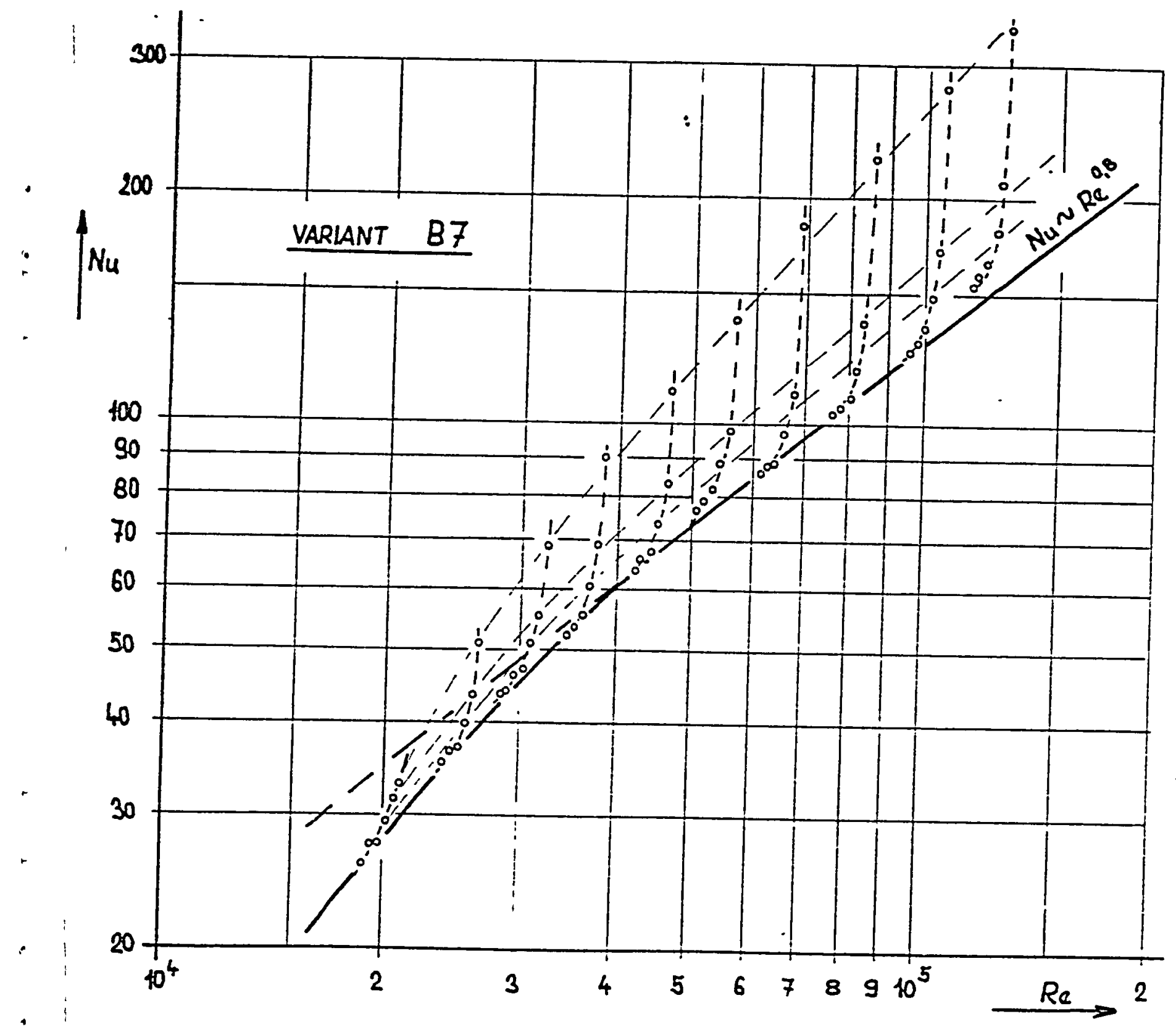

Fig. 20 Effects of the length of a heated model on the accuracy of determination of the dependence of $N u=b(R . e)$. 


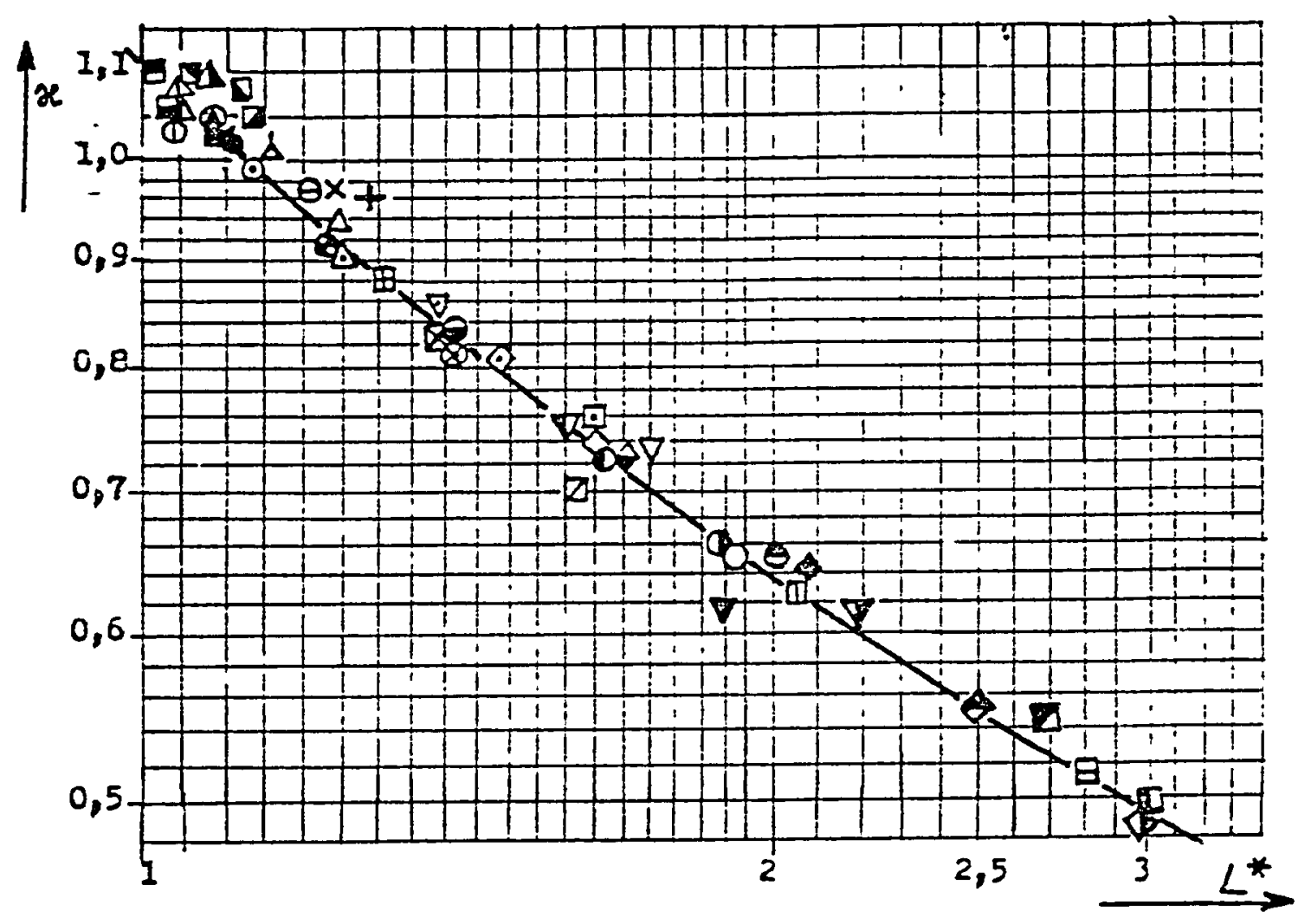

Fig. 21. Assessment of the dependence of the geometrical factor on the geometrical criterion $L^{*}$ from the experiments conducted by the Institute of Nuclear Research. 


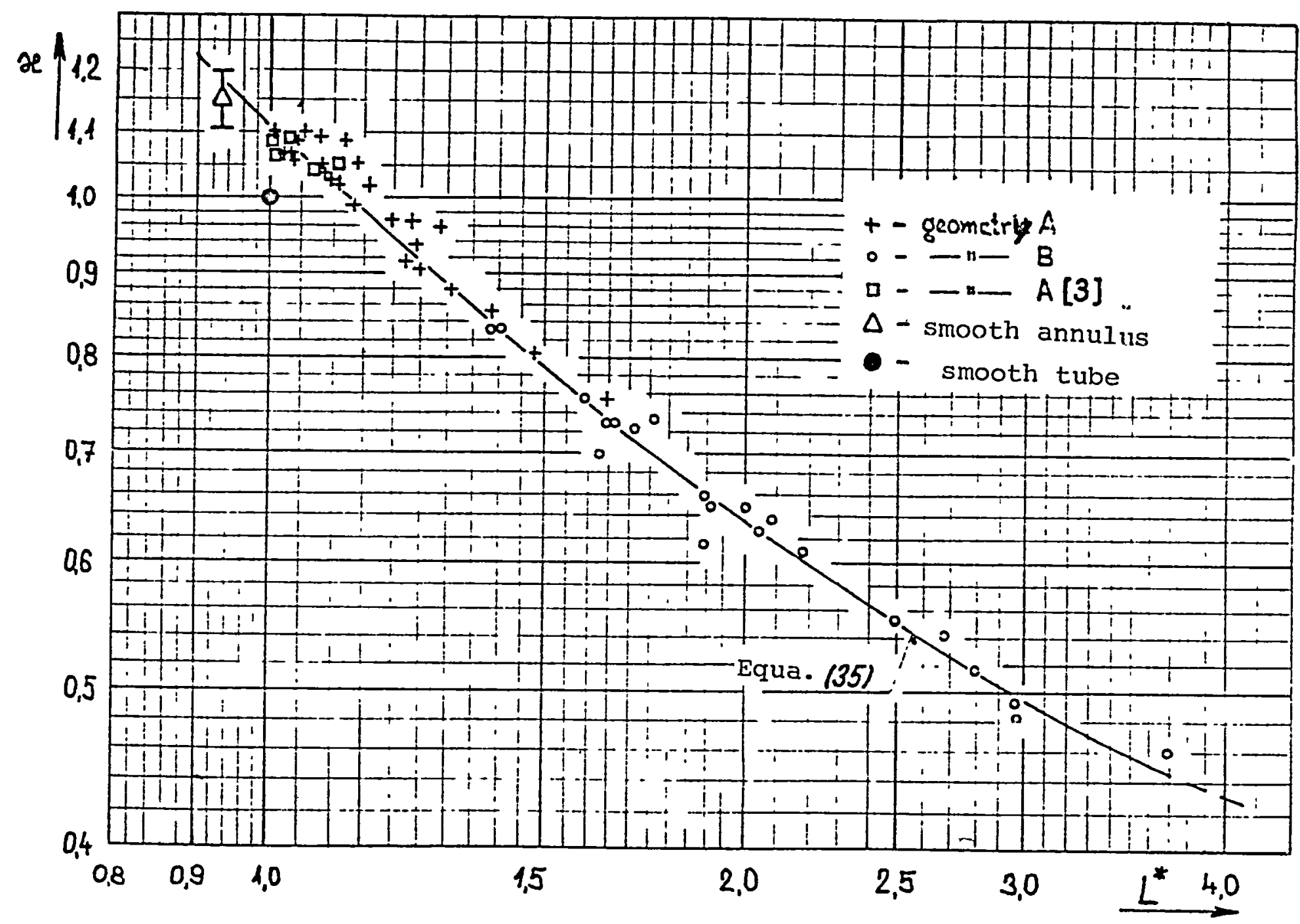

Fig. 22. Experimental dependence of $H=f\left(L^{*}\right)$ - results for geometries $A$ and $B$ and results obtained by $K$. Rybáček [3]. 


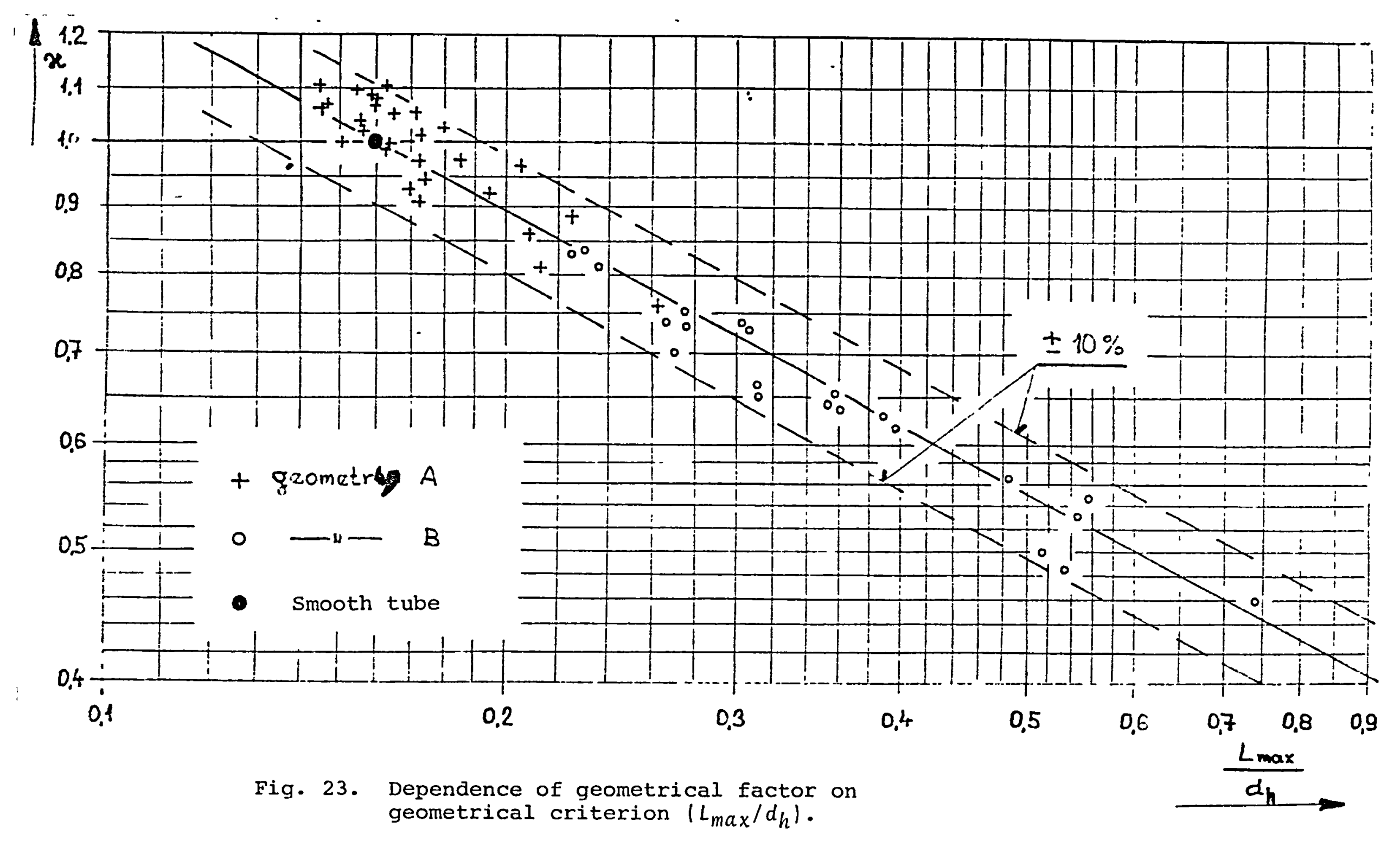




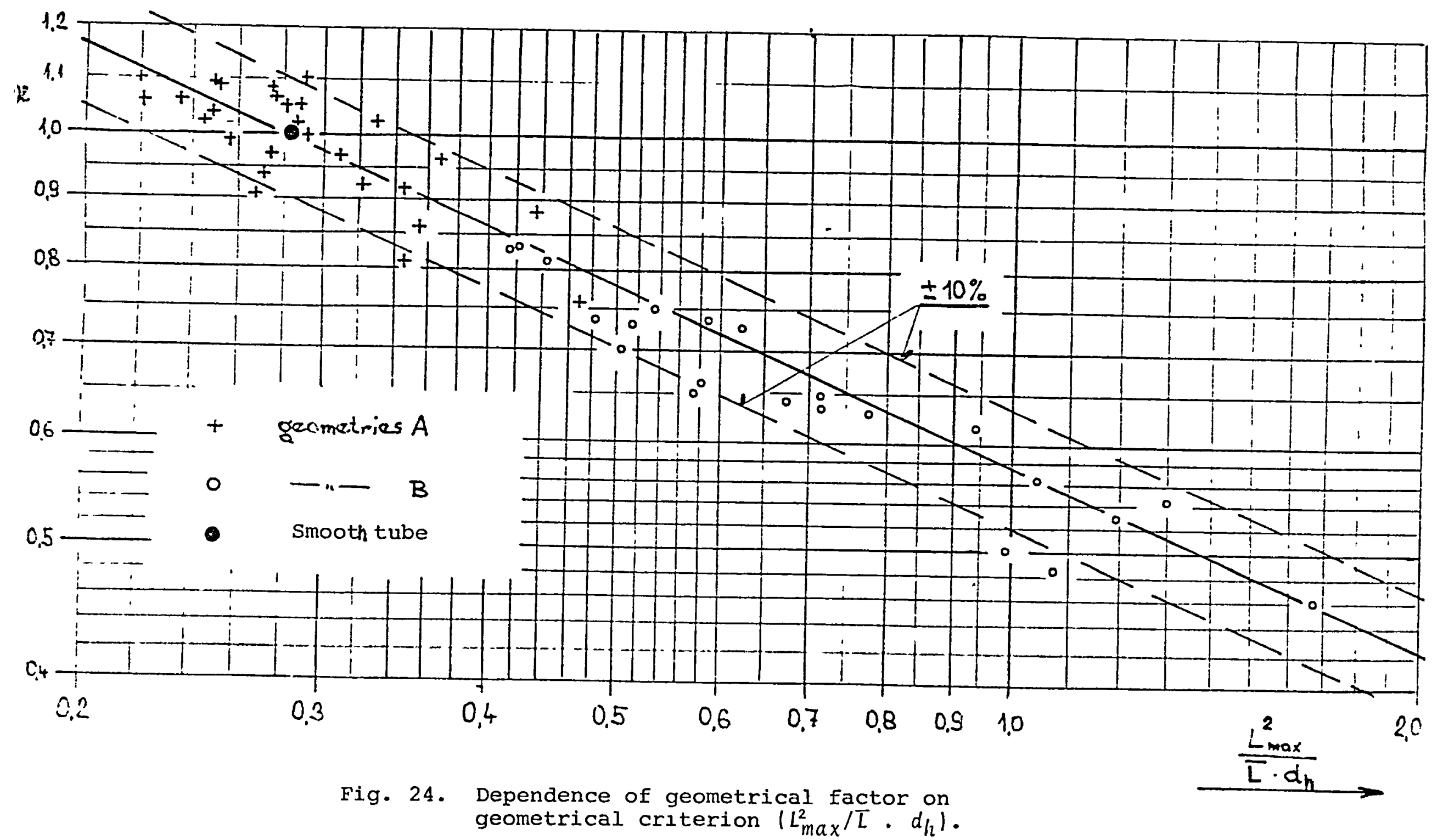




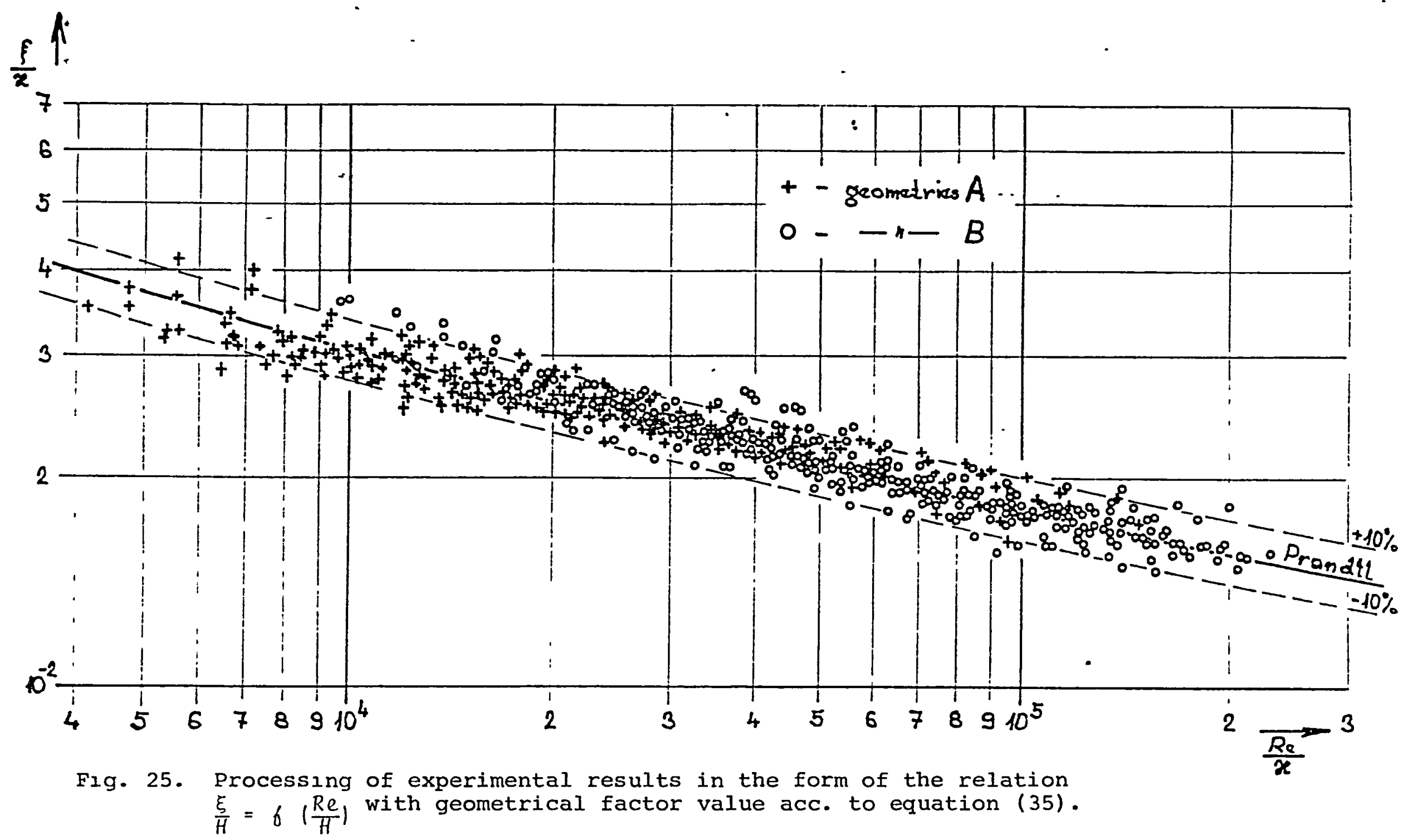



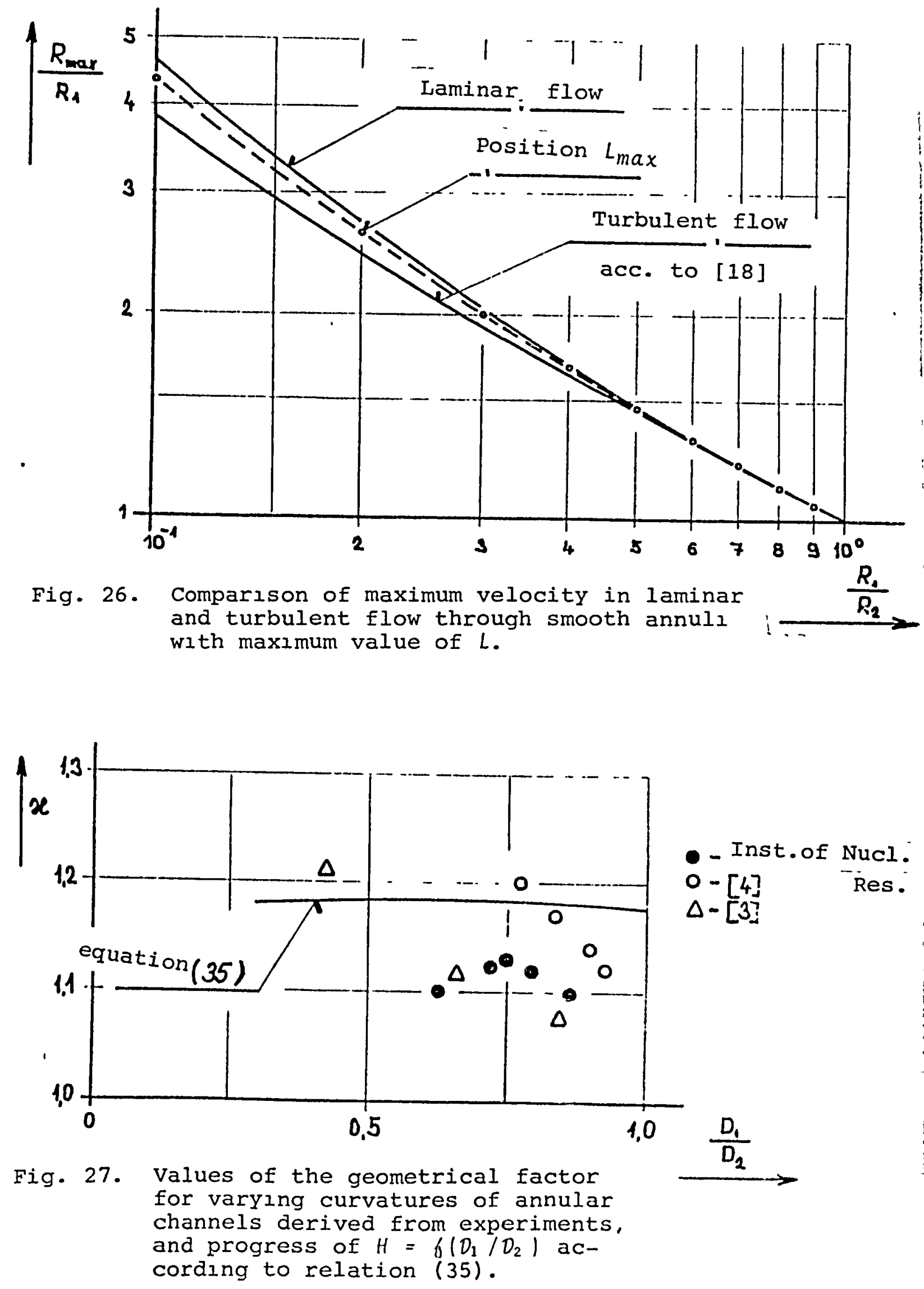


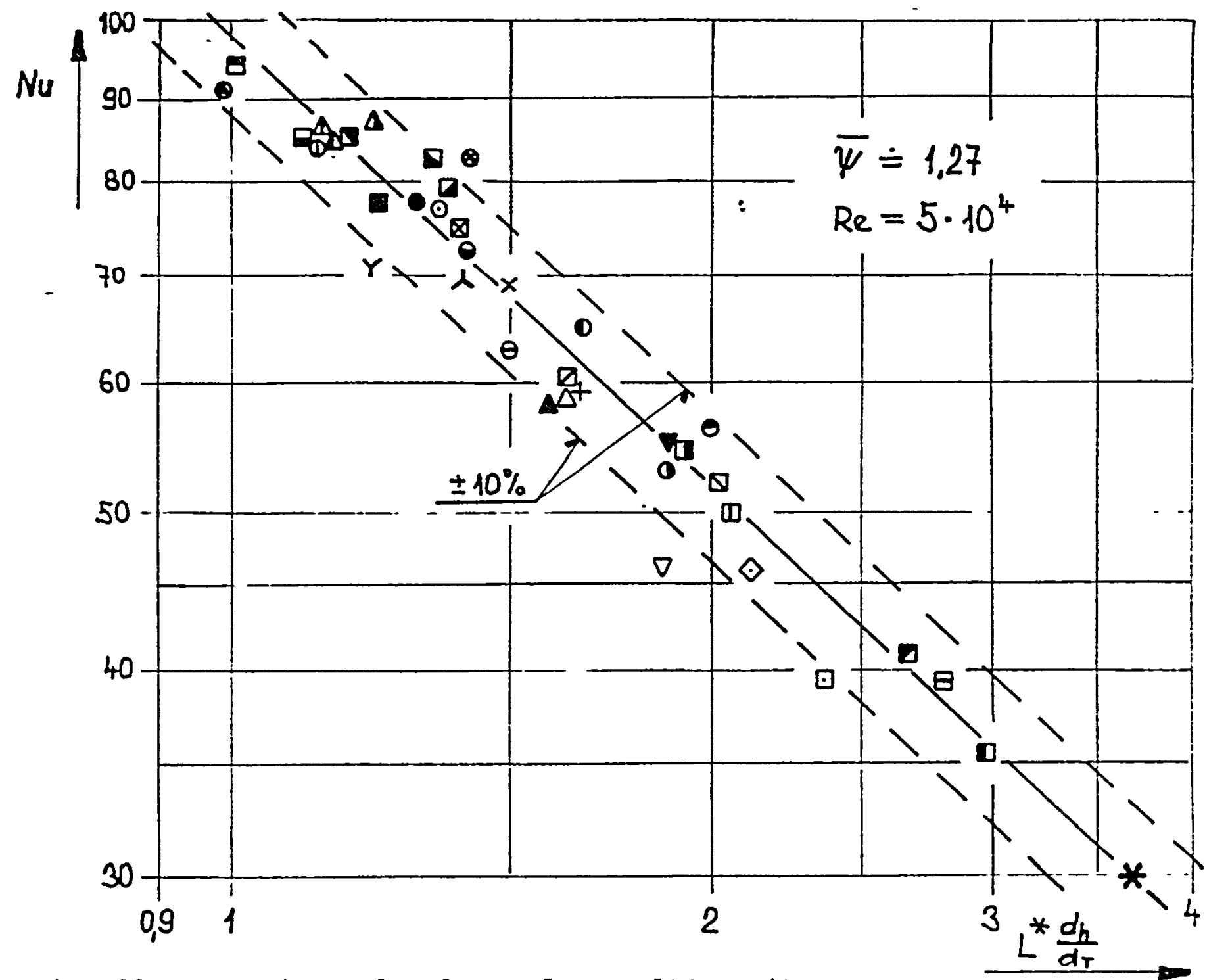

Fig. 28. Experimental values of Nusselt's criterion for $\operatorname{Re} 5.10^{4}$ and $\psi=1.27$ and their dependence on the geometrical criterion $\left(L^{*} \frac{d h}{d T}\right)$. 


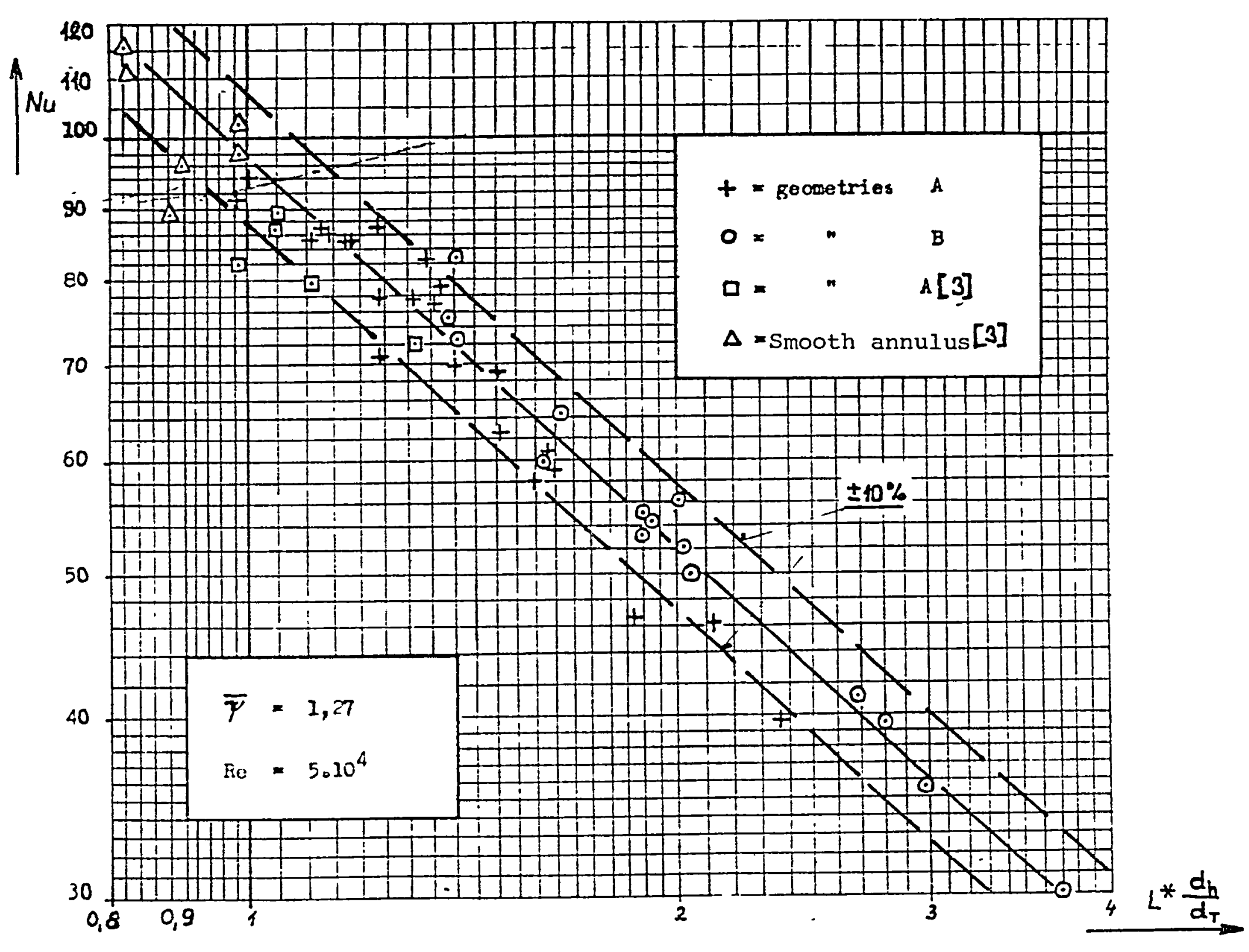

Fig. 29. Experimental values of Nusselt's criterion for $\operatorname{Re}=5.10^{4}$ and $\Psi=1.27$ and their dependence on the geometrical criterion $\left(L^{*} \frac{d}{h}\right)$; differentiation between geometry $A$ and $B$, including results obtained by $K$. Rybfrek [3]. 
$\stackrel{\circ}{\perp}$

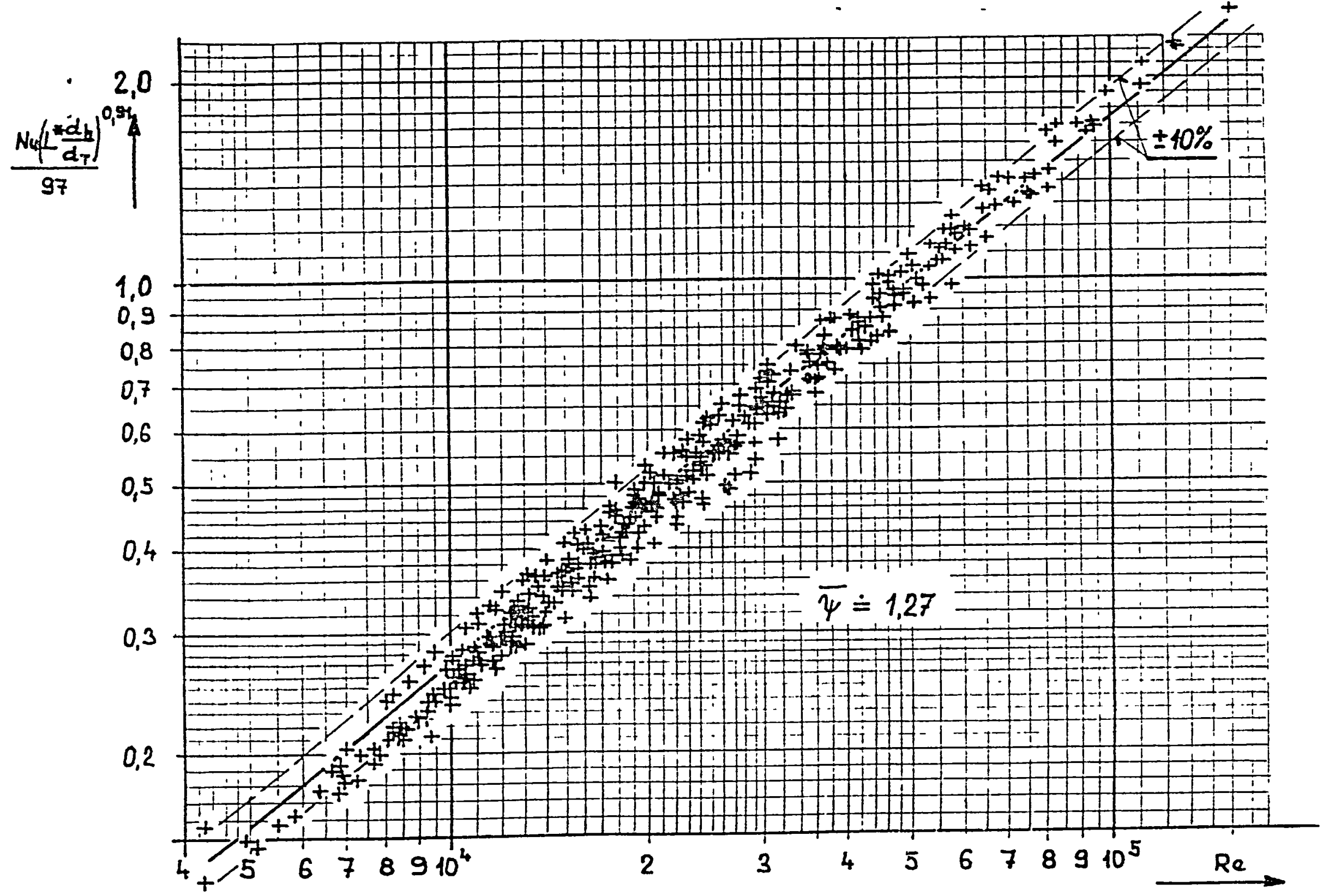

F1g. 30. processing of the results of thermokinetic experiments on geometry $A$ into the dependence form $\frac{1}{97}\left(L^{*} \frac{d h}{d T}\right)^{0.91}$. Nu $=6(R e)$. 


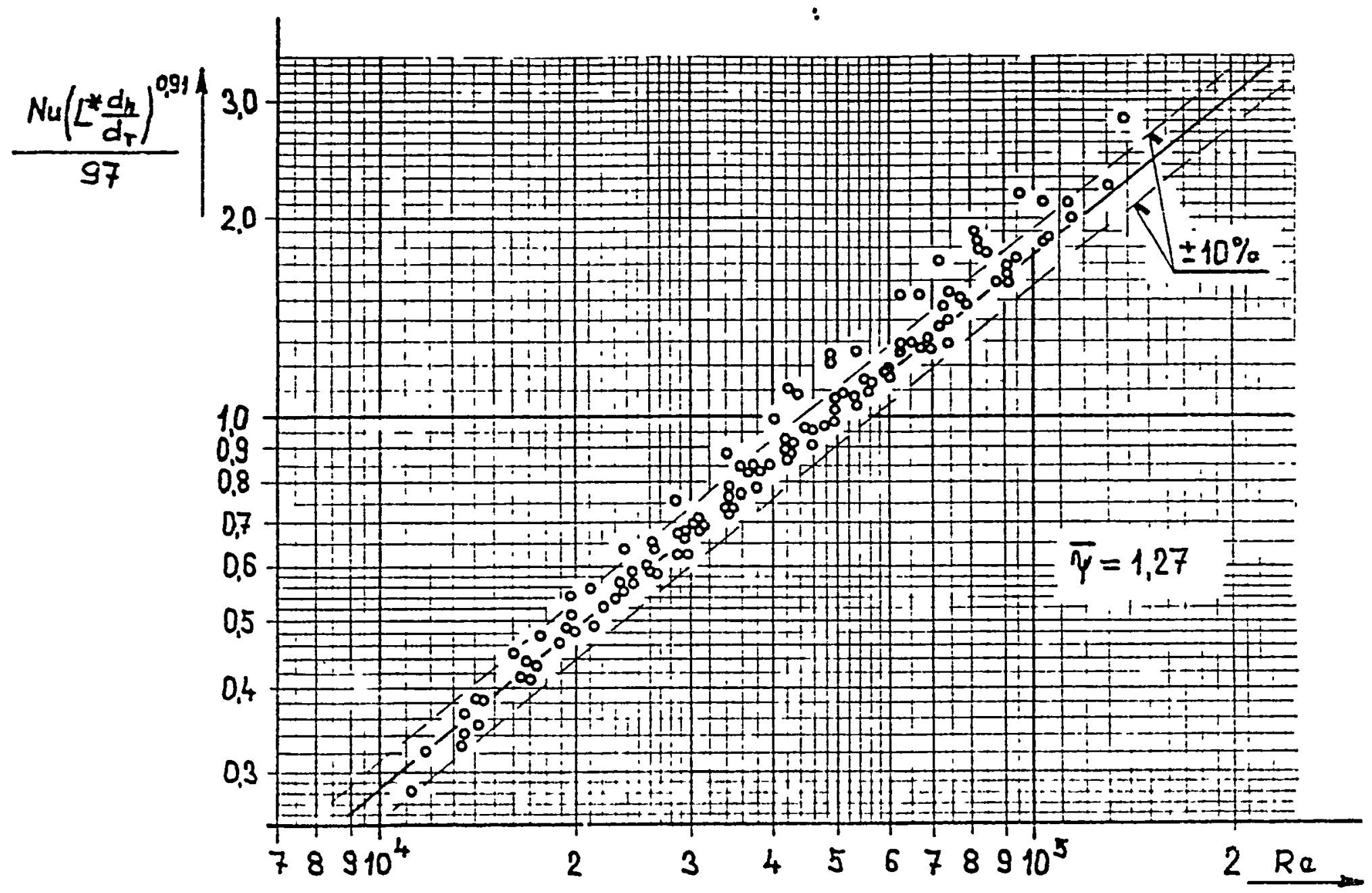

Fig. 31 Processing the results of thermokinetic experiments on geometry $B$ into the dependence form $\frac{1}{97}\left(L^{*} \frac{d h}{d T}\right)^{0.91}$. Nu $=6(r e)$. 


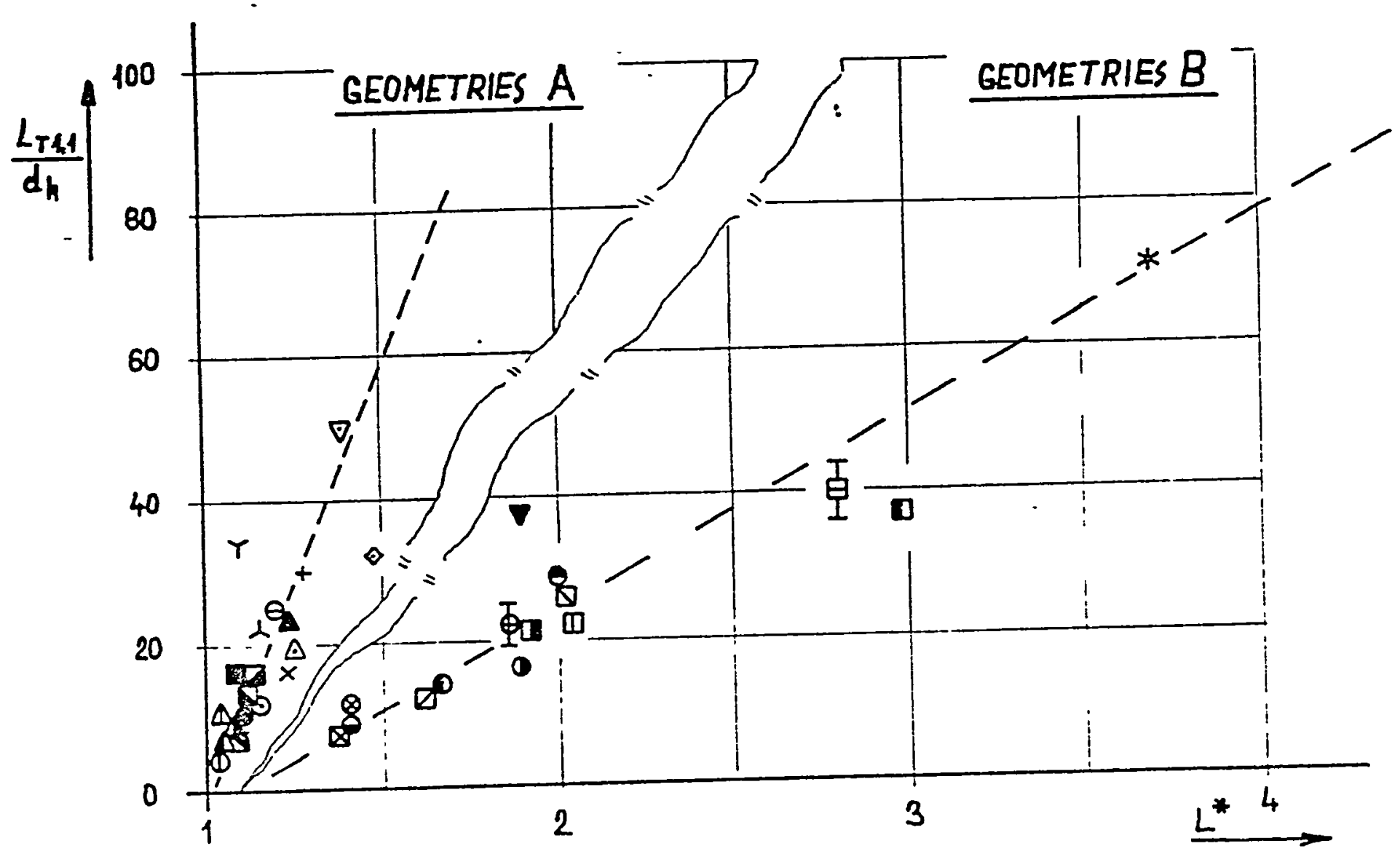

Fig. 32. Experimental values of $\frac{L T_{1}, 11}{d h}$ and their dependence on $L^{*}$. 


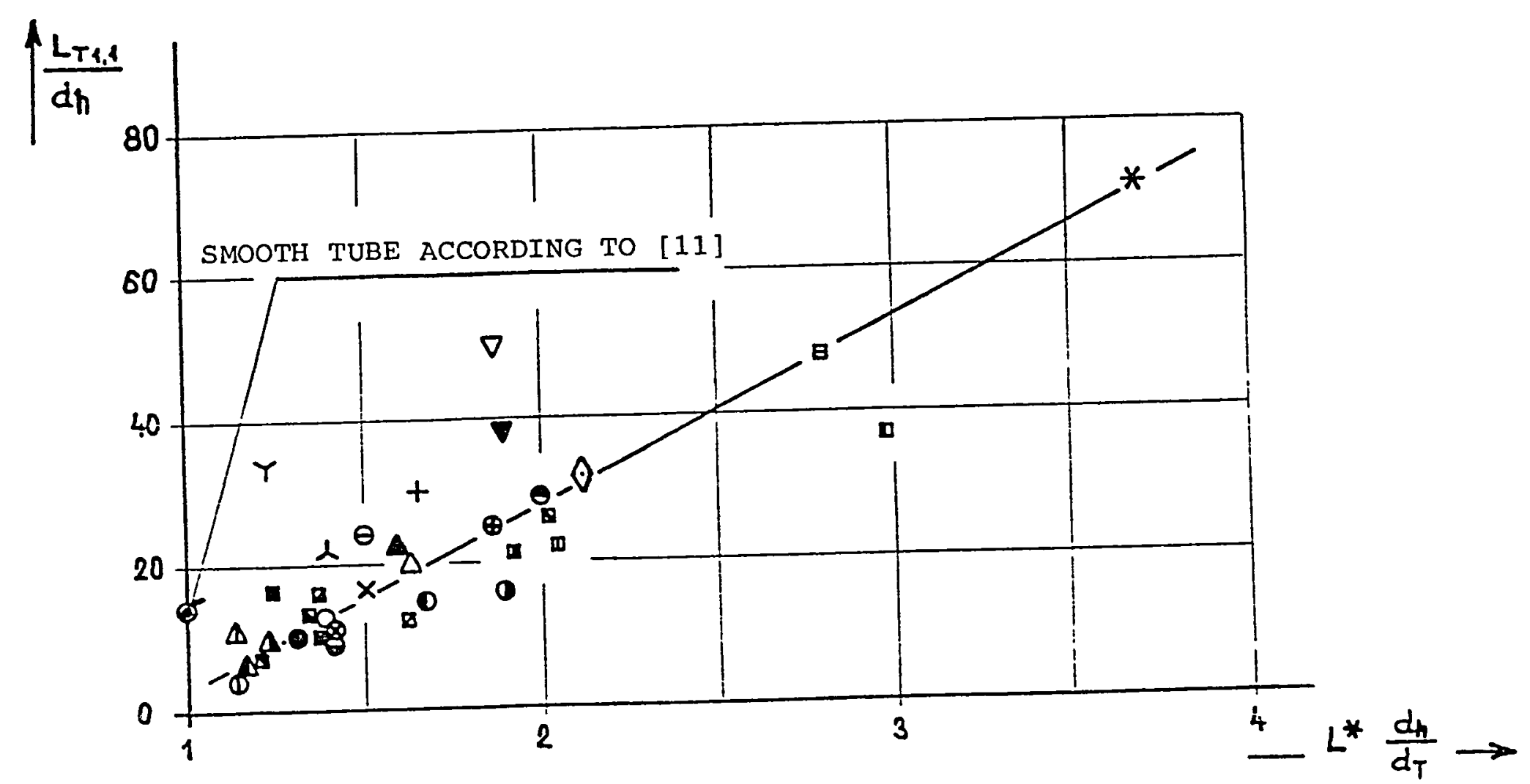

Fig. 33. Experimental values of $\frac{L_{h, 1 l}}{d h}$ and their dependence on $\left(L^{*} \frac{d h}{d T}\right)$. 


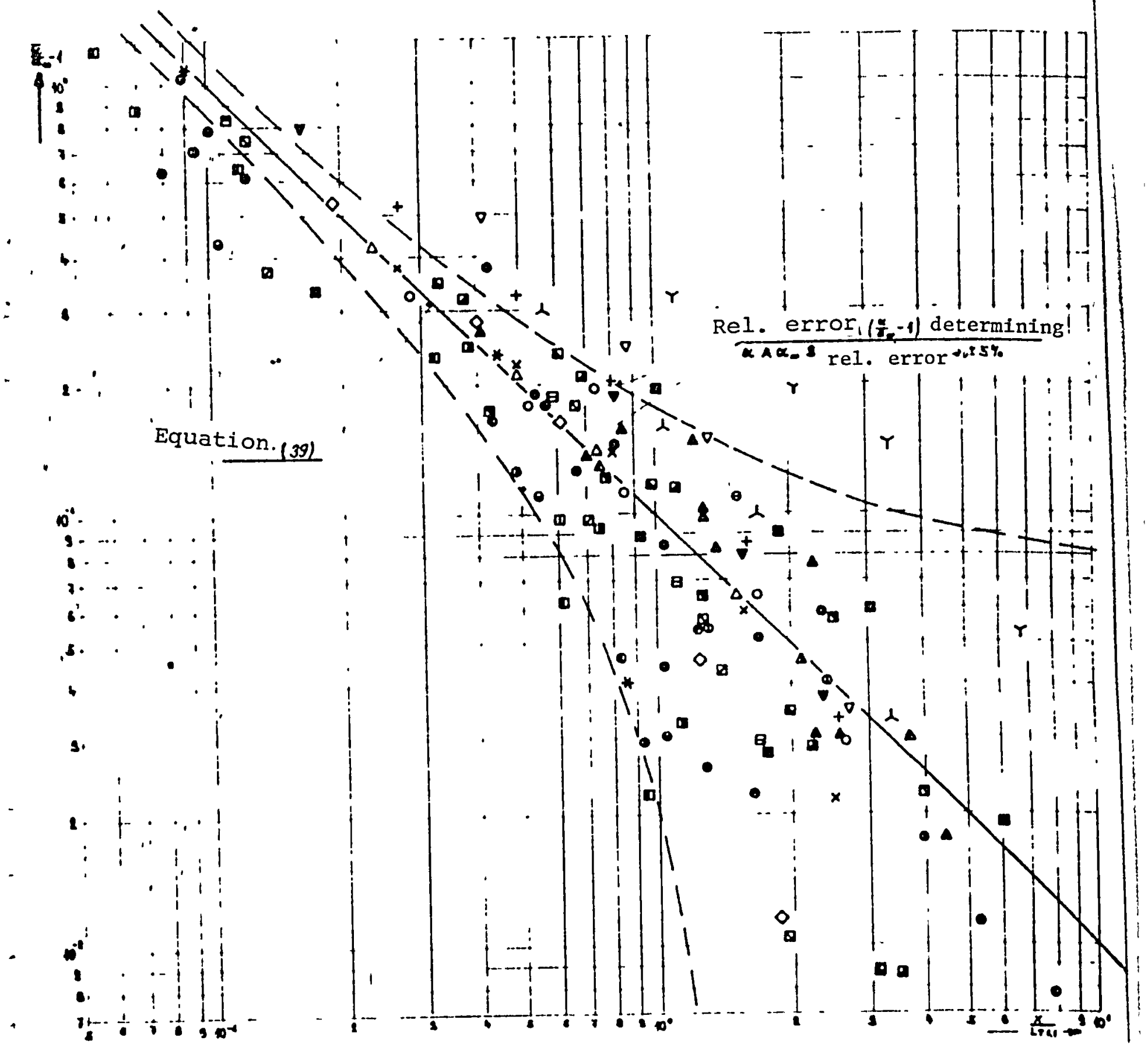

Fig. 34. Distribution of $\bar{\alpha}$ along the length of the model in the form of dependence $\frac{\bar{x}}{\bar{\alpha}_{\infty}}-1=6\left(\frac{x}{L T_{1.1}}\right)$. Values of $L_{T_{1.1}}$ for 1 individual variants were computed from equation (42). 


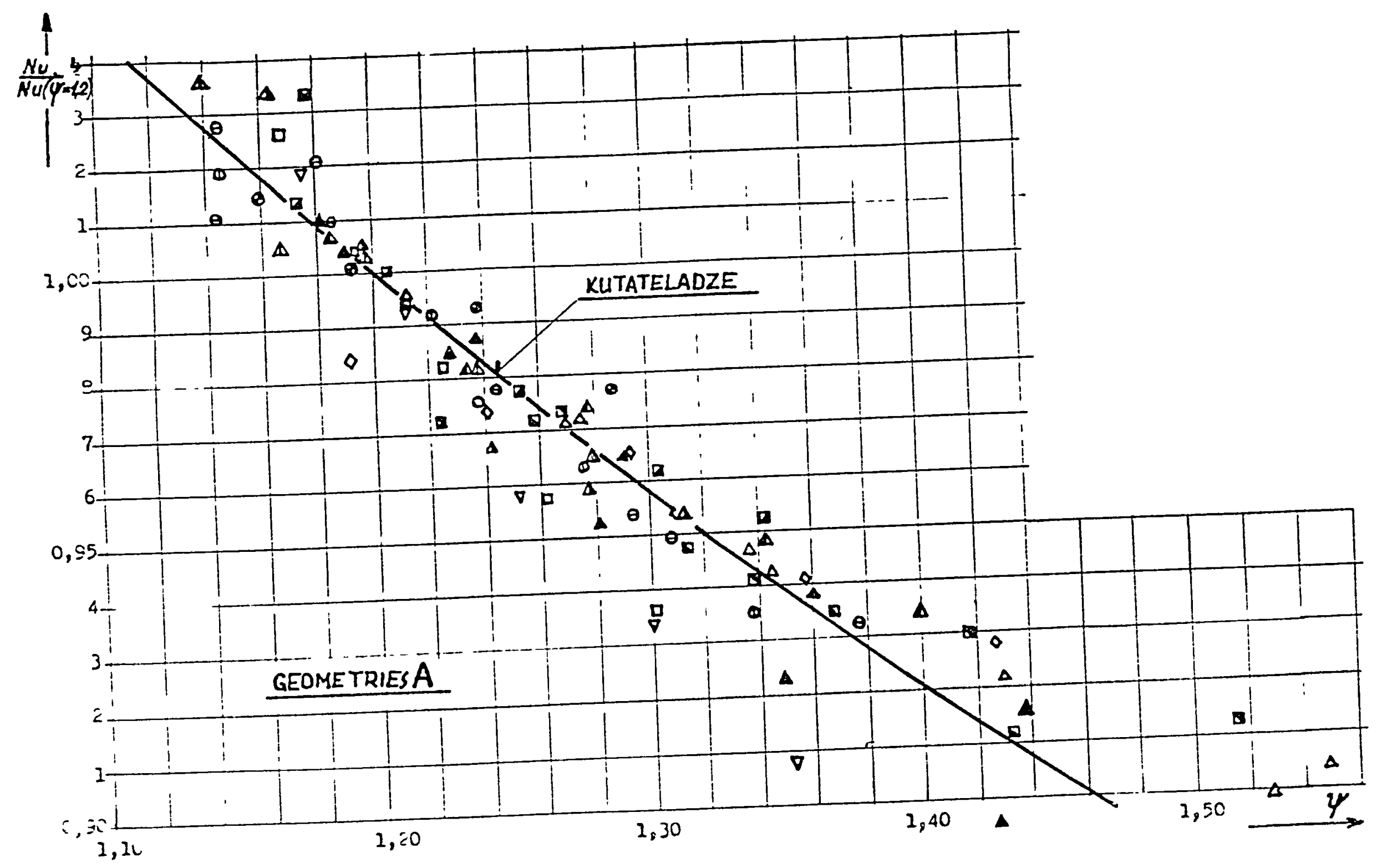
F1g. 35. Effects of the thermal factor on Nusselt's criterion at constant flow-through (with no ter change on $\mathrm{Nu}$ ). 


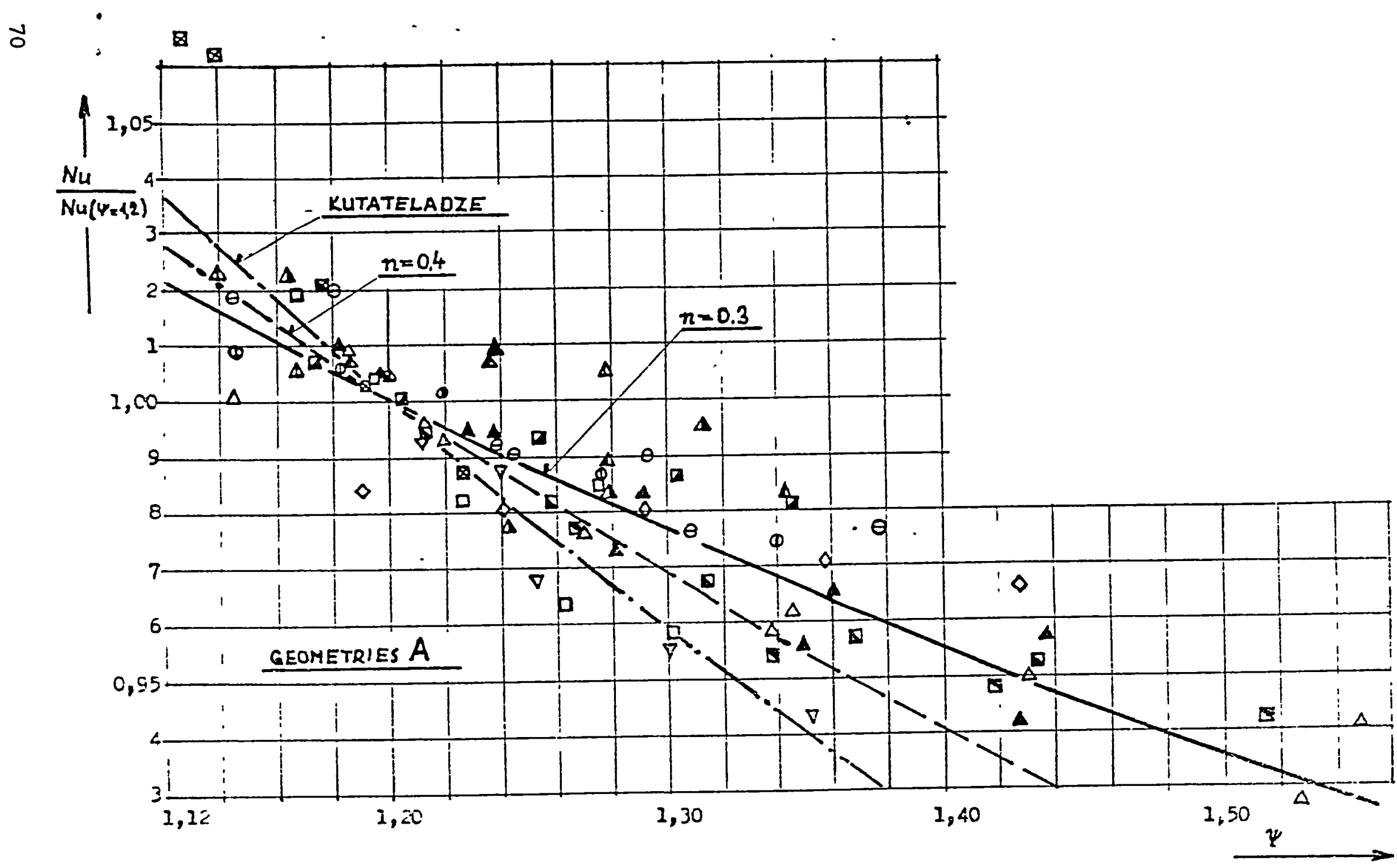

Fig. 36. Effects of the thermal factor on Nusselt's criterion at constant values of Re. 


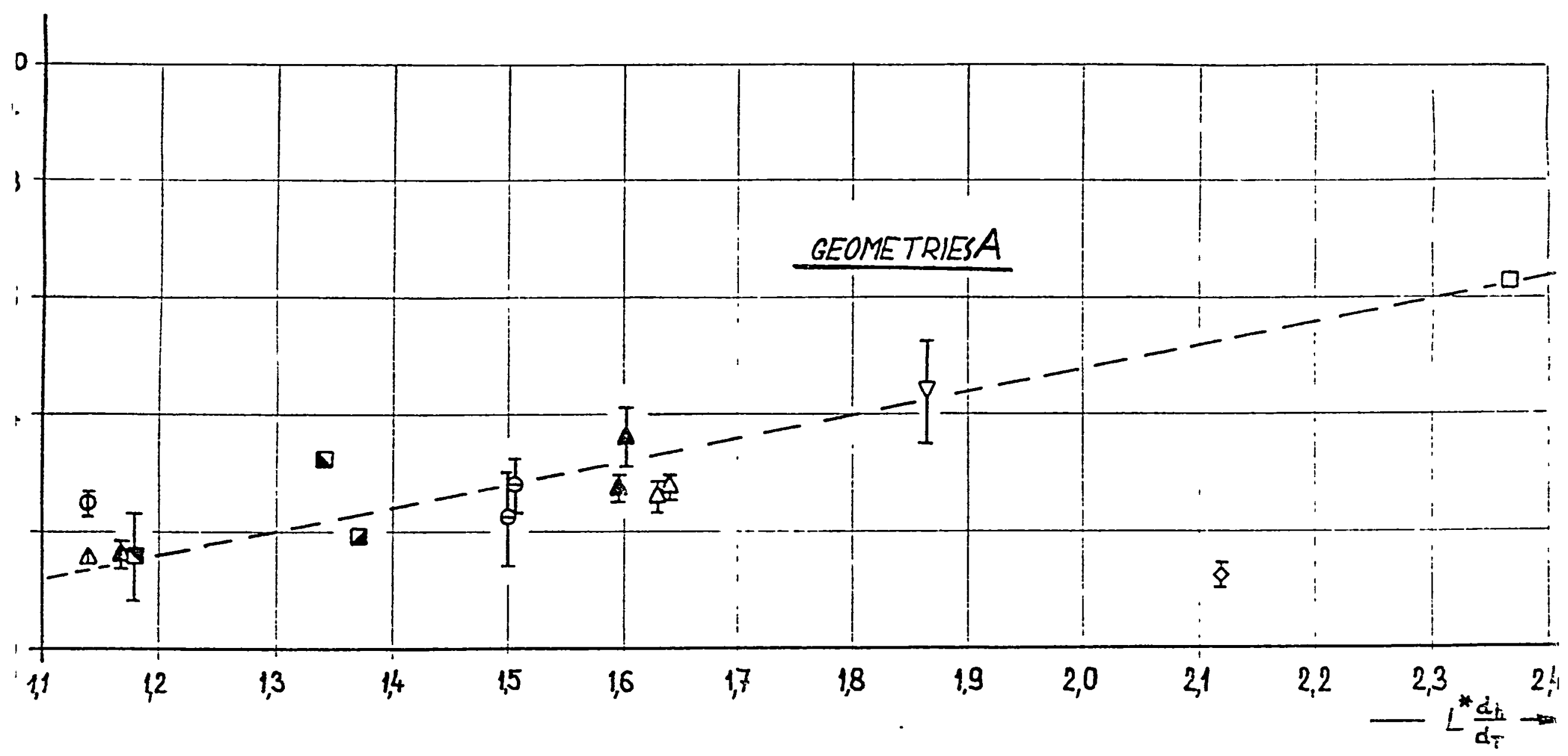

Fig. 37. Experimental values of exponent $n$ as a function of criterion $\left(L^{*} \frac{d h}{d T}\right)$. 


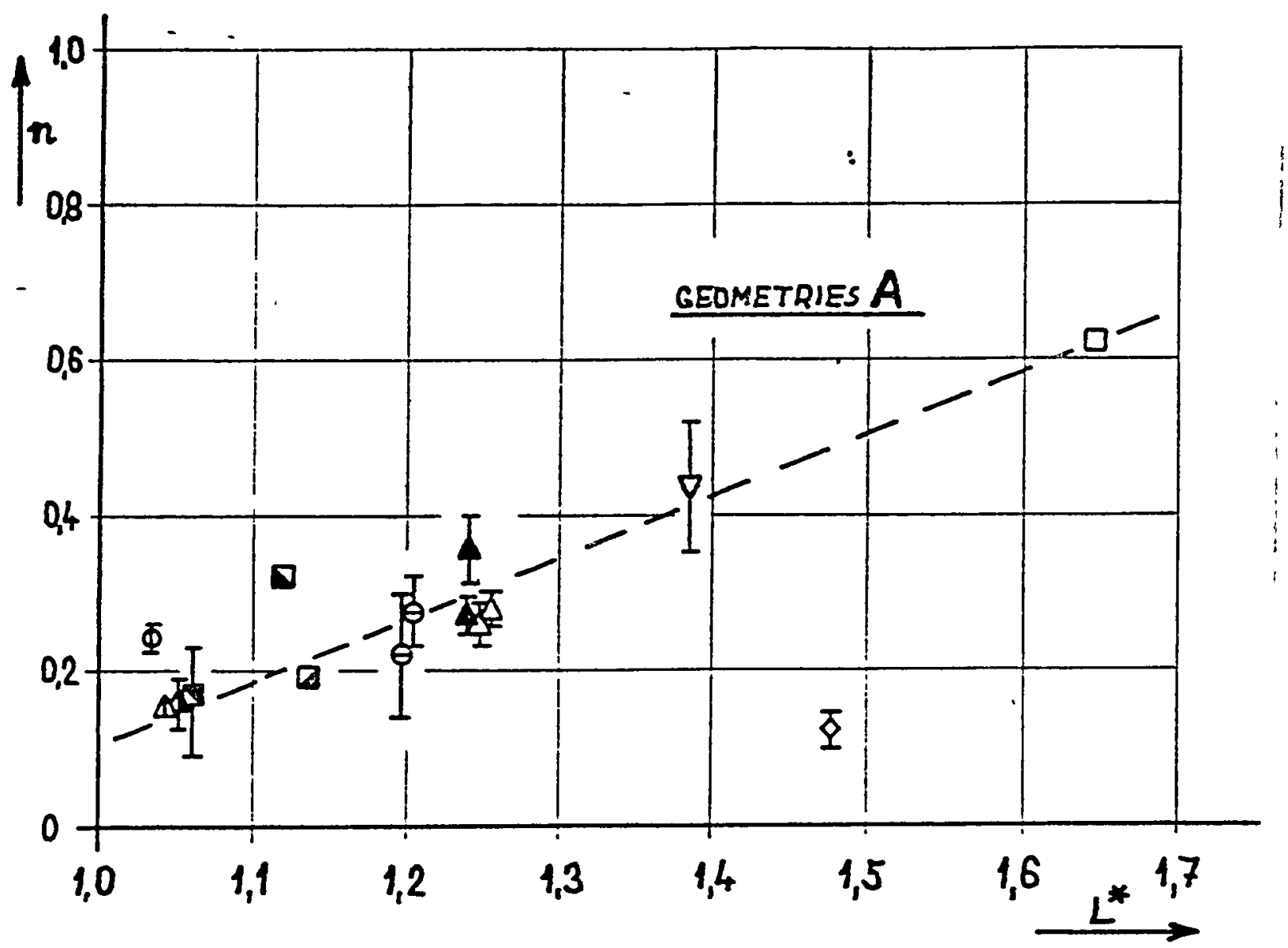

F1g. 38. Experimental values of exponent $n$ as a function of criterion $L^{*}$. 

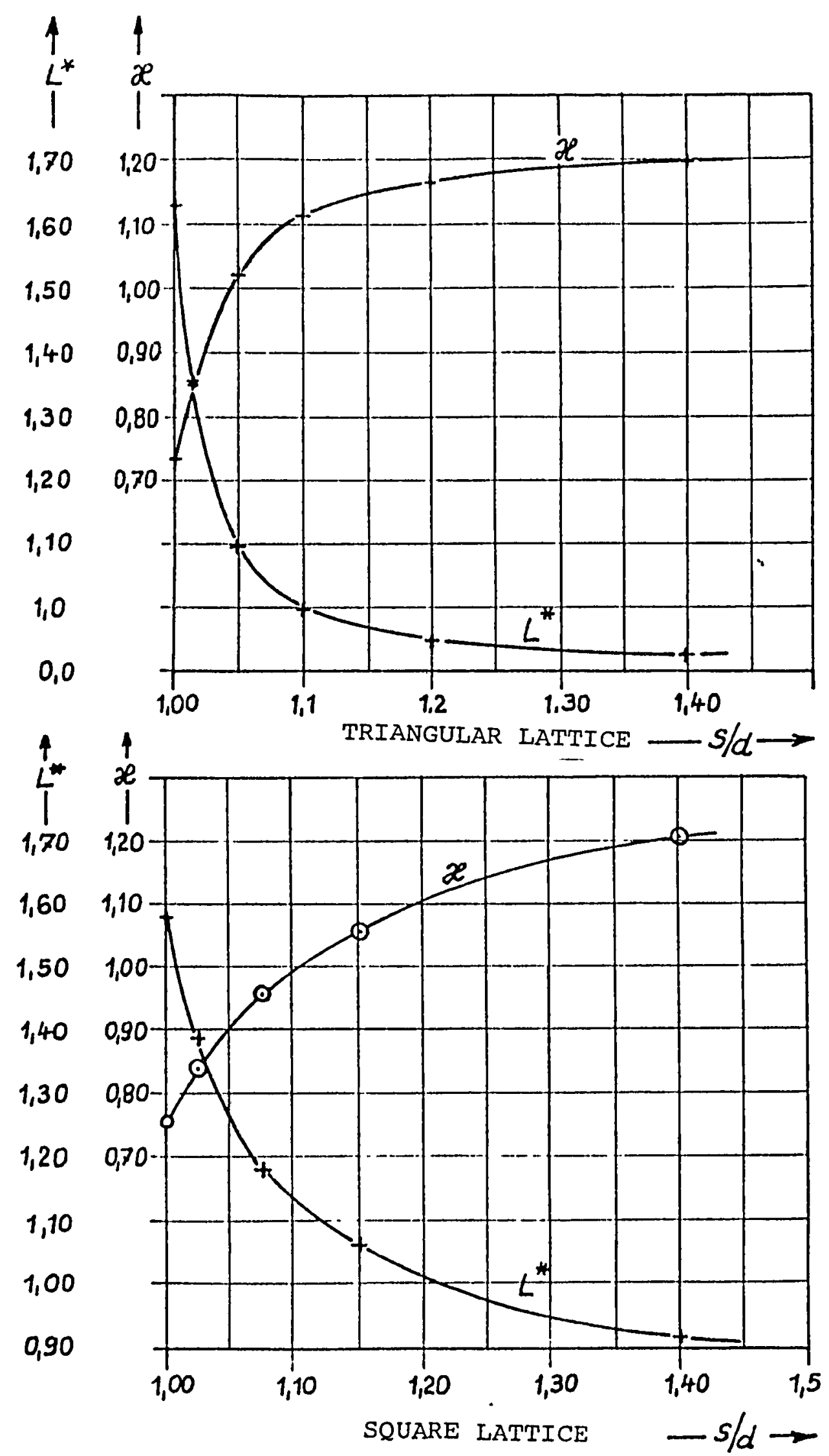

Fig. 39. Dependence of the geometrical criterion $L^{*}$ and the grometrical factor $H$ on the density of triangulat and square lattices. 


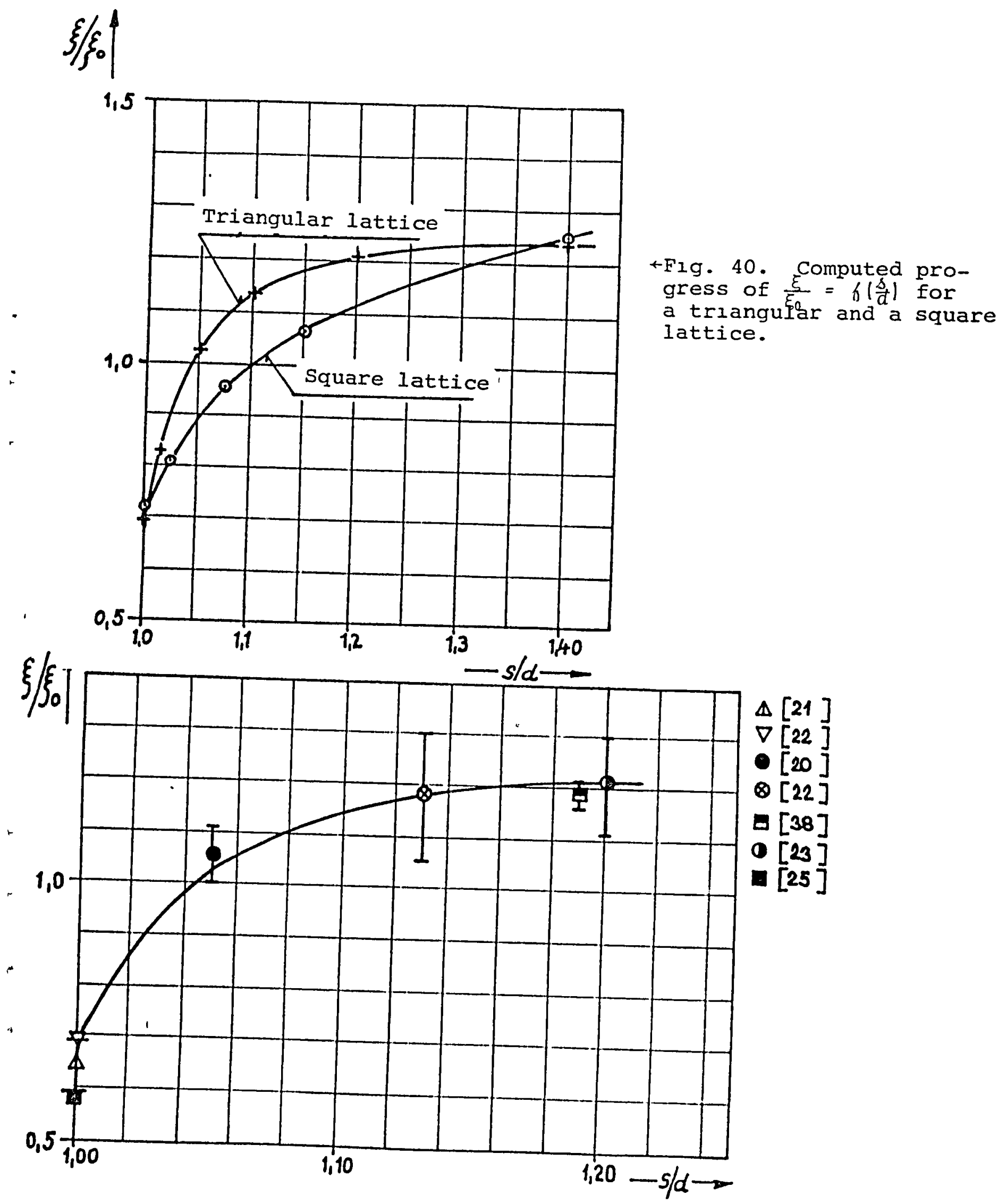

Fig. 41. Change in coefficient of friction losses with the density of a trlangular lattice: comparison of criterlal relation (21) with experiments. 


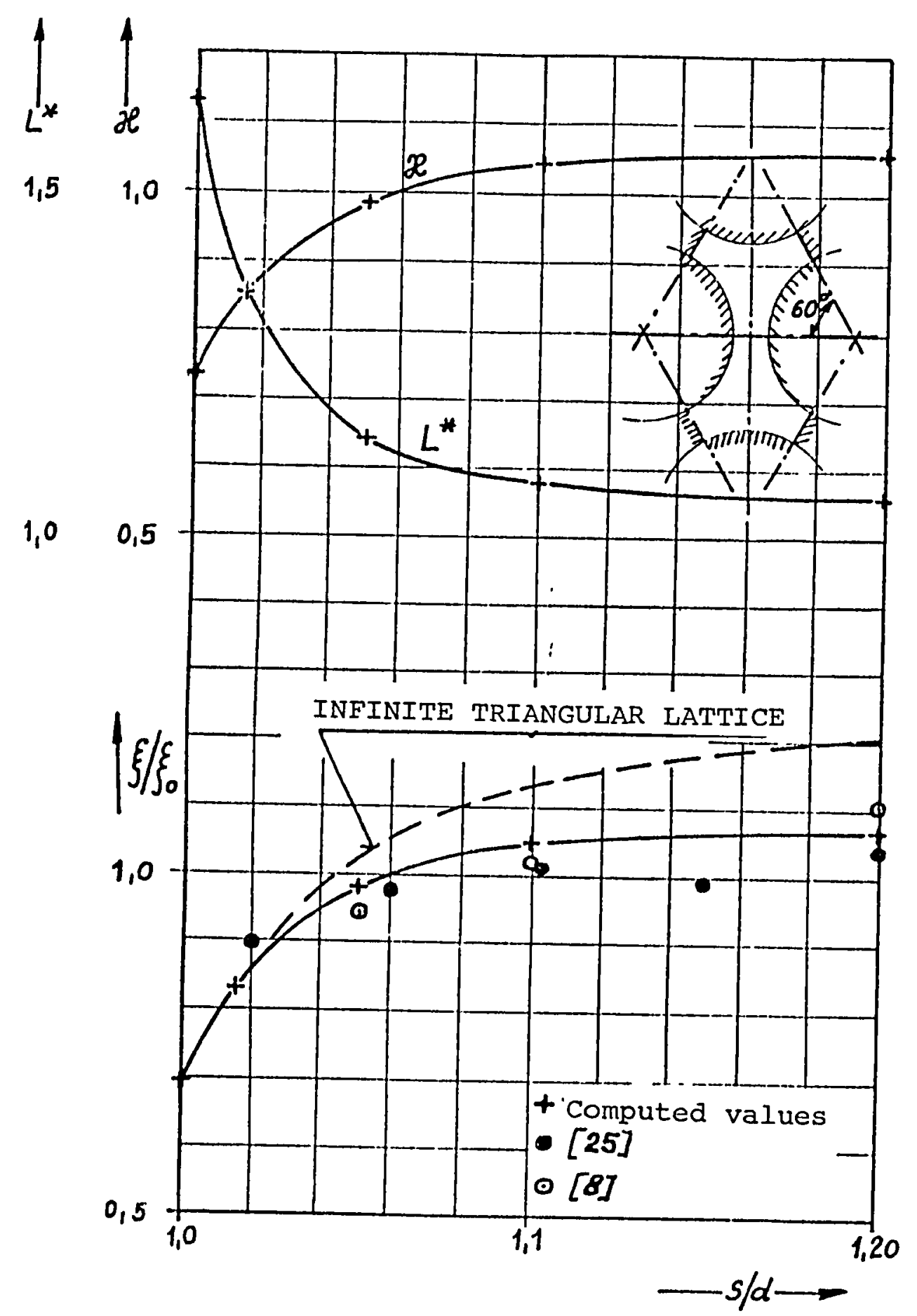

Fıg. 42. Comparison of computed and experimental values of $\xi / \xi_{0}$ for the used cell models of an infinite triangular lattıce. 


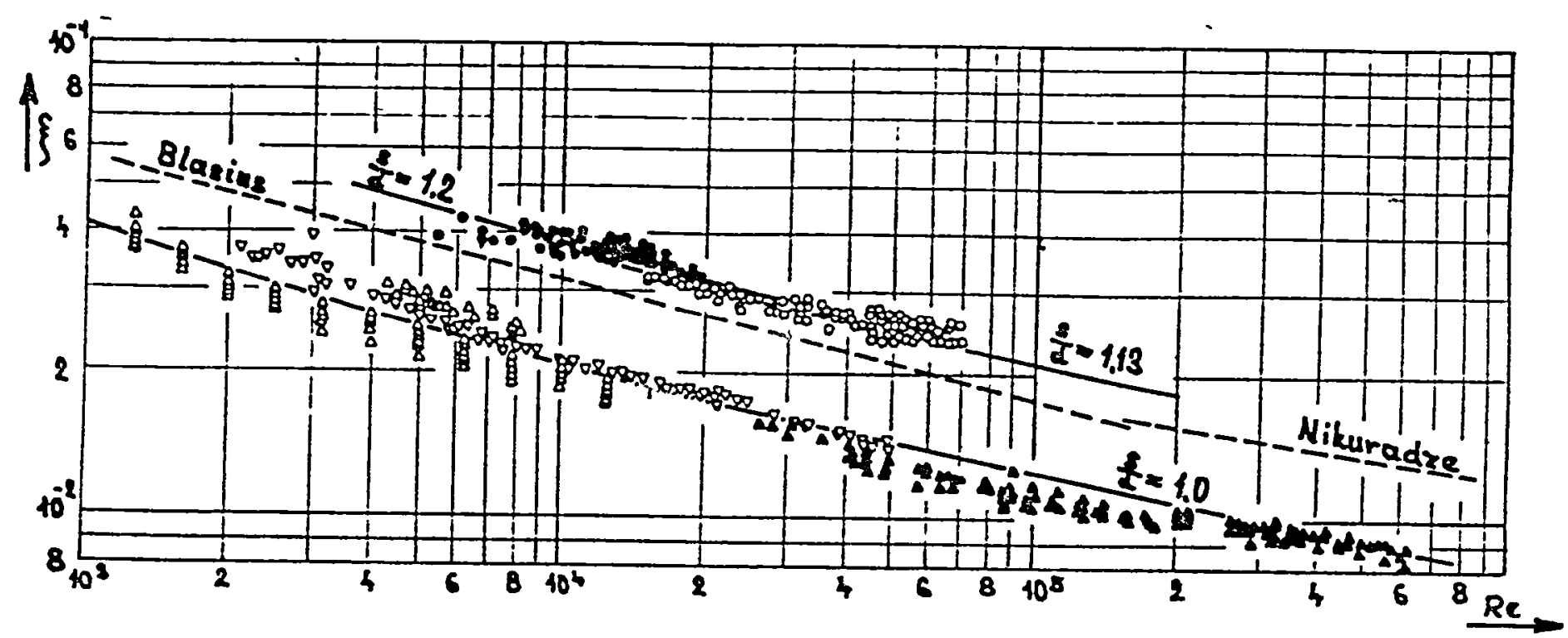

\begin{tabular}{|c|c|c|c|c|c|c|c|c|c|c|}
\hline Ref: & $\frac{s}{d}$ & $N$ & d & $d_{h}$. & $d_{h}$ & $L$ & 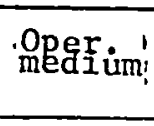 & $\begin{array}{l}\text { Range } \\
\operatorname{Re} \cdot 10^{3}\end{array}$ & Sym & $\begin{array}{l}\text { Model } \\
\text { section }\end{array}$ \\
\hline 22 & 1.0 & 19 & 17,6 & 1,81 & 1,81 & 700 & water & $1-20$ & $\Delta \nabla$ & (2) \\
\hline 21 & 1,0 & & 205 & 20,9 & & 1800 & water & $8-630$ & $\Delta$ & $\Delta$ \\
\hline 22 & $\mid 1,13$ & 19 & 12,0 & 4,8 & 5.0 & 980 & water & $14-70$ & 。 & (2) \\
\hline 23 & 1,2 & 7 & 22,0 & 12,94 & 41.43 & 1050 & water & 5.20 & - & 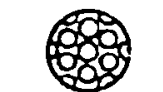 \\
\hline
\end{tabular}

Fig. 43. Comparison of experiments and computations for a triangular lattife (in cases when it can be considered to be infinite). 

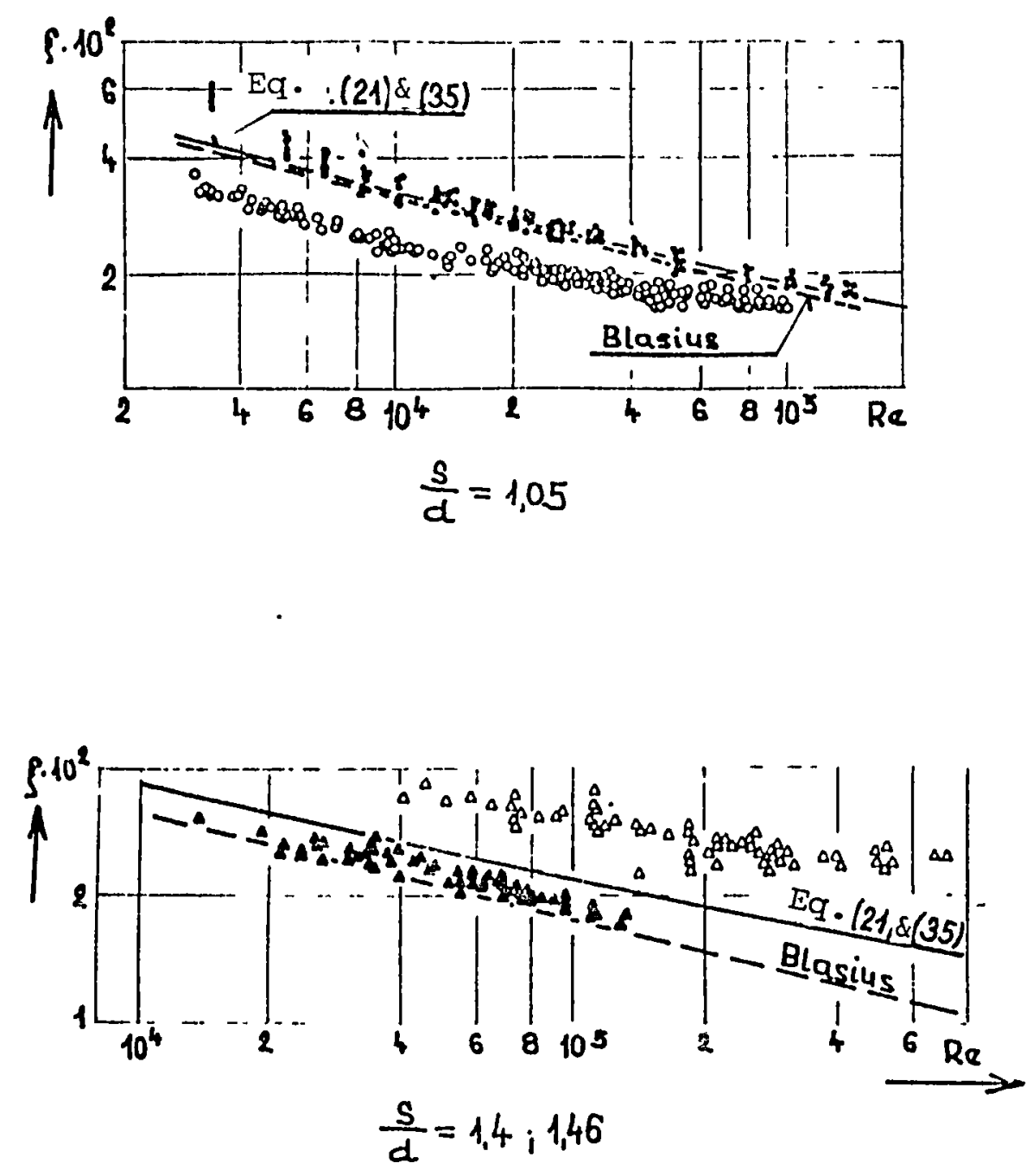

\begin{tabular}{|c|c|c|c|c|c|c|c|c|c|c|}
\hline $\begin{array}{l}\text { Litero } \\
\text { ture }\end{array}$ & $\frac{8}{d}$ & $N$ & $d$ & $d_{h}$. & $d_{h}$ & $L$ & $\begin{array}{l}\text { Oper. } \\
\text { medium }\end{array}$ & $\begin{array}{l}\text { range } \\
\text { Re.10 }\end{array}$ & $\begin{array}{l}y m- \\
\text { bo }\end{array}$ & $\begin{array}{l}\text { Model } \\
\text { section }\end{array}$ \\
\hline 20 & 1,05 & 37 & 14,0 & 3,02 & 3,00 & 1000 & water & $3-120$ & - & 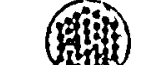 \\
\hline 20 & 1,05 & 37 & 10,0 & 2,16 & 2,16 & 840 & water & $3-100$ & 0 & (19) \\
\hline 20 & 1.4 & 37 & 10,0 & 11,62 & 11,53 & 840 & water & $12-120$ & 4 & $(340)$ \\
\hline 24 & 1.46 & 37 & 15,9 & 19,5 & 24,5 & 1220 & water & $40 \cdot 800$ & $\Delta$ & (1) \\
\hline
\end{tabular}

Fig. 44. Continuation of Fig. 43. 

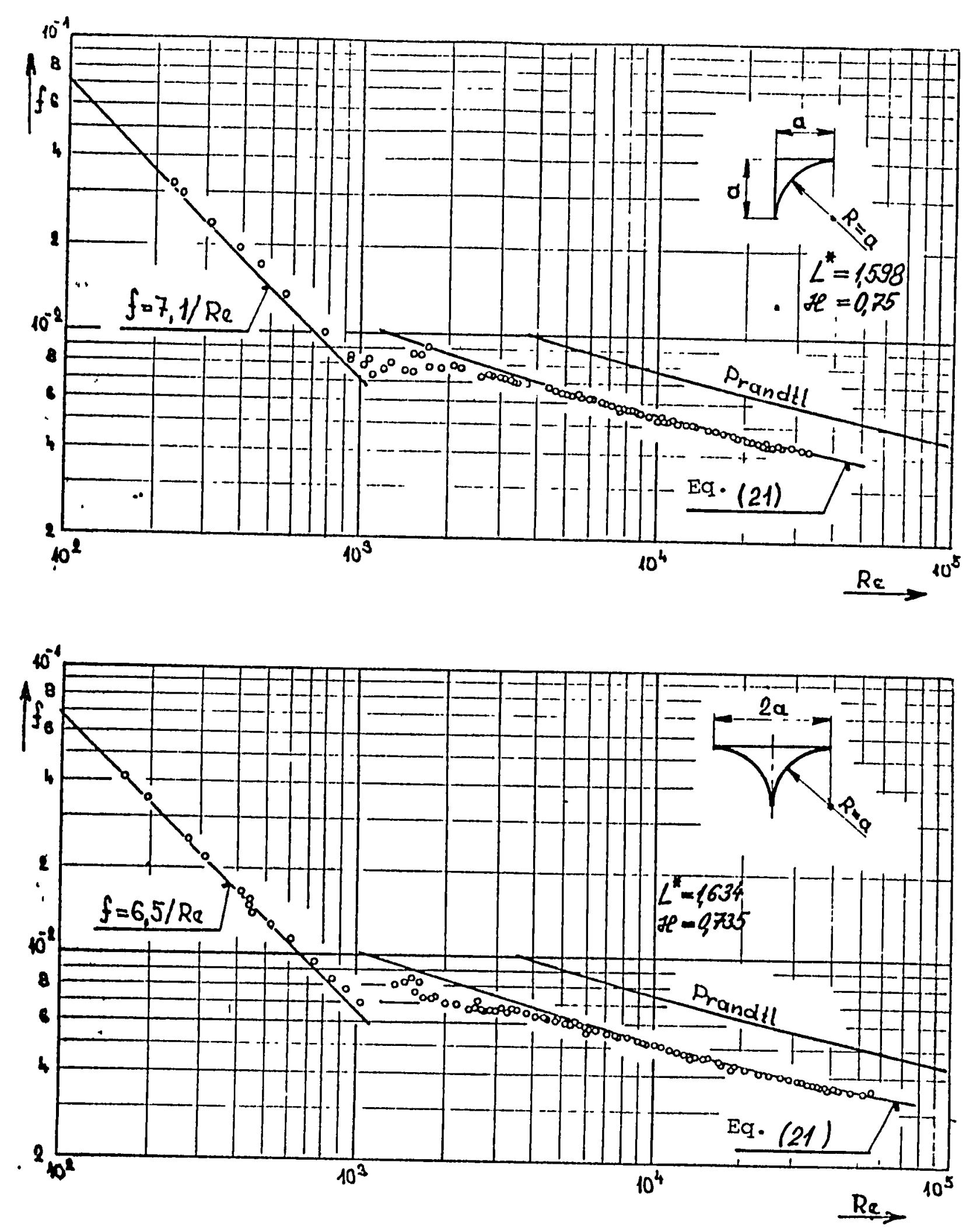

Fig. 45. Comparıson of experiments and computations for elements of a square lattice [27]. 

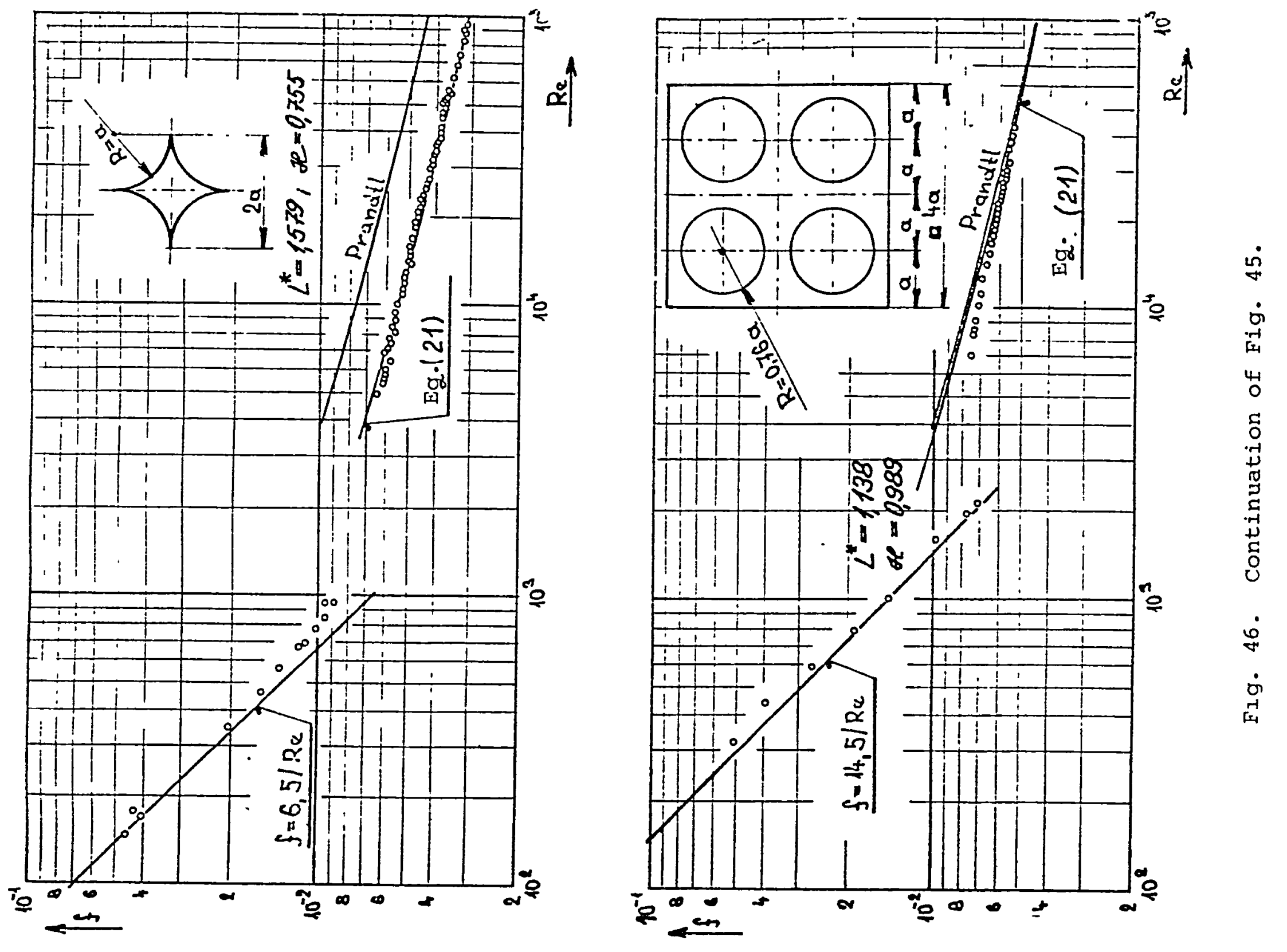


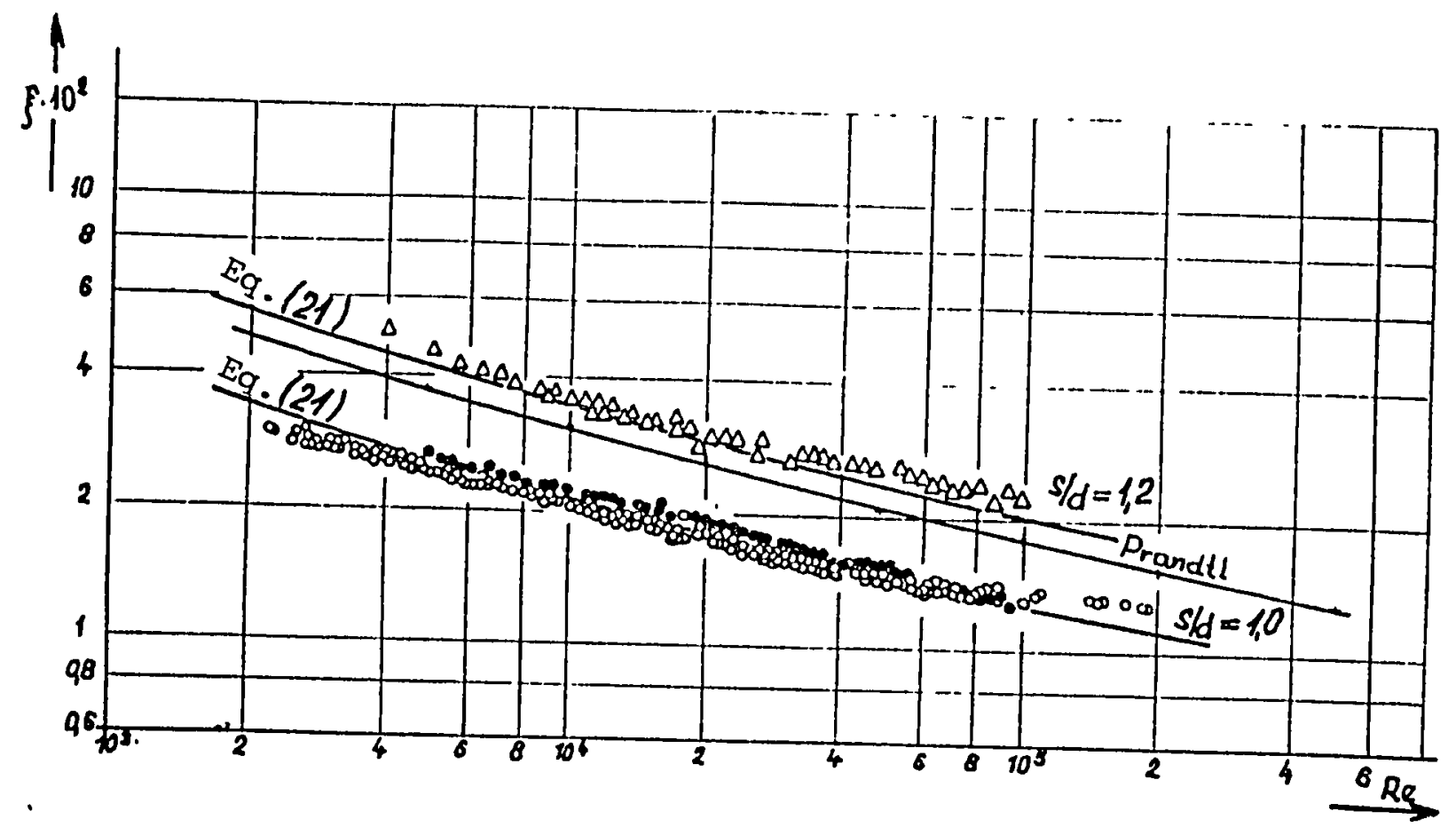

\begin{tabular}{|c|c|c|c|c|c|c|c|c|c|c|}
\hline $\begin{array}{l}\text { Likera. } \\
\text { ture }\end{array}$ & $\frac{s}{d}$ & $N$ & $d$ & $d h_{\infty}$ & $d h$ & $L$ & $\begin{array}{l}\text { Oper. } \\
\text { Medium }\end{array}$ & $\begin{array}{l}\text { Range } \\
\operatorname{Re} 10^{-3}\end{array}$ & Sym- & $\begin{array}{c}\text { Model } \\
\text { section }\end{array}$ \\
\hline [28] & 1.0 & 25 & 11.4 & 3,12 & 3,12 & 600 & water & $2-200$ & - & \\
\hline [27] & 10 & & 48,2 & 13,2 & 13,2 & 3400 & water & $5-100$ & - & \\
\hline [26] & 1,2 & 64 & 7,92 & 6,6 & 5,6 & & & $5-100$ & $\Delta$ & \% \\
\hline
\end{tabular}

Fig. 47. Comparison of computations and experiments for a square lattice. 


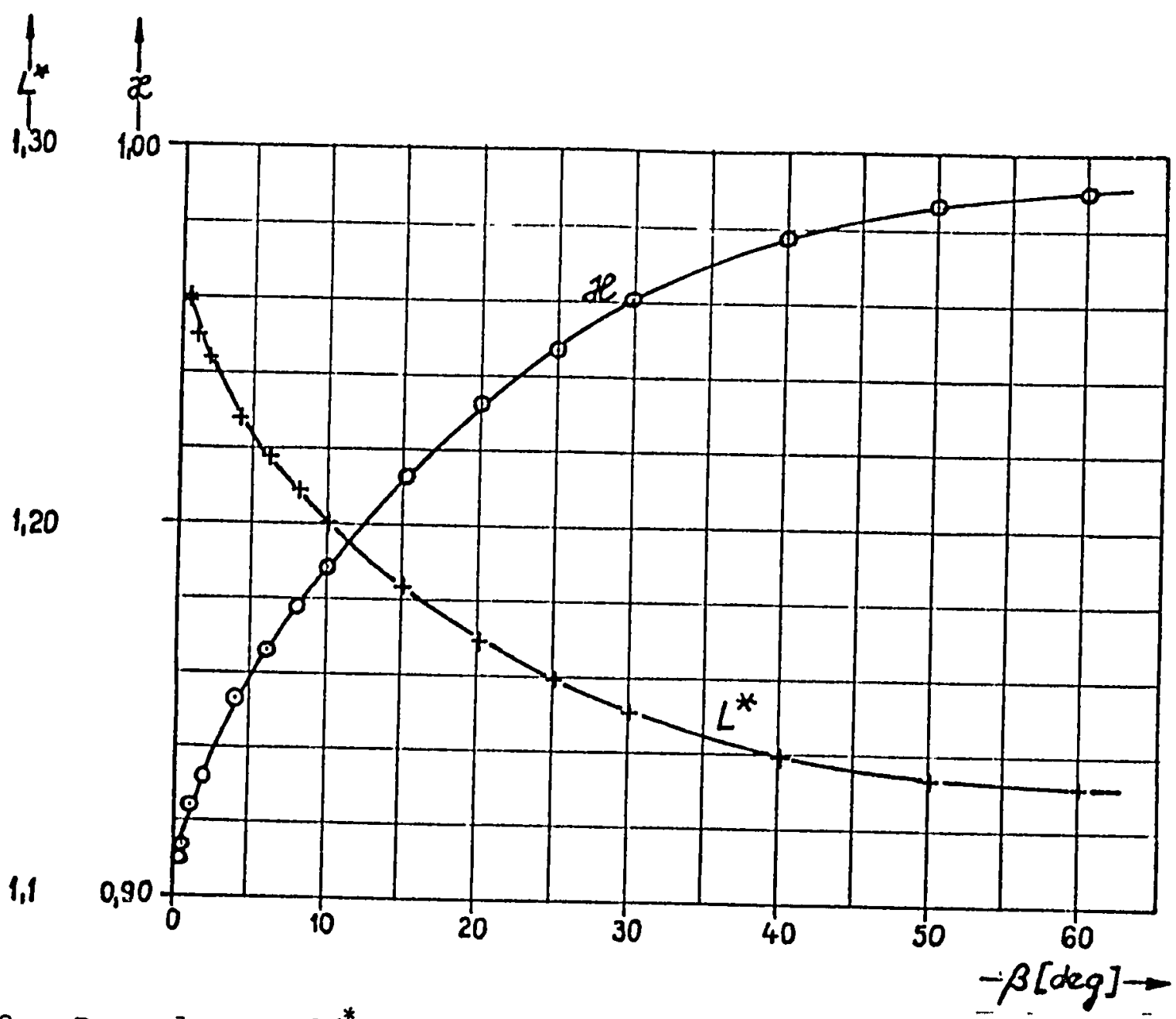

Fig. 48. Dependence of $L^{*}$ and $H$ on the apex angle of an isosceles triangle.

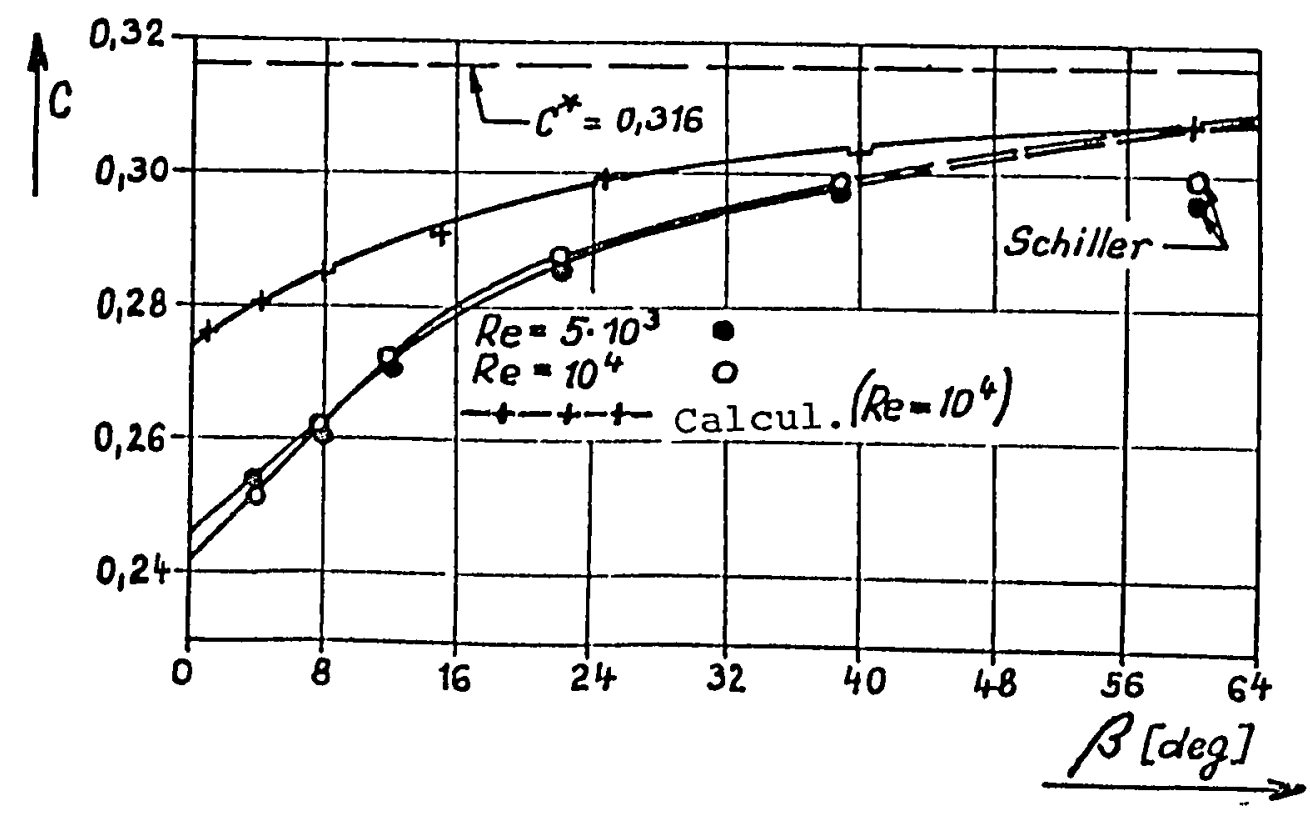

Fig. 49. Comparison of computed and experimental values [32] for a channel with a cross section in the shape of an isoscles triangle. 


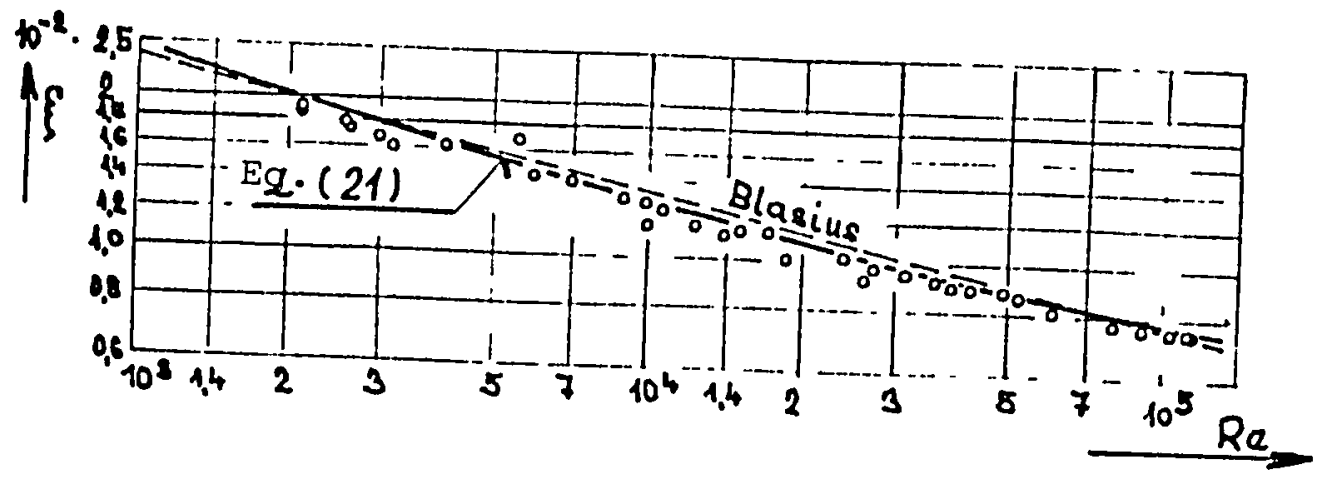

Fig. 50. Coefficient of friction losses in an isosceles triangle [29].

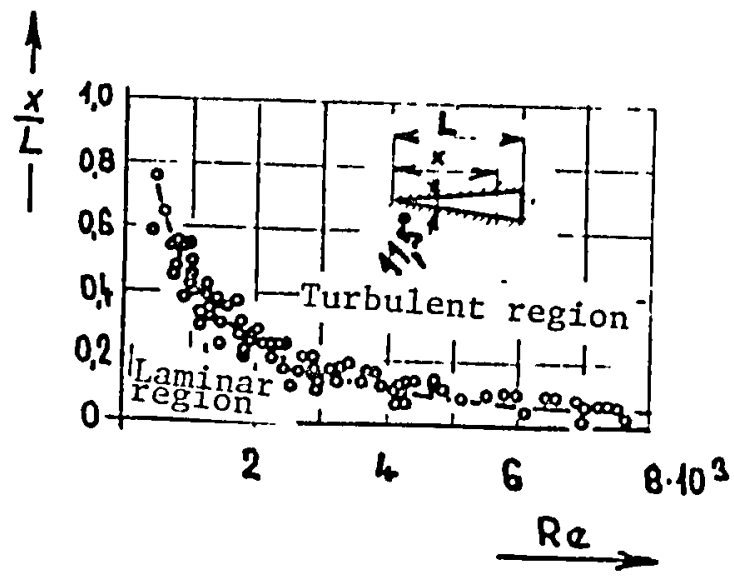

Fig. 51. Extent of the laminar region in a channel with an isosceles triangle cross section with an apex angle of $11.5^{\circ}$ [30]. 
<smiles>C1=[Si]=[Al][Al]1</smiles> 


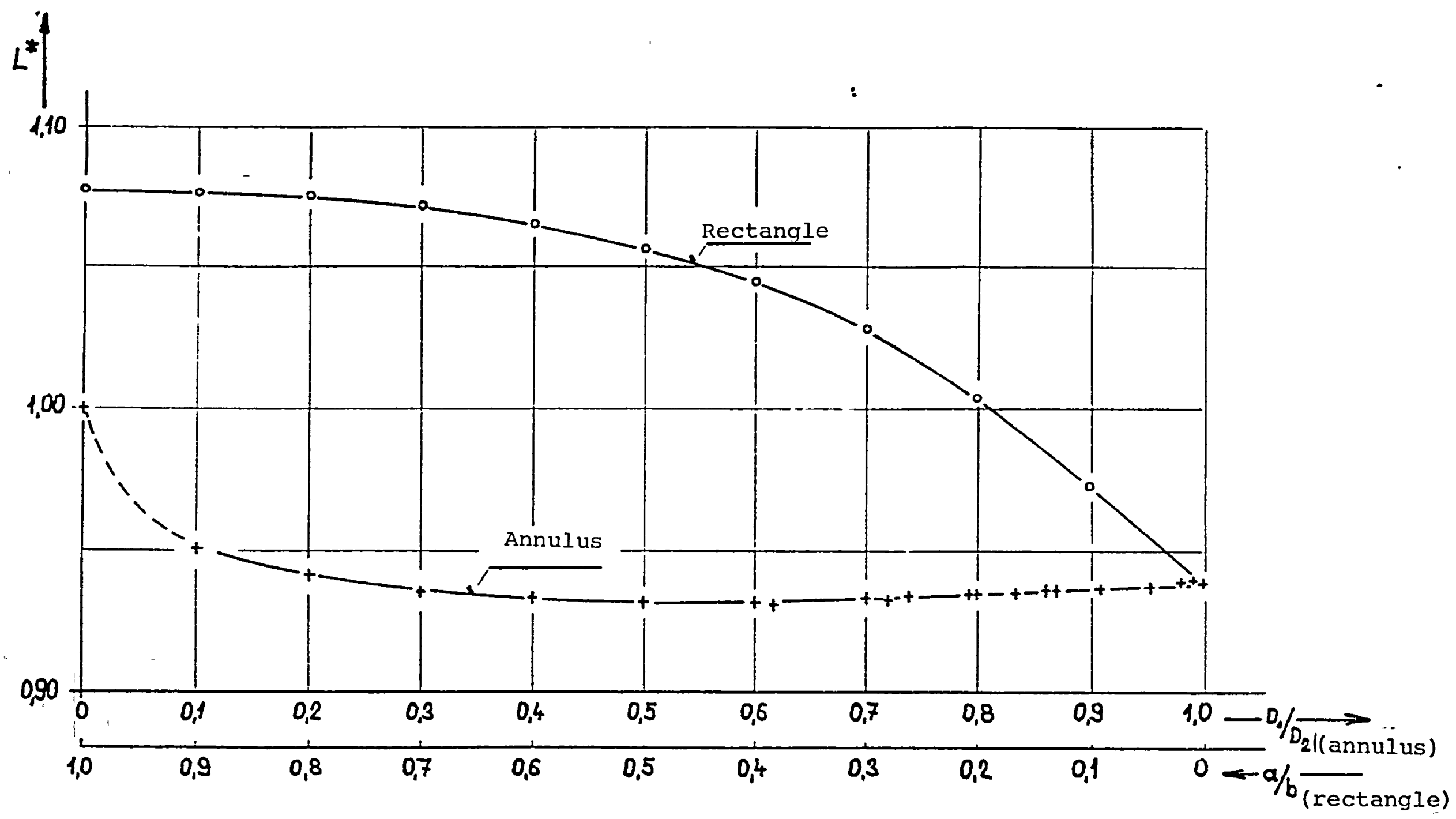

Fig. 53 Values of $L^{*}$ for a rectangle and an annulus. 

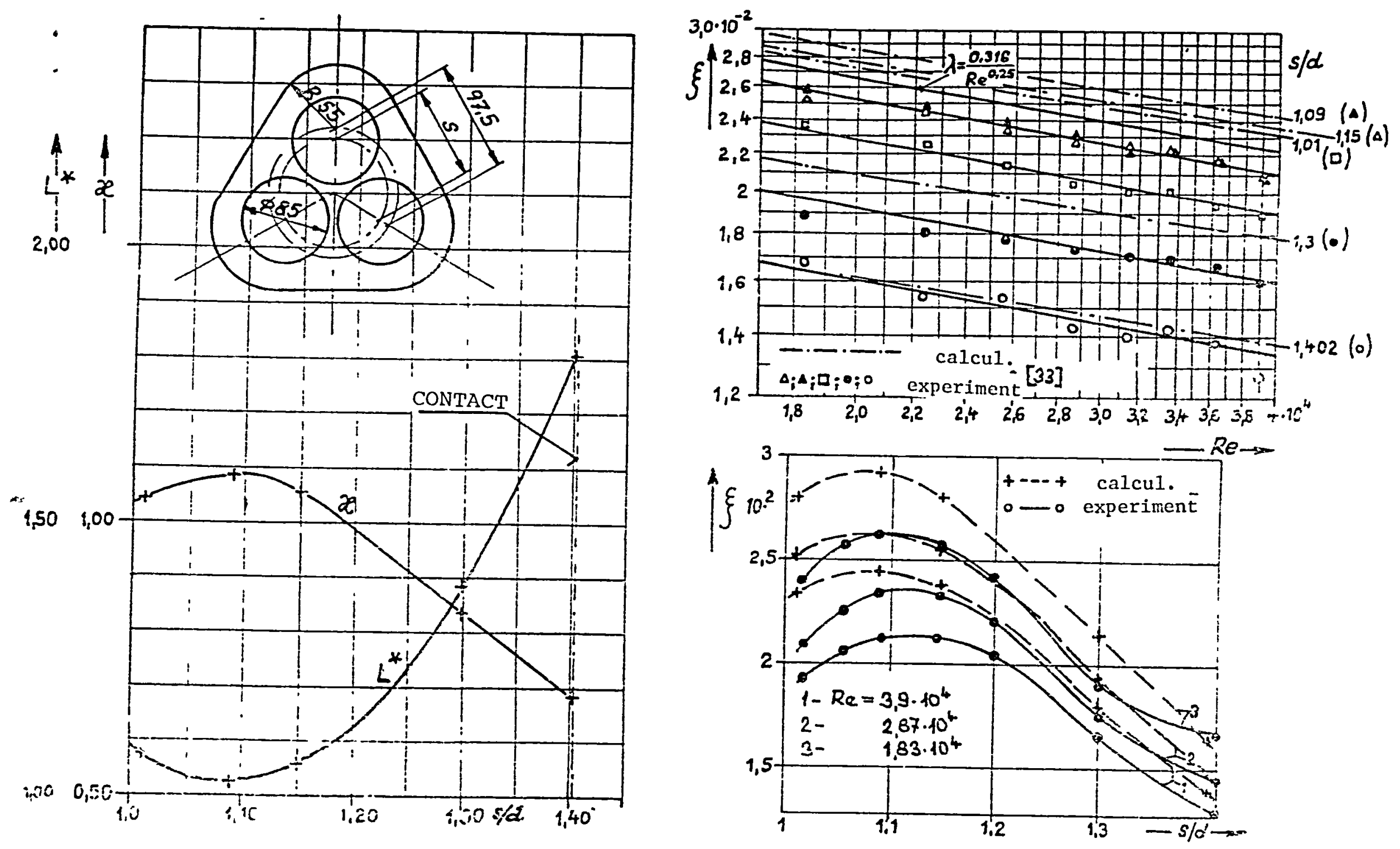

Fig. 54. Comparison of computed and experimental data of study [33]. 


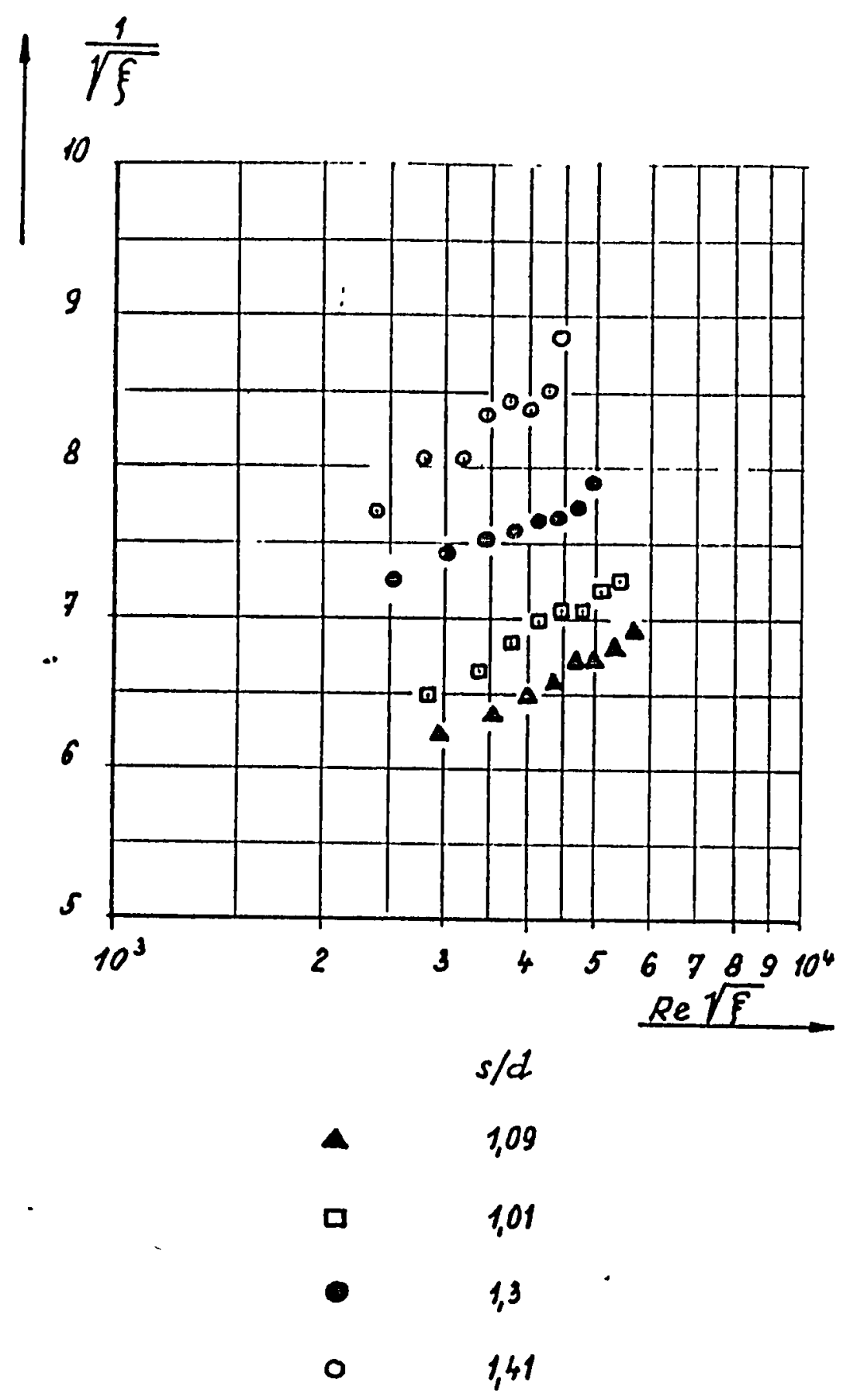

Fig. 55. Results of study [33] recomputed 1 nto form $1 / \sqrt{\xi}=6(\operatorname{Re} \sqrt{\xi})$. 


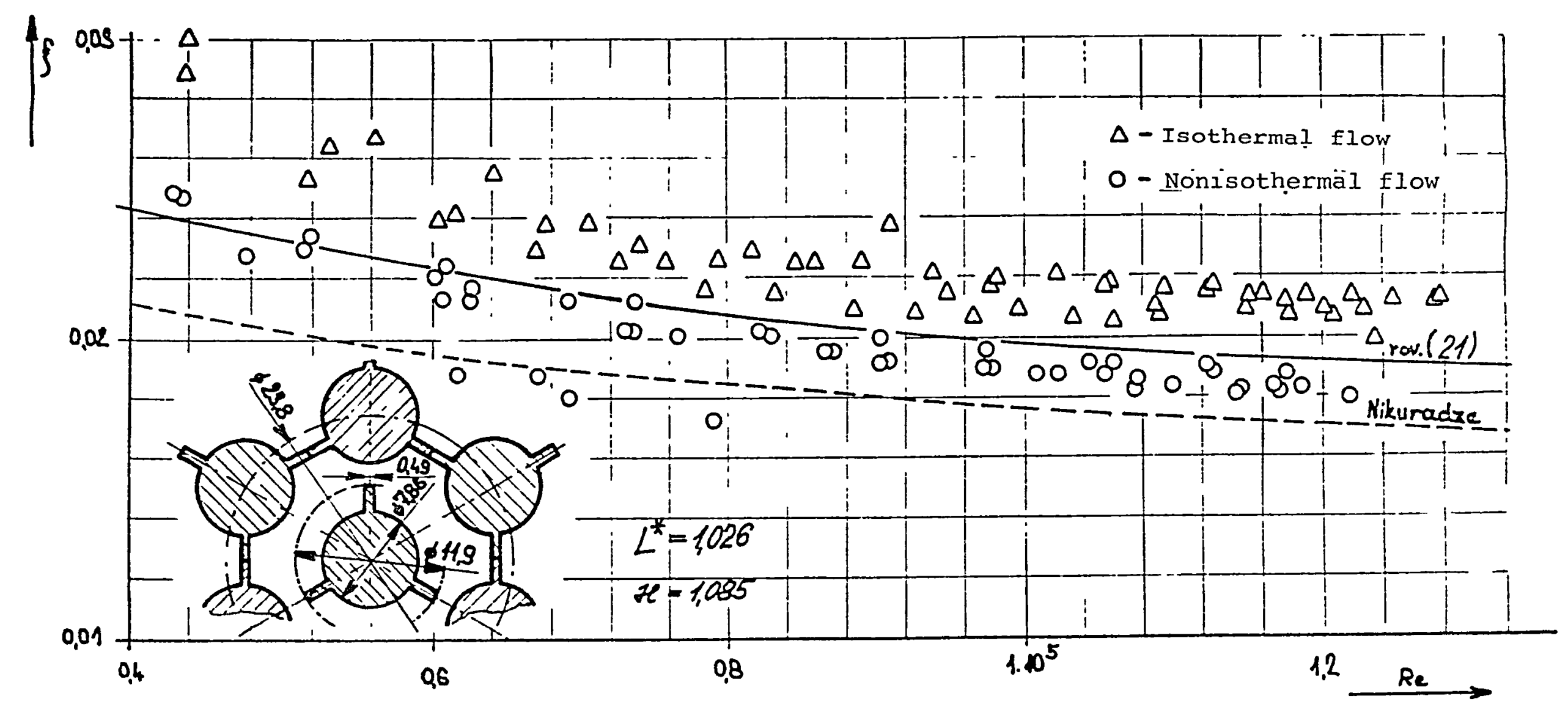

Fig. 56. Coefflcient of friction losses in a sheaf of rods w1th longitudinal fins [37]. 


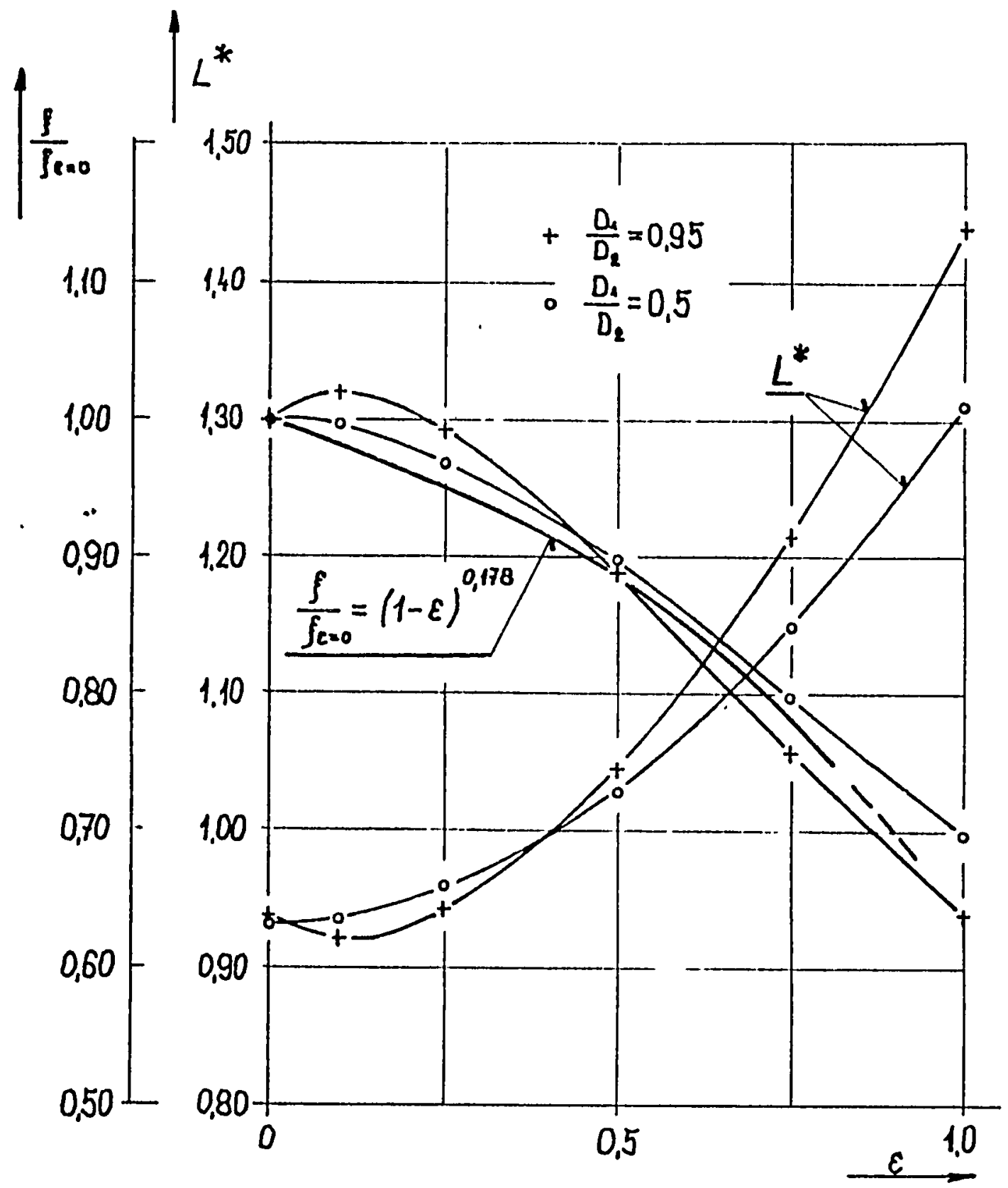

Fig. 57. Dependence of the coefficient of friction losses on eccentricity of an annular channel. Comparison of computations with the relation from study [34]. 


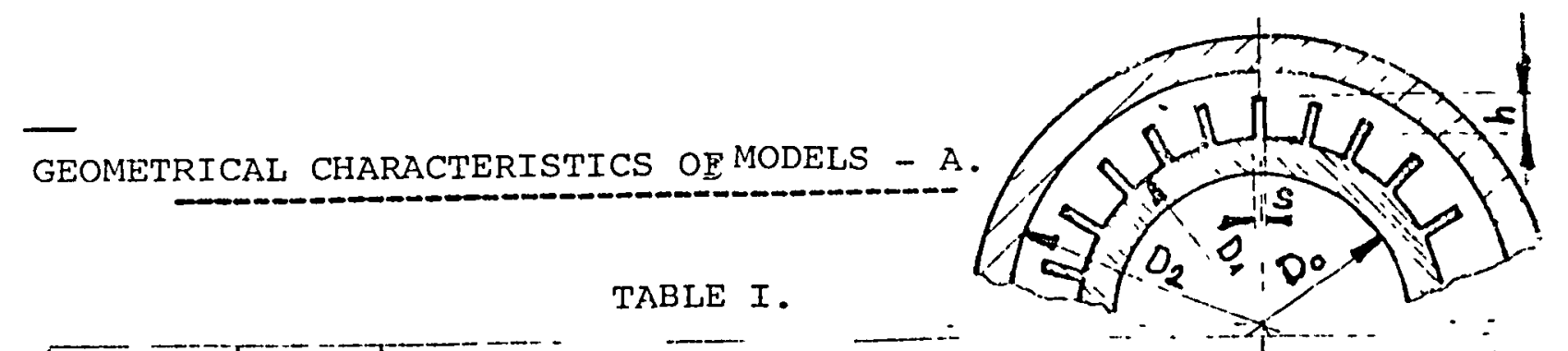

\begin{tabular}{|c|c|c|c|c|c|c|}
\hline $\begin{array}{l}\text { Variant } \\
\alpha \text { symbol } \\
\text { ozmoceni. }\end{array}$ & $\begin{array}{c}\text { No. of } \\
\text { fins } \\
n\end{array}$ & $\begin{array}{c}\text { Main } \\
\text { chąnne1 } \\
D_{?}\end{array}$ & ${ }_{D_{1}}^{\text {modol model }}$ & $\begin{array}{l}\text { Inner dia } \\
\text { tube } I_{0}\end{array}$ & $\begin{array}{c}\text { Height } \\
\text { of tins } \\
h\end{array}$ & $\begin{array}{c}\text { Thipkness } \\
\text { of fins } \\
B\end{array}$ \\
\hline & & m & $\operatorname{mon}$ & $\operatorname{Ing}$ & 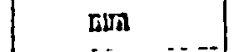 & $\ln a$ \\
\hline $1 \square$ & 24 & $81,0^{+} 0,1$ & $\begin{array}{r}50,25+0,03 \\
-0,09 \\
\end{array}$ & $\begin{array}{r}41,85+0,03 \\
-0,03\end{array}$ & $\begin{array}{l}4,73+0,3 \\
-0,25\end{array}$ & $1,15+0,15$ \\
\hline 28 & $\omega$ & $-\cdots$ & $-\cdots-$ & $-\cdots$ & $\begin{array}{l}3,02+c,] \\
-0,02\end{array}$ & $-\infty-\infty$ \\
\hline $3 \Delta$ & $\bullet$ & $-"-$ & -" - & - - - & 2,5 & $-n-$ \\
\hline $4+$ & 36 & $-{ }^{*}-$ & $\begin{array}{r}50,70^{+0,08} \\
-0,03\end{array}$ & $\begin{array}{r}41,30^{+0,17} \\
-0,75\end{array}$ & $5,24^{+c}-6$ & $\begin{array}{r}1,09+0,11 \\
-0,09\end{array}$ \\
\hline $5 x$ & $n$ & $-\cdots$ & $\ldots$ & -n - - & 2,91 & $-n--$ \\
\hline 6 & $\omega$ & $-\cdots$ & $-{ }^{n}-$ & $-"$ & $1,57^{+}$ & -. n - . \\
\hline $7 \square$ & 60 & $-n-$ & $\begin{array}{r}50,35^{+0,1}-0,05 \\
\end{array}$ & $\begin{array}{c}41,95=0,05 \\
-0,1\end{array}$ & 5,34 & $\begin{array}{l}1,34+0,15 \\
-0,15 \\
\end{array}$ \\
\hline 80 & $\omega$ & $-\cdots-$ & $-n-$ & 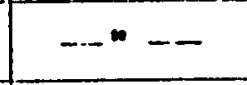 & $2,34^{+0,115}$ & $-\infty-$ \\
\hline $9 \Delta$ & $\omega$ & $-{ }^{n}-$ & $-\pi-$ & $="-$ & $1,45^{+0}-0$ & $-n-$ \\
\hline $10 \Delta$ & 24 & $70,3^{+} 0,04$ & $\begin{array}{r}50,25+0,03 \\
-0,03 \\
\end{array}$ & $\begin{array}{r}41,25+0,03 \\
-0,03\end{array}$ & & $\begin{array}{c}7,15^{+0,15} \\
-0,3\end{array}$ \\
\hline $11 \Delta$ & $n$ & $-"$ & $\dot{-1}-$ & $-n-$ & $3,02^{+1}$ & $-n-$ \\
\hline $12 \Delta$ & n & $-"$ & $--\infty$ & $-n-$ & 1,5 & $\div$ \\
\hline $13 Y$ & 36 & $-"$ & $\begin{array}{r}50,70+0,03 \\
-0,03\end{array}$ & $\begin{array}{r}41,80^{40,17}-0,25 \\
-0,2\end{array}$ & $\begin{array}{r}5,24+0,16 \\
-0,14 \\
\end{array}$ & $\begin{array}{r}1,29+0,11 \\
-0,09 \\
\end{array}$ \\
\hline $14 \lambda$ & 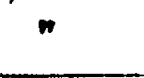 & $-"-$ & $-"-$ & $-\cdots$ & $2,91^{+0}-0$ & - " - \\
\hline 15 & $n$ & $-{ }^{n}-$ & $-"$ & $-"-$ & $1,57_{-0,03}^{+0,03}$ & $-"$ \\
\hline
\end{tabular}


GEOMETRICAL CHARACTERISTICS OF MODELS A.

TABLE II.

\begin{tabular}{|c|c|c|c|c|c|c|}
\hline $\begin{array}{l}\text { Variant } \\
\text { number }\end{array}$ & $\begin{array}{l}\text { Flow-thru } \\
\text { surfaçe } \\
+\quad F .10^{\circ}\end{array}$ & $\begin{array}{l}\text { Wetted } \\
\text { circuit } \\
5.10 \\
\end{array}$ & $\begin{array}{l}\text { Heated } \\
\text { circuit } \\
\mathrm{S}_{\mathrm{T} .10}\end{array}$ & $a_{h} \cdot 10^{?}$ & $L^{*}$ & $\frac{d h}{d T}$ \\
\hline & $\mathrm{m}^{2}$ & in & m & $\underline{\underline{m}}$ & & \\
\hline 1 & 3,037 & 6,334 & 3,843 & 1,900 & 1,136 & 1,205 \\
\hline 2 & 3,084 & $5,57 ?$ & 3,028 & 2,214 & 1,120 & 1,135 \\
\hline 3 & 3,326 & 4,053 & 2,309 & 2,576 & 1,056 & 1,116 \\
\hline 4 & $?, 887$ & 7,208 & 5,363 & 1,460 & 1,281 & 1,236 \\
\hline 5 & $?, 395$ & 6,236 & 3,692 & 1,921 & 1,233 & 1,215 \\
\hline 6 & 3,057 & $5, ? .65$ & 2,721 & $2,3 \% 3$ & 1,136 & 1,192 \\
\hline 7 & 2,691 & 10,549 & 8,004 & 1,020 & 1,646 & 1,430 \\
\hline 8 & 2,884 & 7,671 & 5,127 & 1,504 & 1,478 & 1,436 \\
\hline 9 & 3,005 & $5, \cap 32$ & 3,338 & 2,043 & 1,249 & 1,304 \\
\hline 10 & 1,767 & 6,058 & 3,049 & $1,16^{\circ}$ & 3,047 & 1,091 \\
\hline 11 & 1,815 & 5,236 & $3,0 ? 8$ & 1,386 & 1,076 & $1,141 "$ \\
\hline $1 ?$ & 1,856 & 4,517 & 2,309 & 3,643 & 1,049 & 1,118 \\
\hline 13 & 1,617 & 7,572 & 5,363 & 0,854 & 1,098 & 1,119 \\
\hline 14 & 1,725 & 5,900 & 3,692 & 1,169 & 1,160 & 1,210 \\
\hline 15 & 3,738 & 4,979 & 2,721 & 1,450 & 1,111 & 1,179 \\
\hline 16 & $1,4 ? .1$ & 10,212 & 8,004 & 0,557 & 1,309 & 1,243 \\
\hline 17 & 1,614 & 7,335 & 5,127 & 0,8380 & 1,386 & 1,347 \\
\hline 18 & $1, " 35$ & 5,546 & 3,338 & $\begin{array}{l}1,251 \\
\ldots\end{array}$ & 1,240 & 1,285 \\
\hline 19 & 1,303 & 5,860 & 3,849 & 0,758 & $1, \mathbf{a 2}$ & 0,392 \\
\hline
\end{tabular}


$\div$

..$=r^{\prime}$ 


\section{렬 $\frac{1}{y}$}

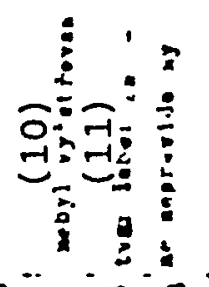

iो 产

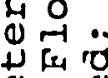

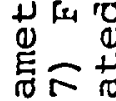

4.

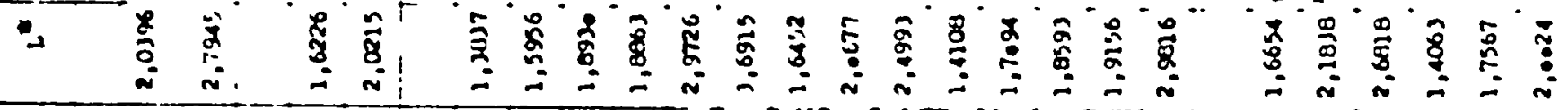

-4 $\widehat{2} \begin{gathered}4 \\ 0\end{gathered}$

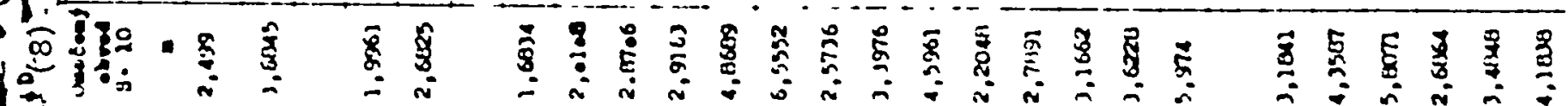
б.

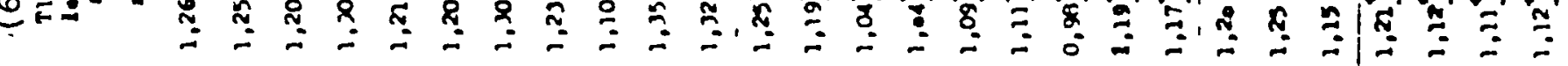
...

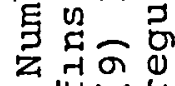
तิ山्丶 $C$ व $\because+3$ $-1,0,0$ है.

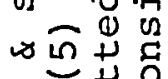

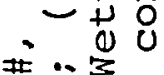

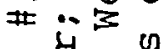

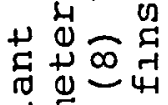
牙砶.

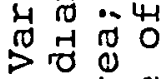

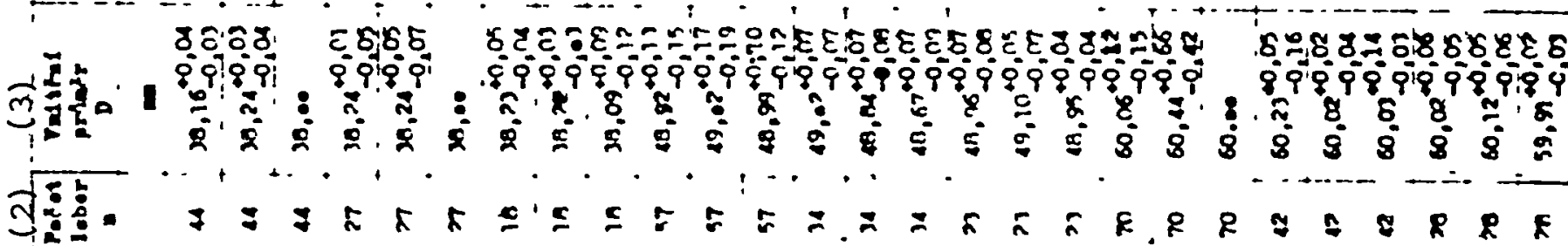

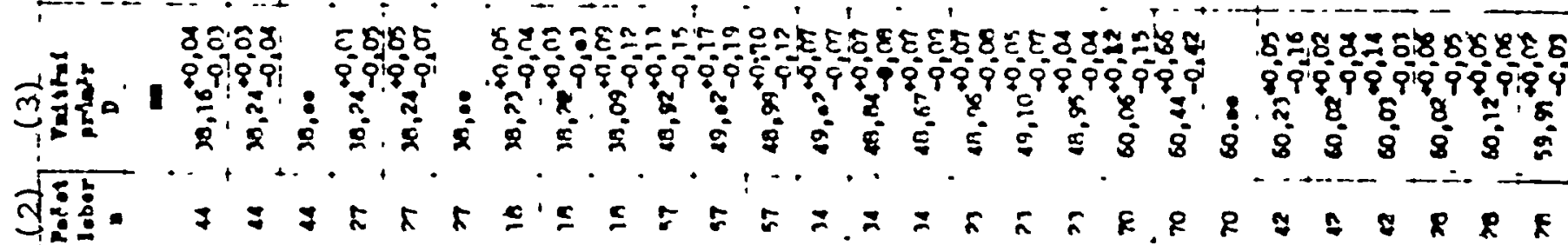

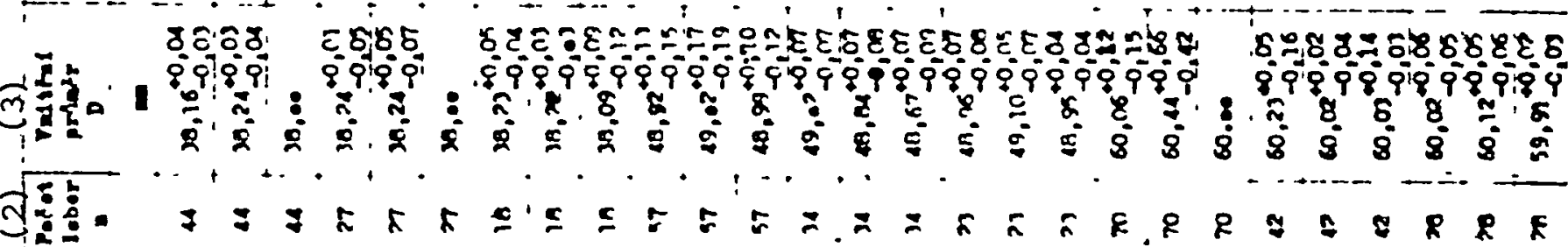

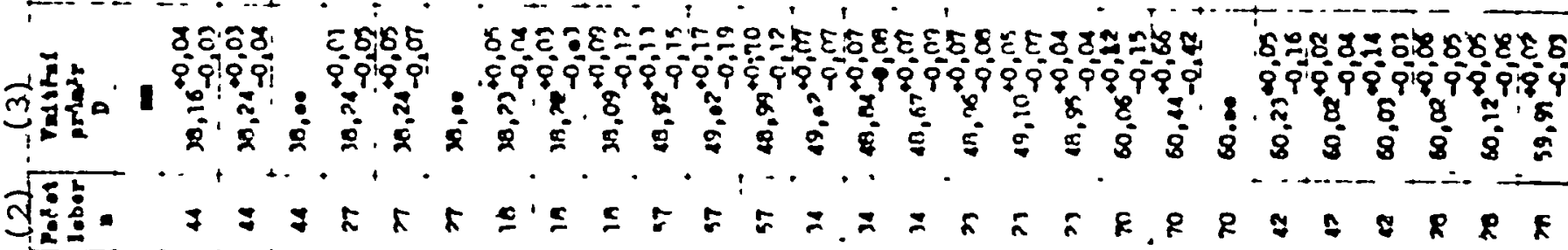

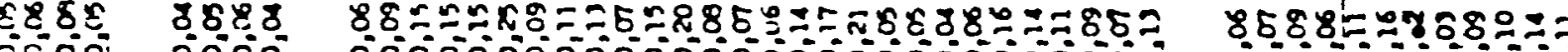

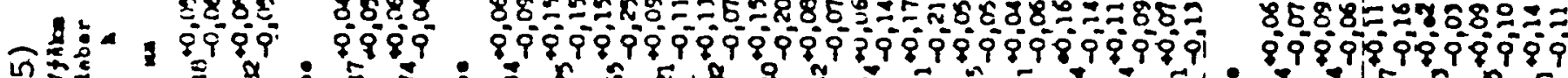

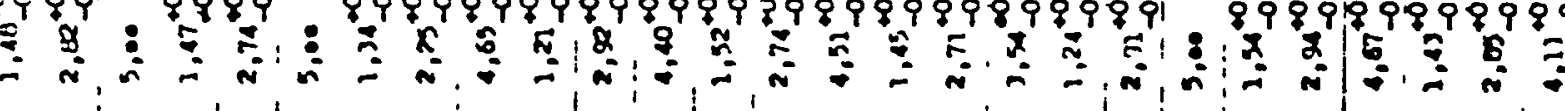

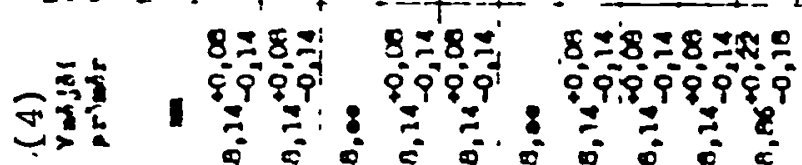
盾 
Table of Annular Channels

Measured at the Institute of Nuclear Research.

\begin{tabular}{|c|l|l|l|l|}
\hline Designation & $D_{2}[\mathrm{~mm}]$ & $D_{1}[\mathrm{ma}]$ & $d_{h} \cdot 10^{2}[\mathrm{~m}]$ & $\frac{D_{1}}{D_{2}}$ \\
\hline$M M$ & 80,98 & 50,65 & 3,033 & 0,625 \\
\hline$M 2$ & 80,98 & 60,55 & 2,043 & 0,748 \\
\hline$M 3$ & 70,3 & 50,65 & 1,965 & 0,72 \\
\hline$M_{4}$ & 70,3 & 60,55 & 0,975 & 0,861 \\
\hline$M 5$ & 63,99 & 50,65 & 1,334 & 0,792 \\
\hline$M 6$ & 63,93 & 60,55 & 0,344 & 0,946 \\
\hline
\end{tabular}

Geometrical Characterıstics of Models from study [3].

SMOOTH ANNULAR CHANNELS

\begin{tabular}{|c|c|c|c|c|c|c|c|}
\hline $\mathrm{n}_{2}$ & $D_{1}$ & $\mathrm{D}_{2} / \mathrm{D}_{1}$ & $\begin{array}{l}\text { Length } \\
\text { of mode1 }\end{array}$ & $d_{h}$ & $\mathrm{~L}^{\mathrm{H}}$ & Type of cooling & $d_{h} / d_{T}$ \\
\hline ina & $\operatorname{mrn}$ & & $\bar{m}$ & $\mathrm{~mm}$ & & & • \\
\hline 38 & 16 & 2,376 & 2,0 & $2 p$ & 0,932 & cooled core & 0,882 \\
\hline 38 & 25 & 1,52 & 2,0 & 13 & 0,932 & $--n--$ & 0,967 \\
\hline 38 & 32 & 1,180 & 2,0 & 6 & 0,935 & $--n-\infty$ & 0,943 \\
\hline 38 & 16 & $?, 776$ & 2,0 & ?2 & 0,932 & bilateral cooling & $\begin{array}{l}\frac{d h}{d_{\mathrm{T} 1}}=0,802 \\
\frac{d h}{d_{\mathrm{h}}}=1,06\end{array}$ \\
\hline 38 & 16 & 2,376 & 2,0 & 22 & 0,932 & cooled sleeve & 1,06 \\
\hline
\end{tabular}

ANNULAR CHANNELS WITH A LONGITUDINALLY FINNED CORE (GEOMETRY A)

\begin{tabular}{|c|c|c|c|c|c|c|c|c|}
\hline$n$ & $D_{2}$ & $D_{1}$ & $h$ & B & $\begin{array}{l}\text { Length } \\
\text { of model }\end{array}$ & $d_{h}$ & $I^{*}$ & $d_{h} / d_{T}$ \\
\hline & mans & $\mathrm{mm}$ & $\mathrm{mm}$ & $\mathrm{mm}$ & $m$ & $\operatorname{mm}$ & & \\
\hline 12 & 45,8 & 16 & 6,23 & 1,26 & 1,936 & 15,75 & 1,108 & 1,106 \\
\hline 12 & 15,8 & 2.5 & 5,73 & 1,05 & 1,990 & 12,05 & 1,008 & 1,035 \\
\hline 12 & 38 & 16 & $6,2 ?$ & 2,26 & 1,096 & 10,52 & 1,036 & 1,074 \\
\hline 12 & 38 & 25 & 5,73 & 1,05 & 1,930 & 6,81 & 1,074 & 0,976 \\
\hline 12 & 32 & 16 & 6,22 & 1,26 & 1,996 & 6,79 & 1,019 & 0,967 \\
\hline
\end{tabular}




\section{End of Document}

